\title{
The Atomic-Level Structure of Cementitious Calcium Silicate Hydrate
}

\author{
Abhishek Kumar, ${ }^{1}$ Brennan J. Walder, ${ }^{2}$ Aslam Kunhi Mohamed, ${ }^{1}$ Albert Hofstetter, ${ }^{2}$ Bhuvanesh Srini- \\ vasan, ${ }^{1,3}$ Aaron J. Rossini, ${ }^{4}$ Karen Scrivener, ${ }^{5}$ Lyndon Emsley ${ }^{* 2}$ and Paul Bowen ${ }^{* 1}$ \\ ${ }^{1}$ Powder Technology Laboratory, Institut des Matériaux, Ecole Polytechnique Fédérale de Lausanne (EPFL), CH-1015 Lau- \\ sanne, Switzerland \\ 2Institut des Sciences et Ingénierie Chimiques, Ecole Polytechnique Fédérale de Lausanne (EPFL), CH-1015 Lausanne, \\ Switzerland \\ ${ }^{3}$ Department of Earth \& Environmental Sciences, Ludwig-Maximilian University, D-80333, Munich, Germany \\ ${ }^{4}$ Department of Chemistry, Iowa State University, Ames, IA 50011-3020, USA \\ ${ }^{5}$ Construction Material Laboratory, Institut des Matériaux, Ecole Polytechnique Fédérale de Lausanne (EPFL), CH-1015 \\ Lausanne, Switzerland
}

\begin{abstract}
Efforts to tune the bulk physical properties of concrete are hindered by a lack of knowledge related to the atomiclevel structure and growth of calcium silicate hydrate phases, which form about $50-60 \%$ by volume of cement paste. Here we describe the first synthesis of compositionally uniform calcium silicate hydrate phases with Ca:Si ratios tunable between 1.0 and 2.0. The calcium silicate hydrate synthesized here does not contain a secondary $\mathrm{Ca}(\mathrm{OH})_{2}$ phase, even in samples with Ca:Si ratios above 1.6, which is unprecedented for synthetic calcium silicate hydrate systems. We then solve the atomic-level three-dimensional structure of these materials using dynamic nuclear polarization enhanced ${ }^{1} \mathrm{H}$ and ${ }^{29} \mathrm{Si}$ nuclear magnetic resonance experiments in combination with atomistic simulations and density functional theory chemical shift calculations. We discover that bridging interlayer calcium ions are the defining structural characteristic of single-phase cementitious calcium silicate hydrate, inducing the strong hy-

drogen bonding that is responsible for stabilizing the structure at high Ca:Si ratios.
\end{abstract}

\section{INTRODUCTION}

Calcium silicate hydrate (C-S-H) is the primary binding component of concrete, forming about $50-60 \%$ by volume of hardened cement paste and making it one of the most common substances of the modern world. Because of its ubiquity, it is surprising that a complete description of its atomiclevel structure remains the subject of debate ${ }^{1,2}$, and consequently its structure-property relationships are not well known. This makes it difficult to engineer C-S-H not only for its primary uses in construction, in which high reactivity and strength at low carbon footprints are desirable, but also for emerging applications such as dental filling and bone repair, 3,4 which require biocompatibility; waste water treatment, ${ }^{5,6}$ which requires high specific surface areas; and encasement of nuclear waste, ${ }^{7}$ which requires high structural integrity in the presence of significant radionuclide concentrations.

For Portland cements the precipitation of C-S-H occurs in conjunction with the precipitation of other material phases such as crystalline $\mathrm{Ca}(\mathrm{OH})_{2}$, ettringite, and $\mathrm{CaCO}_{3}{ }^{8,9}$ The $\mathrm{C}-\mathrm{S}-\mathrm{H}$ phases are known to be rich in calcium, with $\mathrm{Ca}$ :Si ratios exceeding 1.75 at early stages of hardening. ${ }^{10}$ In contrast, synthetic C-S-H with Ca:Si ratios above $\sim 1.5$ are often observed in coexistence with a $\mathrm{Ca}(\mathrm{OH})_{2}$ phase. Because of an inability to synthesize pure $\mathrm{C}-\mathrm{S}-\mathrm{H}$ with $\mathrm{Ca}$ :Si ratios above 1.5, many researchers believe that Ca-rich C-S-H systems are intrinsically a binary mixture of a chemically disordered single phase C-S-H material. In such a case, one phase consists of a "proper" C-S-H phase, with a layered silicate chain structure related to that of the naturally occurring calcium silicate hydrate mineral tobermorite and limited to $\mathrm{Ca}: \mathrm{Si}$ ratios around 1.6. The other phase consists of nanocrystalline $\mathrm{Ca}(\mathrm{OH})_{2}$, which is thought to occur in bulk form occupying pores in the proper C-S-H phase or as chemically distinct ribbons or sheets interwoven within the $\mathrm{C}-\mathrm{S}-\mathrm{H}$ structure itself.11-15 This interpretation has the support of thermodynamic and solubility data analyzing a multitude of C-S-H systems. ${ }^{16}$ Furthermore, in spite of a vast amount of experimental data yielding partial characterization, the positions of the calcium atoms in the interlayer, which are the essential aspects of high $\mathrm{Ca}: \mathrm{Si}$ ratios in $\mathrm{C}-\mathrm{S}-\mathrm{H}$, remain undefined. Thermodynamic modeling and crystal chemical reasoning have been applied to propose complete C-S-H structural models at Ca:Si ratios greater than $1.5,{ }^{15}$ but for these compositions the focus has been on the binary C-S-H/Ca $(\mathrm{OH})_{2}$ representation, for which experimental validation is ongoing. ${ }^{17}$

Here we introduce a method which achieves the synthesis of C-S-H possessing Ca:Si ratios between 1.0 and 2.0, maintaining a single phase composition even for C-S-H whose Ca:Si ratio exceeds 1.6. Aqueous calcium nitrate and sodium silicate solutions are reacted under conditions of high supersaturation and constant $\mathrm{pH}$, the latter of which is set by the addition of a predetermined amount of alkali hydroxide. 
The production of a single phase composition at such Ca:Si ratios has not been achieved using conventional methods for C-S-H synthesis ${ }^{18-22}$ relying on combinations of dissolution and direct precipitation ${ }^{23-25}$ reactions that operate at either lower supersaturation or uncontrolled $\mathrm{pH}$ conditions. We also use $\left\{{ }^{1} \mathrm{H}\right\}{ }^{29} \mathrm{Si}$ cross-polarization (CP) MAS NMR to measure populations of $\mathrm{Q}$ species, the connectivity between those species, and correlations between ${ }^{29} \mathrm{Si}$ and ${ }^{1} \mathrm{H}$ chemical shifts of the single-phase C-S-H produced using our rapid precipitation method. The greatest drawback of ${ }^{29} \mathrm{Si}$ solidstate NMR is its low sensitivity, which we circumvent by using modern dynamic nuclear polarization (DNP) strategies ${ }^{26-28}$ that have been recently used to study the hydration of cementitious systems with tremendous success.29 The $Q$ species information allows us to quantify the extent of silicate polymerization in the structure. Finally, we use atomistic modeling to establish a connection between the measured ${ }^{1} \mathrm{H}$ chemical shifts and the atomic-level position of calcium atoms in the interlayer, allowing us to solve the threedimensional atomic-level structure of synthetic cementitious C-S-H.

\section{METHODS}

Synthesis: $\mathrm{pH}$ governs the type of silicates species available for precipitation of C-S-H. The Ca:Si ratio attained in the solid phase was found to depend on the $\mathrm{pH}$ of the solution. Thermodynamic modeling 30,31 also predicts that $\mathrm{Ca}: \mathrm{Si}$ ratios above 1.5 can only be produced under high $\mathrm{pH}$ conditions, as occurs in the hydration of real Portland cement systems, in order to ensure that the electrostatically stable monomeric $\mathrm{SiO}_{2}(\mathrm{OH})_{2}{ }^{2-}$ species remains in abundance at high supersaturation and rapid precipitation conditions.

To maintain the desired supersaturation, $\mathrm{pH}$, and mixing conditions, and to avoid carbonation, we developed a synthetic apparatus for controlling the reaction conditions to the degree of precision required, aided by real-time acquisition of kinetic data such as $\mathrm{Ca}^{2+}$ ion concentration, $\mathrm{pH}$ and conductivity. Details regarding its construction are given in the Supporting Information section II.

All reaction solutions were prepared in decarbonized, demineralized ultrapure water. The reaction chamber was kept under an inert nitrogen atmosphere in order to prevent carbonation. C-S-H precipitates were collected after a duration of 3 hours and again after 24 hours. The products were separated from mother liquor using vacuum filtration over a 20 $\mathrm{nm}$ organic filter and later washed with ethanol and water to remove salts and unwanted ions from the surfaces of C-S-H. We produced five different $\mathrm{C}-\mathrm{S}-\mathrm{H}$ powders with nominal $\mathrm{Ca}$ :Si ratios of 1.0, 1.25, 1.5, 1.75 and 2.0. The precise experimental conditions for the precipitation of the different stoichiometry of the C-S-H were determined using thermodynamic modelling, ${ }^{30,32}$ with the exclusion of calcium hydroxide, as there was no experimental evidence for its formation. Additional details are given in Section IV of the SI.

Dynamic nuclear polarization: DNP solid-state NMR experiments were carried out on the aqueous suspensions of freshly prepared C-S-H nanoparticles with added impregnation agent and were not dried. The impregnation agent used was $22 \mathrm{mM}$ AMUPol in 65:35 v:v d -glycerol: $\mathrm{D}_{2} \mathrm{O}$, which was purged of dissolved oxygen by bubbling with $\mathrm{N}_{2}$ gas for roughly five minutes. The addition of the radical polarizing agent further dilutes the samples by about $20 \%$, but simple drying steps to increase the concentration of C-S-H led to sample deterioration (SI section VI). About $25 \mathrm{mg}$ of the impregnated gels were worked into a $3.2 \mathrm{~mm}$ OD sapphire rotor and plugged with a PTFE insert. The drive caps were zirconia. The DNP enhanced NMR experiments were carried out at a nominal field strength of $9.4 \mathrm{~T}$ using a commercial Bruker AV I 400 MHz/263 GHz DNP NMR spectrometer. 33 The samples were rapidly transferred into the stator of the NMR probe which was pre-cooled to $100 \mathrm{~K}$ to promote glass formation. Proton DNP enhancements were found to exceed 35 for all samples.

High resolution electron microscopy: HRSEM micrographs were obtained by coating the samples with $6 \mathrm{~nm}$ of osmium (gas phase coating). The metallization reduces charging and provides enhanced image contrast. High resolution SEM analysis was performed on a Zeiss Merlin, equipped with the GEMINI II column which combines ultra-fast analytics with high resolution imaging using advanced detection modes. Osmium coated samples were analyzed with acceleration voltage of $1 \mathrm{kV}$ with probing current of $300 \mathrm{nA}$. On-axis inlens secondary electron detection mode was employed for imaging. The instrument provides up to $0.6 \mathrm{~nm}$ resolution in STEM mode. In TEM mode, the samples were imaged at room temperature using a Tecnai F20 (FEI, The Netherlands) operating at an acceleration voltage of $100 \mathrm{kV} \mathrm{LaB} 6$ gun with a line resolution of $0.34 \mathrm{~nm}$, with images being recorded on a high sensitivity $4 \mathrm{k} \times 4 \mathrm{k}$ pixel CCD camera. For SEM and TEM analysis, $50 \mathrm{mg}$ of sample was dispersed in $40 \mathrm{~mL}$ of isopropanol. A drop of the suspended liquid was allowed to dry on a copper grid (200 mesh grids). The copper grids were glow discharged prior to sample disposition.

FTIR: Freshly prepared samples were analyzed with a PerkinElmer FT-IR spectrometer, with a resolution of $0.5 \mathrm{~cm}^{-1}$ to $64 \mathrm{~cm}^{-1}$. Wavelength accuracy was about $0.1 \mathrm{~cm}^{-1}$ at 1600 $\mathrm{cm}^{-1}$. FTIR measurements were performed with an attenuated total reflectance (ATR) unit and data was recoded and processed using Spectrum One software. The ATR unit included a diamond crystal and a clamp for pressing solid materials onto the crystal with constant pressure. The transmittance results of 256 scans were recorded between 4000 and $450 \mathrm{~cm}^{-1}$, with individual measurements taken every $2 \mathrm{~cm}^{-1}$. For the solid gels, air was used as the background.

Raman: Non-invasive Raman microscopy was carried out using a Renishaw inVia Reflex spectrometer equipped with a $785 \mathrm{~nm}$ diode laser. The power delivered to the sample was $164 \mathrm{~mW}$ at a full power specification. The grating size was 1200 lines/mm with an edge filter for Rayleigh rejection. $\mathrm{Ca}(\mathrm{OH})_{2}$ and $\mathrm{CaCO}_{3}$ standards were measured at $5 \%$ power with a single $10 \mathrm{~s}$ accumulation period. Freshly prepared C$\mathrm{S}-\mathrm{H}$ was measured with multiple accumulation periods, each of $13 \mathrm{~s}$ exposure.

$M D$ : Classical molecular dynamics simulation with force field potentials were used to test the structural stability of the proposed structures. The force field parameters used are known to describe well cementitious material systems. ${ }^{34}$ Simulations were done in a constant pressure ensemble at $300 \mathrm{~K}$ and a time step of 0.7 fs using Velocity Verlet integration algorithms implemented in DLPOLY. ${ }^{35}$ Ewald summation was used to take into account the long range forces above a cutoff distance of $8.5 \AA$. 


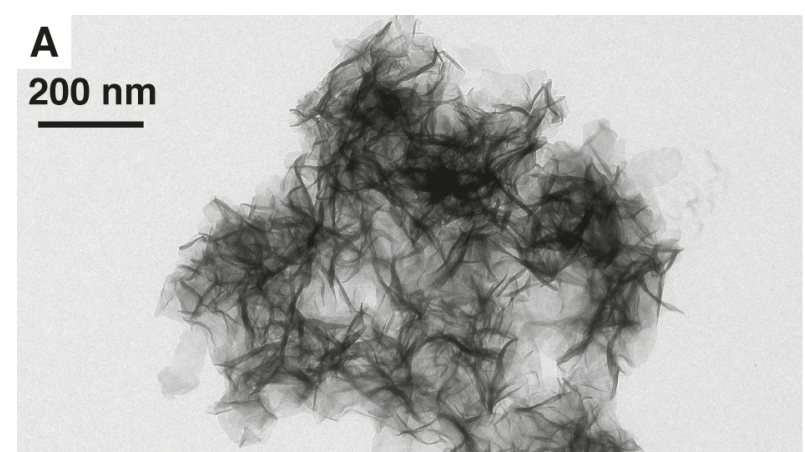

B

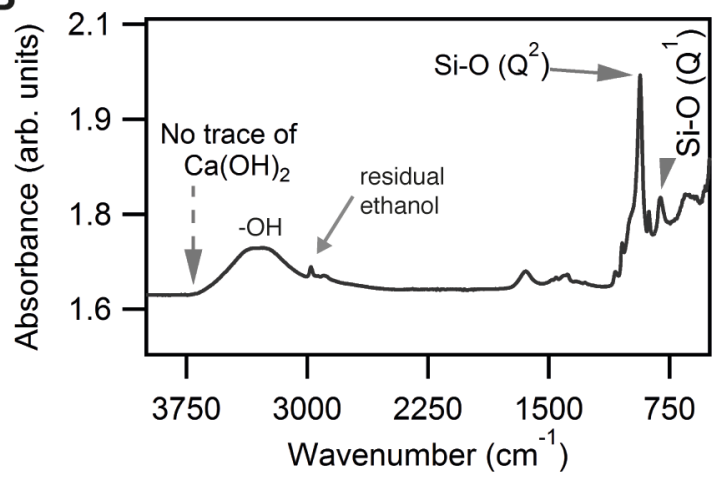

C

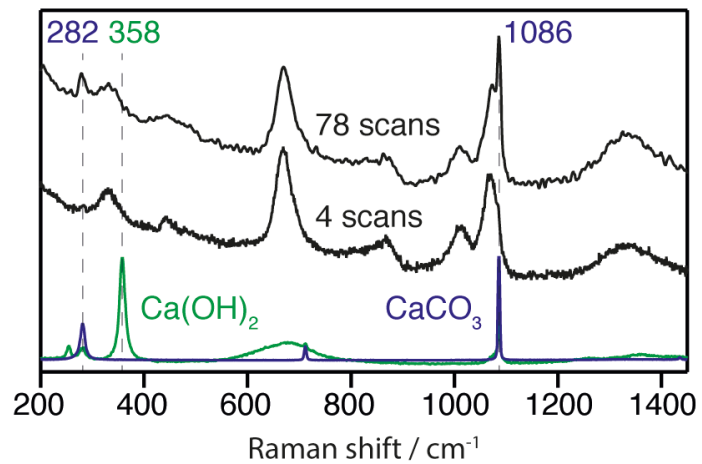

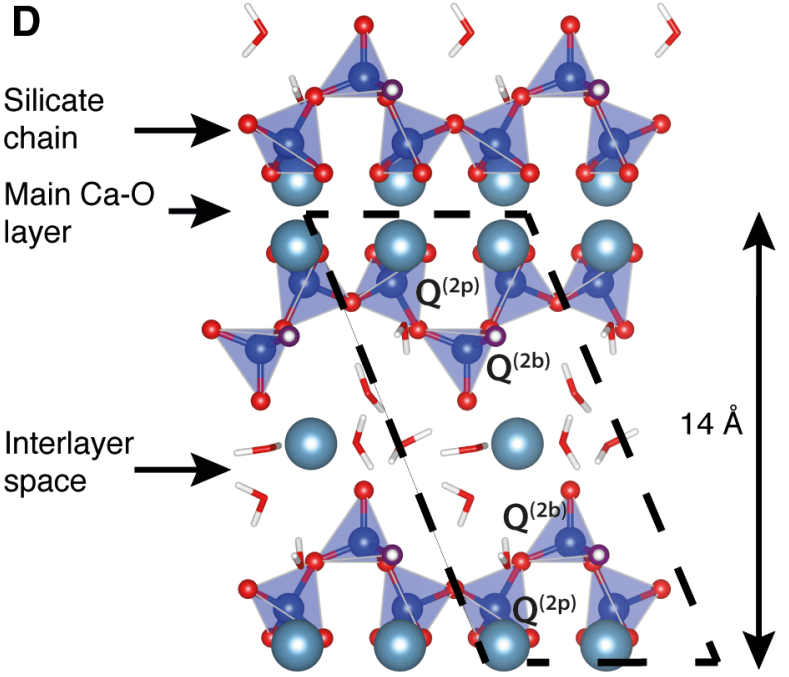

E

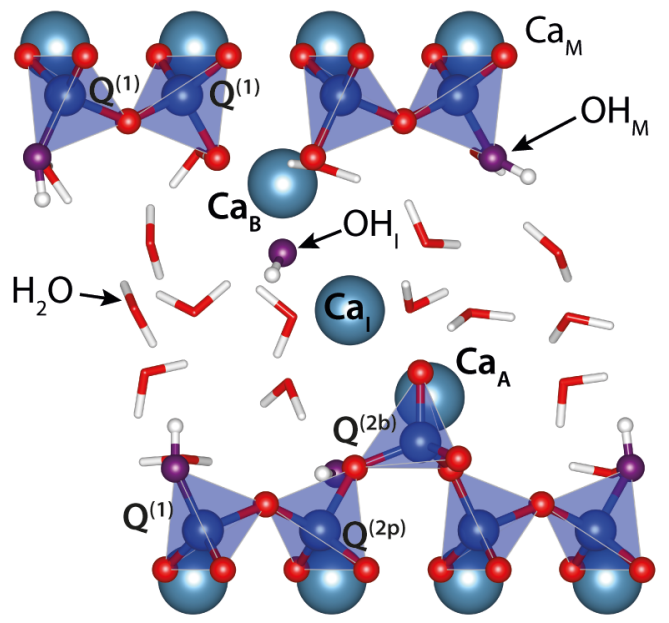

Figure 1. Structural elements of C-S-H. (A) High-resolution TEM image of pure C-S-H with Ca:Si ratio of 2.00, showing its "nanofoil" morphology. (B) Fourier transform IR spectroscopy showed no evidence of phases other than the C-S-H, including $\mathrm{Ca}(\mathrm{OH})_{2}$. $(\mathrm{C}) \mathrm{Compari}-$ son of Raman spectra of $\mathrm{Ca}(\mathrm{OH})_{2}$ (green), $\mathrm{CaCO}_{3}$ (blue), a sample of C-S-H with Ca:Si $=2.0$ after 4 scans (lower black), and a sample of C-S-H with $\mathrm{Ca}: \mathrm{Si}=2.0$ after 78 scans (upper black). (G) Chain topology in the layered $14 \AA$ tobermorite $(\mathrm{Ca}: \mathrm{Si}=0.83)$. (D) Defective and short dreierketten chains in C-S-H, showing two dimers $(n=0)$ and one pentamer $(n=1)$.

NMR shift calculations: Atomic positions and unit cell parameters were optimized as described in the SI section XII. The chemical shielding $\sigma_{\text {calc }}$ was calculated using the generalized gradient approximation (GGA) functional $\mathrm{PBE}^{36}$ within the Quantum Espresso code ${ }^{37}$ and the GIPAW method. ${ }^{38}$ In every calculation a plane-wave maximum cutoff energy of 80 Ry, and a Monkhorst-Pack grid of $k$-points ${ }^{39}$ corresponding to $0.03 \AA^{-1}-0.04 \AA^{-1}$ in reciprocal space was employed. The chemical shielding was converted into calculated chemical shifts $\delta_{\text {calc }}$ by the relation $\delta_{\text {calc }}=\sigma_{\text {ref }}-\sigma_{\text {calc }}$, with the value of $\sigma_{\text {ref }}$ determined by a linear regression between the calculated and experimental values for the calcium hydroxide structure ( ${ }^{1} \mathrm{H}$ chemical shifts) and the unperturbed tobermorite structure ${ }^{40}$ ( ${ }^{29} \mathrm{Si}$ chemical shifts).

\section{RESULTS AND DISCUSSION}

\section{Morphology}

Two typical morphologies were seen by electron microscopy: "nanoglobules", for the Ca:Si ratio of 1.00; and "nanofoils", for $\mathrm{Ca}: \mathrm{Si}$ ratios $\geq 1.25$, which is the morphology shown in Figure 1A. The foil morphology is very similar to morphologies for C-S-H seen in Portland cement systems with high alkaline contents. ${ }^{32,41}$ Thicknesses of the foil-like structures are generally between $6 \mathrm{~nm}$ and $10 \mathrm{~nm}$. The pure phase CS-H systems were all shown by high-resolution analytical transmission electron microscopy (TEM) to be uniform for Ca:Si ratios between 1.0 and 2.0 at less than a $9 \mathrm{~nm}^{2}$ pixel size. This is also supported by X-ray diffraction (XRD) and scanning TEM with energy dispersive X-ray analysis (STEM-EDX), as described in the SI section V. No secondary phases such as $\mathrm{Ca}(\mathrm{OH})_{2}$ were detected by IR or thermogravimetric analysis (TGA), as shown in Figure 1B; however, long exposure of C-S-H sample to open air (for example in TGA or XRD analysis) does eventually lead to the formation of $\mathrm{CaCO}_{3}$. This phenomenon manifests well in the Raman spectra of Figure $1 \mathrm{C}$, showing that $\mathrm{CaCO}_{3}$ forms during prolonged measurements in air, whereas the signature of $\mathrm{Ca}(\mathrm{OH})_{2}$ is never observed regardless of measurement duration. $\zeta$-potential measurements on the samples 

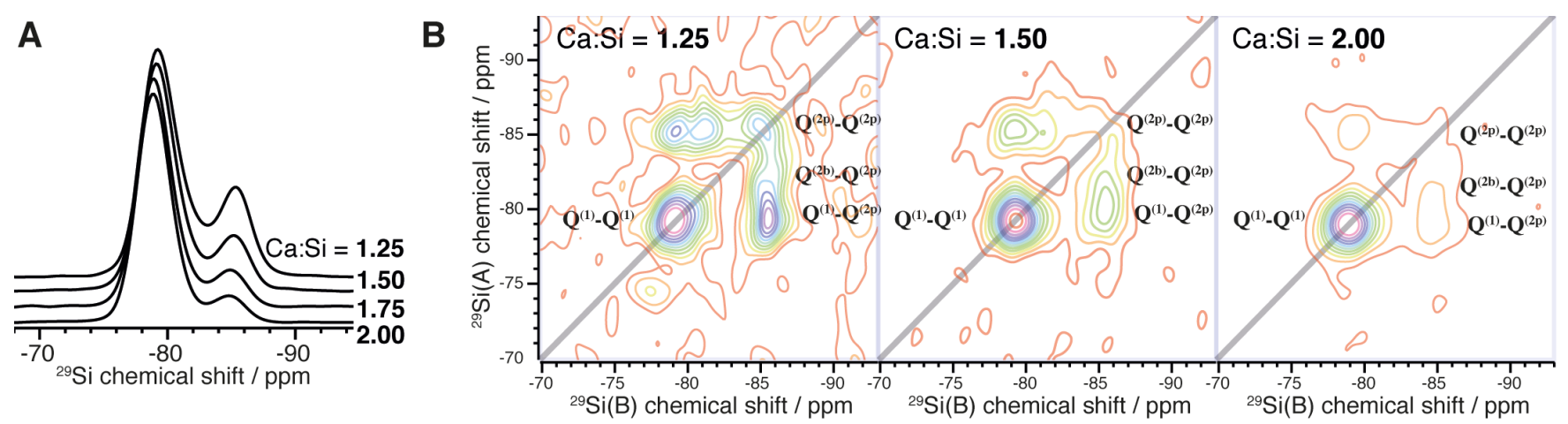

Figure 2. One- and two- dimensional DNP enhanced ${ }^{29} \mathrm{Si}$ CP MAS spectra of C-S-H samples for quantification of silicate chain distributions. (A) 1D spectra across the compositional series. (B) Experimental 2D refocused INADEQUATE spectra for three of the C-S-H compositions studied (the spectra have been sheared to produce a COSY-like representation). Contours are drawn in $10 \%$ intervals beginning at $5 \%$ of the maximum signal intensity.

show negative potential surfaces indicating that calcium does not reside at the surface but is incorporated into the particles.

\section{Characterization by DNP NMR}

C-S-H is a poorly ordered material, making atomic level structural determination using conventional X-ray and neutron diffraction methods challenging, especially for non-dried samples. Solid-state magic-angle spinning (MAS) NMR is a powerful method for studying disordered systems, and has been extensively used to study the molecular structure of C$\mathrm{S}-\mathrm{H}$ and related mineral phases. ${ }^{42}$ Previous ${ }^{29} \mathrm{Si}$ MAS NMR ${ }^{40,43-47}$ and diffraction studies, often on dried materials, have established that the silicate chains in C-S-H are arranged according to the "dreierketten" model, ${ }^{44,46,48,49}$ which specifies a repeating unit for the chains comprised of a bridging-type $Q^{(2 b)}$ silicate tetrahedron flanked by pairing-type $\mathrm{Q}^{(2 \mathrm{p})}$ silicate tetrahedrons, highlighted in the tobermorite structure shown in Figure 1D. The silicate chains are flanked by a calcium oxide layer and a hydrous interlayer. Each silicate tetrahedron shares two $\mathrm{O}$ atoms with other silicate tetrahedrons and on this basis are both classified as $\mathrm{Q}^{(2)}$ species. The pairing-type $\mathrm{Q}^{(2 \mathrm{p})}$ species direct the other two $\mathrm{O}$ atoms toward the main calcium layer whereas the bridging-type $Q^{(2 b)}$ species direct them toward the hydrous interlayer. Defects occur through the removal of a $\mathrm{Q}^{(2 b)} \mathrm{SiO}_{2}$ unit, breaking up the idealized infinite silicate chains of tobermorite into finite segments consisting of $(3 n+2)$ silicate tetrahedrons, as illustrated in Figure 1E. The segments are terminated by $\mathrm{Q}^{(1)}$ silicate species. The interlayer calcium and water present in the original $14 \AA$ tobermorite are $\mathrm{Ca}_{\mathrm{I}}$ and $\mathrm{H}_{2} \mathrm{O}$ respectively whereas the $\mathrm{Ca}_{\mathrm{B}}, \mathrm{Ca}_{\mathrm{A}}$ and $\mathrm{OH}_{\mathrm{I}}$ are only present in the defective structures. $\mathrm{Ca}_{\mathrm{B}}$ sites replace bridging silicate tetrahedrons, $\mathrm{Ca}_{\mathrm{A}}$ sites are additional calcium atoms in the interlayer, and $\mathrm{OH}_{\mathrm{I}}$ are additional hydroxyl groups in the interlayer to charge compensate the additional Ca ions needed to reach high Ca:Si ratios. Silicate dimers $(n$ $=0$ ) have been observed by $\left\{{ }^{29} \mathrm{Si}\right\}{ }^{29} \mathrm{Si}$ correlation NMR experiments to be the dominant species for systems with Ca:Si $\sim 1.5$, both for synthetic C-S-H systems and during the initial formation of C-S-H in hydrating tricalcium silicate. ${ }^{46,50}$

To overcome the low sensitivity of ${ }^{29} \mathrm{Si}$ MAS NMR at natural isotopic abundance we use modern DNP strategies. ${ }^{26-28}$ DNP is based on the transfer of large unpaired electron spin polarization to nearby protons by saturation of the electron spin transitions with microwaves, followed by CP transfer of the enhanced polarization to the ${ }^{29} \mathrm{Si}$ nuclei. The electron polarization is provided here by the organic biradical AMUPol ${ }^{51}$ that is added to the wet C-S-H as a minimal amount of $\mathrm{d}_{8}$-glycerol $/ \mathrm{D}_{2} \mathrm{O}$ solution before the $\mathrm{NMR}$ sample is rapidly cooled to $100 \mathrm{~K}$ for the experiments. ${ }^{28,52-54}$ The cryogenic temperatures are required to maximize the sensitivity enhancements by DNP, but are also important here to quench proton exchange and prevent the C-S-H from degrading during the experiments. Efficient DNP occurs only for those parts of the sample that have successfully passed through the glass transition. We also note that pore water is susceptible to glass formation when rapidly inserted into the pre-cooled NMR probe even without the addition of a glassing agent such as glycerol. ${ }^{55}$ We therefore do not expect the C-S-H structure to be disrupted by our experimental conditions; furthermore, even if pore water does crystallize in parts of the sample, inefficient DNP will suppress the NMR signal from these regions.

The polarizing agent contains labile deuterons, which can lead to the formation of calcium silicate deuterate through isotope exchange. At most, $40 \mathrm{~mol} \%$ of labile hydrogen in the impregnated C-S-H gels $\left(\mathrm{C}-\mathrm{S}-\mathrm{H}\right.$ hydrogen, $\mathrm{D}_{2} \mathrm{O}$, and the -OD groups of the $\mathrm{d}_{8}$-glycerol) are deuterons given our DNP sample formulation and estimated C-S-H composition. If a reasonable allowance for excess pore and adsorbed water is made, this falls to about $25 \%$. In fact, this upper limit is almost certainly never reached. Small-angle neutron scattering studies have shown that deuteron exchange into the gel is a diffusion driven process providing full isotope exchange on the time scale of tens of hours. ${ }^{56}$ Since the impregnated sample never spent more than $1.25 \mathrm{~h}$, and usually just $0.25 \mathrm{~h}$, at room temperature prior to experiments, we expect the highest degree of partial deuteration to be surface based and the NMR signal should be representative of fully protonated bulk C-S-H. Moreover, there is little in the way of evidence in the small-angle neutron scattering literature to suggest that isotope exchange modifies C-S-H in any structurally significant way.

One-dimensional $\left\{{ }^{1} \mathrm{H}\right\}{ }^{29} \mathrm{Si}$ DNP CP echo spectra for the five compositions are shown in Figure 2A. With the exception of the $\mathrm{Ca}: \mathrm{Si}=1.00$ composition, good fits to the line shapes are obtained by modeling each of the constituent $Q$ sites as a Gaussian function, whose amplitudes are used to determine the relative populations of the $\mathbf{Q}$ species. Relative 

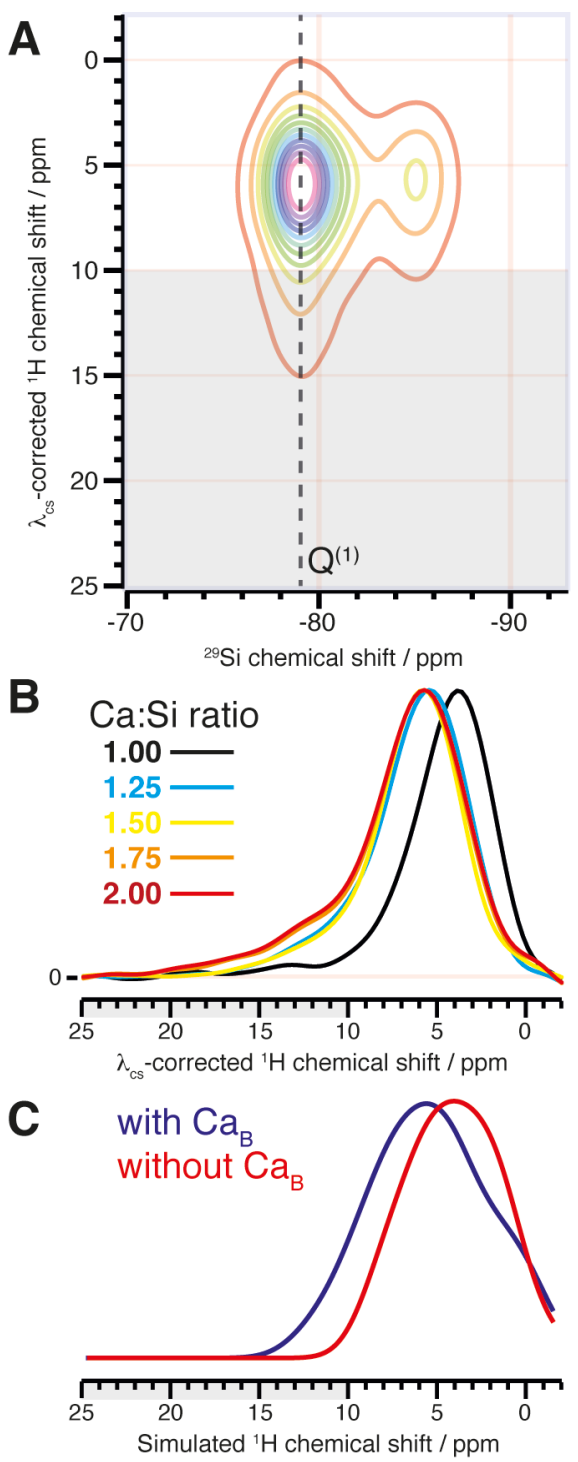

Figure 3. DNP enhanced 2D $\left\{{ }^{1} \mathrm{H}\right\}{ }^{29}$ Si HETCOR correlating ${ }^{1} \mathrm{H}$ spectra to specific $\mathrm{Si}$ sites. (A) The $2 \mathrm{D}$ correlation spectrum for the $\mathrm{Ca}: \mathrm{Si}=1.50$ composition acquired with a $7 \mathrm{~ms} \mathrm{CP}$ contact time. (B) $1 \mathrm{D}$ cross sections parallel to the ${ }^{1} \mathrm{H}$ dimension extracted at the position of the dashed line in the $2 \mathrm{D}$ spectrum, representing ${ }^{1} \mathrm{H}$ spectra correlated to $\mathrm{Q}^{(1)}$. (C) Simulated ${ }^{1} \mathrm{H}$ chemical shift spectra aggregated over C-S-H substructures that either possess (blue) or lack (red) the bridging calcium site CaB. The intensity of these spectra are normalized with respect to the maximum of the $Q^{(1)}$ peak. The region downfield of $10 \mathrm{ppm}$ is shaded to indicate the domain of strongly hydrogen bonded species.

signal intensities in DNP enhanced CP MAS experiments are not usually in proportion to the relative populations of the nuclei generating the signal as they often are in experiments using direct excitation without hyperpolarization unless we assume that 1) the length scale of hyperpolarization nonuniformity is larger than the unit cell of the particle, and 2) cross-polarization kinetics can be measured and used to adjust the signal intensities appropriately.

The size of the C-S-H particles are sufficiently small and have a proton density sufficient for nearly uniform polarization of the particles over the recycle period. To the second point, we performed cross-polarization measurements for different values of the cross-polarization contact time. This data was fit to a simple $I S$ model of CP kinetics for each site $^{57}$. A detailed description of the fitting procedure and the Q populations determined by this method are given in the SI section VIII. We note here that the failure of the $\mathrm{Ca}: \mathrm{Si}=$ 1.00 composition to fit well to the three-Gaussian model suggests a different molecular structure.

The $\left\{{ }^{29} \mathrm{Si}\right\}{ }^{29} \mathrm{Si}$ connectivity is measured using $2 \mathrm{D}$ refocused INADEQUATE experiments, ${ }^{58}$ whose application to cementitious systems has hitherto not been feasible without isotopic enrichment. 46,50 In the $\left\{{ }^{29} \mathrm{Si}\right\}{ }^{29} \mathrm{Si}$ INADEQUATE spectrum only signals from covalently bonded ${ }^{29} \mathrm{Si}-\mathrm{O}-{ }^{29} \mathrm{Si}$ pairs are retained. For linear silicate chains at natural isotopic abundance, these constitute at most $0.5 \%$ of all $\mathrm{Si}-\mathrm{O}-\mathrm{Si}$ pairs. The improvement in NMR sensitivity provided by DNP makes it possible to obtain such spectra, ${ }^{59}$ as shown in Figure 2B. Autocorrelation peaks corresponding to $\mathrm{Q}^{(1)-} \mathrm{Q}^{(1)}$ dimer and $\mathrm{Q}^{(2 \mathrm{p})}-\mathrm{Q}^{(2 \mathrm{p})}$ extender units are observed, but peaks corresponding to $\mathrm{Q}^{(2 \mathrm{~b})}-\mathrm{Q}^{(2 \mathrm{~b})}$ are always absent, consistent with the dreierketten model. Remarkably, the usually dominant $Q^{(1)-} Q^{(1)}$ autocorrelation peak is entirely absent for the

$\mathrm{Ca}: \mathrm{Si}=1.00$ composition (SI section IX), suggesting that this composition does not contain silicate dimers. Cross peaks from all three $Q$ sites to $Q^{(2 p)}$ are also observed. Using the chemical shift constraints from the deconvolution of the 1D CP echo spectra, the INADEQUATE spectra are decomposed using 2D Gaussian line shapes to model each of the six possible correlation peaks. This line shape generates reasonably good fits (SI section IX), suggesting that the chemical disorder is very local. The $2 \mathrm{D}$ peak intensities are fit simultaneously across the four compositions for a conditional probability $P(\mathrm{~A} \mid \mathrm{B})$ that $\mathrm{Q}$ site $\mathrm{A}$ is connected to $\mathrm{Q}$ site $\mathrm{B}$.

2D $\left\{{ }^{1} \mathrm{H}\right\}{ }^{29}$ Si HETCOR experiments were used to correlate ${ }^{1} \mathrm{H}$ chemical shifts with the ${ }^{29} \mathrm{Si}$ chemical shifts. Measurements were made using $\mathrm{CP}$ contact times of $0.7 \mathrm{~ms}$ and $7 \mathrm{~ms}$ for each sample. The use of a short contact time biases the contribution to the NMR signal from those protons that are close to the correlating ${ }^{29} \mathrm{Si}$ nuclei, as compared to longer range correlations observed in the long contact time experiment, which samples proton environments out to $\sim 1 \mathrm{~nm}$.

The line shape in the $2 \mathrm{D}{ }^{1} \mathrm{H}\left\{{ }^{29} \mathrm{Si}\right\}$ HETCOR spectrum shown in Figure 3A is dominated by inhomogeneous broadening resulting from chemical disorder, which prevents an accurate line shape deconvolution on the basis of proton site. Cross sections of these spectra yield ${ }^{1} \mathrm{H}$ chemical shift spectra correlated to specific $Q$ sites, as shown in Figure 3B for the $\mathrm{Q}^{(1)}$ correlation and in the SI section $\mathrm{X}$ for the others. We find that the intensity of the of the $Q^{(1)}$ site relative to the $Q^{(2)}$ sites is greater at shorter contact time, implying that $\mathrm{Q}^{(1)}$ species are located in a relatively hydrogen rich environment. We also see that the ${ }^{1} \mathrm{H}$ chemical shift profiles for the Ca:Si $\geq 1.25$ ratios possess a significant contribution above 10 ppm, indicative of strong hydrogen bonding. ${ }^{60}$ A comparison to HETCOR spectra taken at short contact time (SI section $\mathrm{X}$ ) reveals that the prominence of the downfield region for the $\mathrm{Q}^{(1)}$ correlated cross sections increases significantly at short contact time, a feature which is not shared by the $\mathrm{Q}^{(2 \mathrm{~b})}$ and $Q^{(2 p)}$ cross sections. This suggests that the strong hydrogen bonding occurs primarily in association with $\mathrm{Q}^{(1)}$ sites. We note that the signature of strong hydrogen bonding is almost entirely absent from the HETCOR spectrum of the $\mathrm{Ca}: \mathrm{Si}=1.00$ composition, once again producing a spectrum 


\begin{tabular}{crl} 
Sample & $x_{0}$ & $\sum_{n=0} x_{n} n$ \\
\hline $\mathrm{Ca}: \mathrm{Si}=1.25$ & 0.751 & 0.450 \\
$\mathrm{Ca}: \mathrm{Si}=1.50$ & 0.816 & 0.285 \\
$\mathrm{Ca}: \mathrm{Si}=1.75$ & 0.873 & 0.185 \\
$\mathrm{Ca}: \mathrm{Si}=2.00$ & 0.900 & 0.136
\end{tabular}

Table 1. Dimer mole fraction $x_{0}$ and mean repeat index for the four compositions analyzed.

deviating substantially from its relatively calcium rich counterparts.

The line shapes lack any significant features near 2 ppm, where basic hydroxide protons would be prominent, suggesting any secondary amorphous or crystalline $\mathrm{Ca}(\mathrm{OH})_{2}$ phase, if present, is not intimately mixed with the C-S-H structure. Such a signal was previously reported for C-S-H compositions with Ca:Si ratios up to $1.5{ }^{46,50}$ It may be that the C-S$\mathrm{H} / \mathrm{Ca}(\mathrm{OH})_{2}$ nanocomposite results from excessive drying and aging of the sample. Indeed, a recent high energy X-ray study lending support for a secondary phase of $\mathrm{Ca}(\mathrm{OH})_{2}$ nanosheets interwoven into the C-S-H interlayer suggests that the $\mathrm{Ca}(\mathrm{OH})_{2}$ phase grows as $\mathrm{C}-\mathrm{S}-\mathrm{H}$ ages. ${ }^{17}$

\section{Structural determination}

It is known that C-S-H resembles a defective tobermorite. ${ }^{44,61}$ In contrast to previous structural modeling studies for C-S$\mathrm{H}$, which consider random defects in tobermorite systems containing hundreds of atoms, ${ }^{44,62}$ we adopt a methodology that focuses on the systematic creation of structurally welldefined defects. The defective substructures are then used as building blocks to represent C-S-H at higher Ca:Si ratios.

A suitable base structure is required to begin. Tobermorite structures are generally named after their characteristic interlayer distances; namely, $9 \AA$, $11 \AA$, or $14 \AA$ tobermorite. ${ }^{63-65}$ The choice of base structure for modeling depends the Ca:Si ratio $^{66}$ and drying conditions. ${ }^{2,67} \mathrm{~A}$ dataset compiled by Richardson ${ }^{2}$ shows that the interlayer distance in C-S-H decreases from $\sim 13-14 \AA$ at $\mathrm{Ca}: \mathrm{Si}=0.8$ to $\sim 10 \AA$ at $\mathrm{Ca}: \mathrm{Si}=$ 1.5. Recently, Roosz et. al. ${ }^{68}$ have shown that sample preparation and relative humidity significantly affect the interlayer distance measurement. The interlayer distance measured for a C-S-H of Ca:Si = 1.2 using XRD in dry and fully hydrated states were 9.5 and $12.3 \AA$, respectively. Since our samples are hydrated, we choose $14 \AA$ tobermorite (Figure 1D) as the base motif for constructing our atomic-level model of C-S-H.

A defect is introduced by the removal of an $\mathrm{SiO}_{2}$ unit from a $\mathrm{Q}^{(2 b)}$ unit. The extent to which we need to create defects is determined by the distribution of silicate chain lengths. With the Q species populations and connectivities we can determine the distribution of chain lengths for each composition,

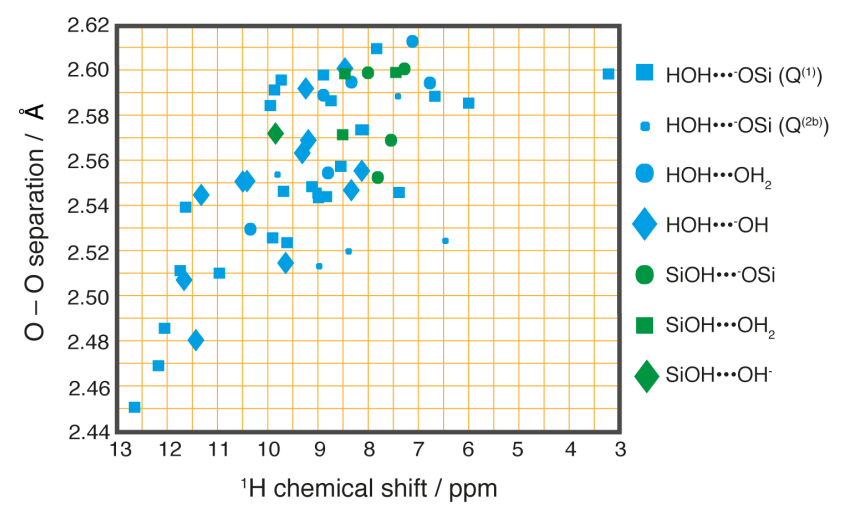

Figure 4. Scatter plot showing the correlation between the $\mathrm{O}-$ $\mathrm{O}$ distances and the chemical shifts of protons participating in the different types of hydroxyl-oxygen interactions occurring in the C-S-H substructures.

as described in the SI section IX and given in Table 1, to find

$$
\sum_{n=0} x_{n} n=\frac{P\left(\mathrm{Q}^{(2 \mathrm{p})}\right)}{P\left(\mathrm{Q}^{(1)}\right)}
$$

where $x_{n}$ is the mole fraction of dreierketten chain species with repeat index $n$, and

$$
x_{0}=P\left(\mathrm{Q}^{(1)} \mid \mathrm{Q}^{(1)}\right) \text {, }
$$

as the mole fraction of dimers. The quantitative NMR results thereby provide three independent constraints for calculating the distribution of silicate chains for each C-S-H composition. Using these constraints, we adopt a Monte Carlo method to predict the mole fraction distribution for chains up to $n$ $=10$, which we report in the SI section XI for each composition.

Defect creation transforms the silicate tetrahedrons adjacent to the removed $\mathrm{Q}^{(2 \mathrm{~b})}$ site into $\mathrm{Q}^{(1)}$ sites, requiring the addition of $\mathrm{H}^{+}$and $\mathrm{CaOH}^{+}$to satisfy requirements of local charge balance. Additional molecular units of $\mathrm{H}_{2} \mathrm{O}$ and $\mathrm{Ca}(\mathrm{OH})_{2}$ can also be incorporated into the structure. The defective motif is deemed acceptable if correct atomic bond distances, coordination numbers, and local charge balance remain satisfied after structural relaxation using density functional theory (DFT), leading to a series of substructures which are classified on the basis of defect geometry. Reduced unit cells are constructed by connecting the defect units through an aqueous interlayer or an aqueous interlayer with a Cai and additional $\mathrm{OH}^{-}$for charge balance. In order to study medium range effects, we also consider different ways to combine the reduced unit cells, resulting in chain, dimer, and pentamer motifs.

We study the effect of these different defect structures on the ${ }^{1} \mathrm{H}$ chemical shifts. A set of reduced unit cells are chosen to ensure a wide variety of different local defect environments as represented by the defect classification scheme described in the SI section XI. In Figure 3C, we show two calculated ${ }^{1} \mathrm{H}$ chemical shift spectra composed by summing over substructures that either possess or lack $\mathrm{Ca}_{\mathrm{B}}$. In comparison with the experimental ${ }^{1} \mathrm{H}$ spectra in Figure $3 \mathrm{~B}$, these 


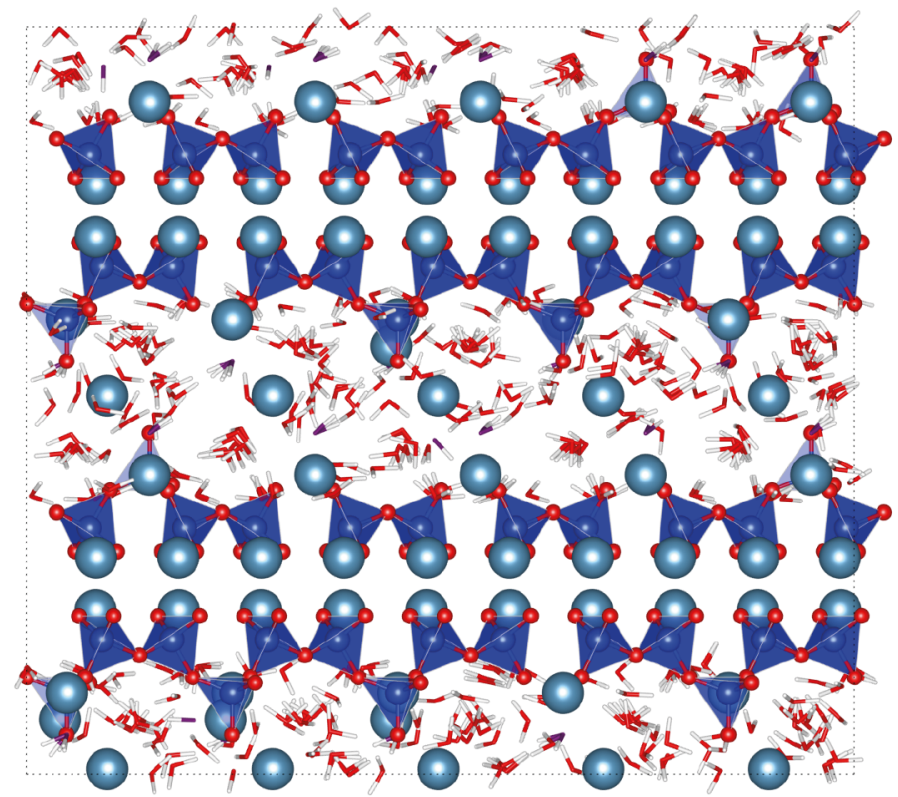

Figure 5. The structure determined here of C-S-H for a Ca:Si ratio of 1.5, viewed along the [A] axis. The relative proportions of dimers, pentamers, octamers, undecamers, and tetradecamers are $81 \%, 14 \%, 3 \% 1 \%$, and $1 \%$, respectively. The chemical composition of this structure is $\mathrm{Ca}_{1.5} \mathrm{SiO}_{3.35}(\mathrm{OH})_{0.3} \cdot 2 \mathrm{H}_{2} \mathrm{O}$. The relative positions of hydroxyls and water molecules have been relaxed keeping all other atoms frozen for ease of visualization.

calculated spectra suggest that $C a_{B}$ is responsible for generating ${ }^{1} \mathrm{H}$ NMR signals downfield of $10 \mathrm{ppm}$. Furthermore, the association between downfield shifted protons and hydrogen bonding leads us to infer that bridging calcium holds terminating chains together by coordinating to the defect site and promoting the formation of strong hydrogen bonds. On this basis we might also conjecture that bridging calcium is preferentially associated with silicate dimers, as suggested by the fact that both strong hydrogen bonds and dimers are lost when crossing under to the $\mathrm{Ca}: \mathrm{Si}=1.00$ composition, though without further evidence this remains speculative.

The proton chemical shift calculations provide additional structural insight regarding the nature of the hydrogen bonding interactions. As Figure 4 shows, there is a linear correlation between the calculated ${ }^{1} \mathrm{H}$ chemical shift and the $\mathrm{O}-\mathrm{O}$ separation of the species engaged in electrostatic hydrogenoxygen interactions, a well-established trend for inorganic oxide systems. ${ }^{60}$ In particular, we observe that interlayer water protons that interact with interlayer hydroxide ions and the oxygen atoms of $\mathrm{Q}^{(1)}$ sites dominate in their contribution to the ${ }^{1} \mathrm{H}$ chemical shift signal above $10 \mathrm{ppm}$. The key observation here is that each of these types of protons are located within 3 to $4 \AA$ of Caв. Furthermore, we may consider that the protons involved in hydrogen bonding between interlayer water and a $Q^{(1)}$ oxygen atom are less than a $3 \AA$ from the $\mathrm{Q}^{(1)}$ silicon atom and are therefore favored in the HETCOR experiments at short contact time. For only two of the substructures analyzed, one of which lacks Caa entirely, the proton from the strongest $\mathrm{OH}_{2}-\mathrm{OH}^{-}$group is located greater than $5 \AA$ away from a $Q^{(1)}$. We infer that it is these types of protons which explains the prominence of the region downfield of $10 \mathrm{ppm}$ in the $\mathrm{Q}^{(1)}$ correlated proton spectrum, and that their association with bridging calcium in the structures that we have analyzed strengthens the confidence of our association.
Construction of structures that are representative of C-S-H proceeds by drawing from these defective substructures and the defect-free motif and tessellating them in a way that satisfies both the constraints of stoichiometry and the chain distribution determined by the ${ }^{29} \mathrm{Si}$ NMR results. High Ca:Si ratios are obtained by deprotonation of a $\mathrm{Q}^{(2 \mathrm{~b})}$ silanol and adding $\mathrm{CaOH}^{+}$and $\mathrm{Ca}(\mathrm{OH})_{2}$ in the form of $\mathrm{Ca}_{\mathrm{A}}$ to the interlayer (Figure 1E). Our representative C-S-H unit cell is a tessellation of sixty such substructures coming to roughly 3 $\mathrm{nm}$ on each side, consistent with the degree of uniformity found by high-resolution analytical TEM. One such bulk C$\mathrm{S}-\mathrm{H}$ structure permitted by the ensemble of experimental NMR constraints determined for the Ca:Si ratio of 1.50 is shown in Figure 5. A 2 ns MD simulation at constant pressure and temperature $(300 \mathrm{~K})$ shows that the resulting structures are stable, with realistic bond lengths and coordination geometries predicted. The C-S-H structures we propose for each the four compositions are given in the SI section XII. Unlike previously proposed structures based upon defective tobermorite, 15,44,69,70 our computational methodology specifies unambiguously the positions and coordination of calcium in the interlayer, rather than leaving them undefined or relegating its existence to a second phase, as in the tobermorite $/ \mathrm{Ca}(\mathrm{OH})_{2}$ model. We do not claim that these structures represent the most energetically stable configurations; rather, we locate a viable, locally minimized configuration satisfying the NMR constraints. The proposed bulk structures are representative of a series of similar structures with similar defect concentrations and slightly different atomic arrangements. This should not change the average properties, but does explain why there is very little structural order seen in X-ray powder diffraction of non-dried C-S-H. 


\section{CONCLUSIONS}

We introduce a new synthetic method for C-S-H which controls $\mathrm{pH}$ throughout the process, and we produced uniform C-S-H with controlled Ca:Si ratios up to 2.0 for the first time. High sensitivity DNP solid-state NMR techniques have been used to characterize unique highly uniform synthetic C$\mathrm{S}-\mathrm{H}$ particles with high $\mathrm{Ca}: \mathrm{Si}$ ratios. In conjunction with atomistic scale modeling, atomic-level structures of defective tobermorite coherent over Ca:Si ratios from 1.25 to 2.00 have been determined without invoking secondary phases or glassy structures as confirmed by the clear absence of a signal from basic $\mathrm{Ca}-\mathrm{OH}$ units in the 2D $\left\{{ }^{1} \mathrm{H}\right\}{ }^{29} \mathrm{Si}$ HETCOR experiments. To interpret this data, we developed a computational approach which explores defective tobermorite substructural candidates, combining them in a manner satisfying our experimental constraints in order to build a full 3D structure which provides an accurate representation of structural and chemical environments in $\mathrm{C}-\mathrm{S}-\mathrm{H}$ for $\mathrm{Ca}: \mathrm{Si}$ ratios up to 2.0. An essential aspect of these structures is the inclusion of a calcium site in the interlayer which bridges chain terminating silicate $Q^{(1)}$ sites. This site is associated with an environment of strong hydrogen bonding which stabilizes the structure and, consequently, promotes high Ca:Si ratios in C-S-H. This thus establishes a clear relation between the atomiclevel defect structure and the high Ca:Si ratio in C-S-H. This knowledge of the defect structure is a prerequisite for overcoming the self-limiting growth of $\mathrm{C}-\mathrm{S}-\mathrm{H}$ and to better understand growth mechanisms and kinetics. Such knowledge can further help formulate new classes of sustainable cements capable of exhibiting strong chain-bridging hydrogen bonding features while ensuring the early age strength development of the material.

\section{ASSOCIATED CONTENT}

\section{Supporting Information}

Supplementary text and figures (.pdf)

Coordinate files for substructures and bulk representations

The Supporting Information is available free of charge on the ACS Publications website.

\section{AUTHOR INFORMATION}

\section{Corresponding Authors}

*Email: lyndon.emsley@epfl.ch,paul.bowen@epfl.ch

\section{Author Contributions}

All authors have given approval to the final version of the manuscript.

\section{ACKNOWLEDGMENT}

The authors would like to acknowledge funding from the Swiss National Foundation (Grants No. 153044 and 200021_160112) and ERC Advanced Grant No. 320860. We would also like to thank Dr. Sandra Galmarini, Dr. V.K. Parashar, Dr. B. Lothenbach, Dr. T. La Grange, and Dr. D. Demurtas for fruitful discussions. Dr. D. Lambert and Prof. G. Massonnet are thanked for their assistance with collecting the Raman data. The authors declare no competing financial interests.

\section{REFERENCES}

(1) Lothenbach, B.; Nonat, A. Calcium Silicate Hydrates: Solid and Liquid Phase Composition. Cem. Concr. Res. 2015, 78, Part A, 57-70.

(2) Richardson, I. G. Model Structures for C-(A)-S-H(I). Acta Crystallog.,. Sect. B: Struct. Sci., Cryst. Eng. Mater. 2014, 70 (6), 903923.

(3) Prati, G.; Gandolfi, M. G. Calcium Silicate Bioactive Cements: Biological Perspectives and Clinical Applications. Dent. Mater. 2015, 31 (4), 351-370.

(4) Ho, C.-C.; Wei, C.-K.; Lin, S.-Y.; Ding, S.-J. Calcium Silicate Cements Prepared by Hydrothermal Synthesis for Bone Repair. Ceram. Int. 2016, 42 (7), 9183-9189.

(5) Okano, K.; Miyamaru, S.; Kitao, A.; Takano, H.; Aketo, T.; Toda, M.; Honda, K.; Ohtake, H. Amorphous Calcium Silicate Hydrates and Their Possible Mechanism for Recovering Phosphate from Wastewater. Sep. Purif. Technol. 2015, 144, 63-69.

(6) Zhao, J.; Zhu, Y.-J.; Wu, J.; Zheng, J.-Q.; Zhao, X.-Y.; Lu, B.-Q.; Chen, F. Chitosan-Coated Mesoporous Microspheres of Calcium Silicate Hydrate: Environmentally Friendly Synthesis and Application as a Highly Efficient Adsorbent for Heavy Metal Ions. 7. Colloid Interface Sci. 2014, 418, 208-215.

(7) Dezerald, L.; Kohanoff, J. J.; Correa, A. A.; Caro, A.; Pellenq, R. J.-M.; Ulm, F. J.; Saúl, A. Cement As a Waste Form for Nuclear Fission Products: The Case of ${ }^{90} \mathrm{Sr}$ and Its Daughters. Environ. Sci. Technol. 2015, 49 (22), 13676-13683.

(8) Taylor, H. F. W. Cement Chemistry; Thomas Telford, 1997.

(9) Scrivener, K. L.; Nonat, A. Hydration of Cementitious Materials, Present and Future. Cem. Concr. Res. 2011, 41 (7), 651665.

(10) Richardson, I. G.; Groves, G. W. Microstructure and Microanalysis of Hardened Ordinary Portland Cement Pastes. $\mathcal{F}$. Mater. Sci. 1993, 28 (1), 265-277.

(11) Chen, J. J.; Sorelli, L.; Vandamme, M.; Ulm, F.-J.; Chanvillard, G. A Coupled Nanoindentation/SEM-EDS Study on Low Water/Cement Ratio Portland Cement Paste: Evidence for C$\mathrm{S}-\mathrm{H} / \mathrm{Ca}(\mathrm{OH})_{2}$ Nanocomposites. 7. Am. Ceram. Soc. 2010, 93 (5), 1484-1493.

(12) Garbev, K.; Beuchle, G.; Bornefeld, M.; Black, L.; Stemmermann, P. Cell Dimensions and Composition of Nanocrystalline Calcium Silicate Hydrate Solid Solutions. Part 1: Synchrotron-Based X-Ray Diffraction. F. Am. Ceram. Soc. 2008, 91 (9), 30053014 .

(13) Garbev, K.; Bornefeld, M.; Beuchle, G.; Stemmermann, P. Cell Dimensions and Composition of Nanocrystalline Calcium Silicate Hydrate Solid Solutions. Part 2: X-Ray and Thermogravimetry Study. F. Am. Ceram. Soc. 2008, 91 (9), 3015-3023.

(14) Grangeon, S.; Claret, F.; Linard, Y.; Chiaberge, C. XRay Diffraction: A Powerful Tool to Probe and Understand the Structure of Nanocrystalline Calcium Silicate Hydrates. Acta Crystallogr., Sect. B: Struct. Sci., Cryst. Eng. Mater. 2013, 69 (5), 465-473.

(15) Richardson, I. G. Model Structures for C-(A)-S-H(I). Acta Crystallog., Sect. B: Struct. Sci., Cryst. Eng. Mater. 2014, 70 (6), 903-923.

(16) Walker, C. S.; Sutou, S.; Oda, C.; Mihara, M.; Honda, A. Calcium Silicate Hydrate (C-S-H) Gel Solubility Data and a Discrete Solid Phase Model at $25^{\circ} \mathrm{C}$ Based on Two Binary NonIdeal Solid Solutions. Cem. Concr. Res. 2016, 79, 1-30.

(17) Grangeon, S.; Fernandez-Martinez, A.; Baronnet, A.; Marty, N.; Poulain, A.; Elkaïm, E.; Roosz, C.; Gaboreau, S.; Henocq, P.; Claret, F. Quantitative X-Ray Pair Distribution Function Analysis of Nanocrystalline Calcium Silicate Hydrates: A Contribution to the Understanding of Cement Chemistry. F. Appl. Crystallogr. 2017, 50 (1), 14-21.

(18) Hirljac, J.; Wu, Z.-Q.; Young, J. F. Silicate Polymerization during the Hydration of Alite. Cem. Concr. Res. 1983, 13 (6), 877-886.

(19) Nicoleau, L.; Bertolim, M. A. Analytical Model for the Alite (C3S) Dissolution Topography. 7. Am. Ceram. Soc. 2016, 99 (3), 773-786. 
(20) Brown, P. W.; Pommersheim, J.; Frohnsdorff, G. A Kinetic Model for the Hydration of Tricalcium Silicate. Cem. Concr. Res. 1985, 15 (1), 35-41.

(21) Brown, P. W.; Franz, E.; Frohnsdorff, G.; Taylor, H. F. W. Analyses of the Aqueous Phase during Early C3S Hydration. Cem. Concr. Res. 1984, 14 (2), 257-262.

(22) Jennings, H. M. Aqueous Solubility Relationships for Two Types of Calcium Silicate Hydrate. 7. Am. Ceram. Soc. 1986, 69 (8), 614-618.

(23) García Lodeiro, I.; Macphee, D. E.; Palomo, A.; Fernández-Jiménez, A. Effect of Alkalis on Fresh C-S-H Gels. FTIR Analysis. Cem. Concr. Res. 2009, 39 (3), 147-153.

(24) Chen, J. J.; Thomas, J. J.; Taylor, H. F. W.; Jennings, H. M. Solubility and Structure of Calcium Silicate Hydrate. Cem. Concr. Res. 2004, 34 (9), 1499-1519.

(25) Lothenbach, B.; Nonat, A. Calcium Silicate Hydrates: Solid and Liquid Phase Composition. Cem. Concr. Res.

(26) Hall, D. A.; Maus, D. C.; Gerfen, G. J.; Inati, S. J.; Becerra, L. R.; Dahlquist, F. W.; Griffin, R. G. PolarizationEnhanced NMR Spectroscopy of Biomolecules in Frozen Solution. Science 1997, 276 (5314), 930-932.

(27) Maly, T.; Debelouchina, G. T.; Bajaj, V. S.; Hu, K.-N.; Joo, C.-G.; Mak-Jurkauskas, M. L.; Sirigiri, J. R.; Van Der Wel, P. C. A.; Herzfeld, J.; Temkin, R. J.; et al. Dynamic Nuclear Polarization at High Magnetic Fields. 7. Chem. Phys. 2008, 128 (5), 52211

(28) Ni, Q. Z.; Daviso, E.; Can, T. V.; Markhasin, E.; Jawla, S. K.; Swager, T. M.; Temkin, R. J.; Herzfeld, J.; Griffin, R. G. High Frequency Dynamic Nuclear Polarization. Acc. Chem. Res. 2013, 46 (9), 1933-1941.

(29) Sangodkar, R. P.; Smith, B. J.; Gajan, D.; Rossini, A. J.; Roberts, L. R.; Funkhouser, G. P.; Lesage, A.; Emsley, L.; Chmelka, B. F. Influences of Dilute Organic Adsorbates on the Hydration of Low-Surface-Area Silicates. 7. Am. Chem. Soc. 2015, 137 (25), 80968112 .

(30) Kulik, D. A. Improving the Structural Consistency of CS-H Solid Solution Thermodynamic Models. Cem. Concr. Res. 2011 41 (5), 477-495.

(31) Kulik, D. A.; Wagner, T.; Dmytrieva, S. V.; Kosakowski, G.; Hingerl, F. F.; Chudnenko, K. V.; Berner, U. R. GEM-Selektor Geochemical Modeling Package: Revised Algorithm and GEMS3K Numerical Kernel for Coupled Simulation Codes. Comput. Geosci. 2012, $17(1), 1-24$

(32) Lothenbach, B.; Winnefeld, F. Thermodynamic Modelling of the Hydration of Portland Cement. Cem. Concr. Res. 2006, 36 (2), 209-226.

(33) Rosay, M.; Tometich, L.; Pawsey, S.; Bader, R.; Schauwecker, R.; Blank, M.; Borchard, P. M.; Cauffman, S. R.; Felch, K. L.; Weber, R. T.; et al. Solid-State Dynamic Nuclear Polarization at 263 GHz: Spectrometer Design and Experimental Results. Phys. Chem. Chem. Phys. 2010, 12 (22), 5850-5860.

(34) Galmarini, S.; Kunhi Mohamed, A.; Bowen, P. Atomistic Simulations of Silicate Species Interaction with Portlandite Surfaces. 7. Phys. Chem. C 2016, 120 (39), 22407-22413.

(35) Todorov, I. T.; Smith, W.; Trachenko, K.; Dove, M. T. DL_POLY_3: New Dimensions in Molecular Dynamics Simulations via Massive Parallelism. 7. Mater. Chem. 2006, 16 (20), 19111918.

(36) Perdew, J. P.; Burke, K.; Ernzerhof, M. Generalized Gradient Approximation Made Simple. Phys. Rev. Lett. 1996, 77 (18), 3865-3868.

(37) Giannozzi, P.; Baroni, S.; Bonini, N.; Calandra, M.; Car, R.; Cavazzoni, C.; Davide Ceresoli; Chiarotti, G. L.; Cococcioni, M.; Dabo, I.; et al. QUANTUM ESPRESSO: A Modular and Open-Source Software Project for Quantum Simulations of Materials. 7. Phys. Condens. Matter 2009, 21 (39), 395502.

(38) Yates, J. R.; Pickard, C. J.; Mauri, F. Calculation of NMR Chemical Shifts for Extended Systems Using Ultrasoft Pseudopotentials. Phys. Rev. B 2007, 76 (2), 24401.

(39) Pack, J. D.; Monkhorst, H. J. Special Points for BrillouinZone Integrations. Phys. Rev. B 1977, 16 (4), 1748-1749.
(40) Rejmak, P.; Dolado, J. S.; Stott, M. J.; Ayuela, A. ${ }^{29 S i}$ NMR in Cement: A Theoretical Study on Calcium Silicate Hydrates. 7. Phys. Chem. C 2012, 116 (17), 9755-9761.

(41) Nicoleau, L.; Nonat, A.; Perrey, D. The Di- and Tricalcium Silicate Dissolutions. Cem. Concr. Res. 2013, 47, 14-30.

(42) Richardson, I. g.; Skibsted, J.; Black, L.; Kirkpatrick, R. j. Characterisation of Cement Hydrate Phases by TEM, NMR and Raman Spectroscopy. Adv. Cem. Res. 2010, 22 (4), 233-248.

(43) Brough, A. R.; Dobson, C. M.; Richardson, I. G.; Groves, G. W. Application of Selective ${ }^{29}$ Si Isotopic Enrichment to Studies of the Structure of Calcium Silicate Hydrate (C-S-H) Gels. 7. Am. Ceram. Soc. 1994, 77 (2), 593-596.

(44) Cong, X.; Kirkpatrick, R. J. ${ }^{29}$ Si MAS NMR Study of the Structure of Calcium Silicate Hydrate. Adv. Cem. Based Mater. 1996, 3 (3-4), 144-156.

(45) Skibsted, J.; Hall, C. Characterization of Cement Minerals, Cements and Their Reaction Products at the Atomic and Nano Scale. Cem. Concr. Res. 2008, 38 (2), 205-225.

(46) Brunet, F.; Bertani, P.; Charpentier, T.; Nonat, A.; Virlet, J. Application of ${ }^{29} \mathrm{Si}$ Homonuclear and ${ }^{1} \mathrm{H}-{ }^{29} \mathrm{Si}$ Heteronuclear NMR Correlation to Structural Studies of Calcium Silicate Hydrates. 7. Phys. Chem. B 2004, 108 (40), 15494-15502.

(47) Rawal, A.; Smith, B. J.; Athens, G. L.; Edwards, C. L.; Roberts, L.; Gupta, V.; Chmelka, B. F. Molecular Silicate and Aluminate Species in Anhydrous and Hydrated Cements. 7. Am. Chem. Soc. 2010, 132 (21), 7321-7337.

(48) Alizadeh, R.; Raki, L.; Makar, J. M.; Beaudoin, J. J.; Moudrakovski, I. Hydration of Tricalcium Silicate in the Presence of Synthetic Calcium-silicate-hydrate. 7. Mater. Chem. 2009, 19 (42), 7937.

(49) Foley, E. M.; Kim, J. J.; Reda Taha, M. M. Synthesis and Nano-Mechanical Characterization of Calcium-Silicate-Hydrate (CS-H) Made with $1.5 \mathrm{CaO} / \mathrm{SiO}_{2}$ Mixture. Cem. Concr. Res. 2012, 42 (9), 1225-1232.

(50) Pustovgar, E.; Sangodkar, R. P.; Andreev, A. S.; Palacios, M.; Chmelka, B. F.; Flatt, R. J.; Lacaillerie, J.-B. d'Espinose de. Understanding Silicate Hydration from Quantitative Analyses of Hydrating Tricalcium Silicates. Nat. Commun. 2016, 7, 10952.

(51) Sauvée, C.; Rosay, M.; Casano, G.; Aussenac, F.; Weber, R. T.; Ouari, O.; Tordo, P. Highly Efficient, Water-Soluble Polarizing Agents for Dynamic Nuclear Polarization at High Frequency. Angew. Chem. Int. Ed. 2013, 52 (41), 10858-10861.

(52) Lesage, A.; Lelli, M.; Gajan, D.; Caporini, M. A.; Vitzthum, V.; Miéville, P.; Alauzun, J.; Roussey, A.; Thieuleux, C.; Mehdi, A.; et al. Surface Enhanced NMR Spectroscopy by Dynamic Nuclear Polarization. f. Am. Chem. Soc. 2010, 132 (44), 15459 15461.

(53) Rossini, A. J.; Zagdoun, A.; Lelli, M.; Lesage, A.; Copéret, C.; Emsley, L. Dynamic Nuclear Polarization Surface Enhanced NMR Spectroscopy. Acc. Chem. Res. 2013, 46 (9), 1942-1951.

(54) Becerra, L. R.; Gerfen, G. J.; Temkin, R. J.; Singel, D. J.; Griffin, R. G. Dynamic Nuclear Polarization with a Cyclotron Resonance Maser at 5 T. Phys. Rev. Lett. 1993, 71 (21), 3561-3564.

(55) Thomas, J. J.; Jennings, H. M.; Allen, A. J. Determination of the Neutron Scattering Contrast of Hydrated Portland Cement Paste Using $\mathrm{H}_{2} \mathrm{O} / \mathrm{D}_{2} \mathrm{O}$ Exchange. Adv. Cem. Based Mater. 1998, 7 (3-4), 119-122.

(56) Gajan, D.; Schwarzwälder, M.; Conley, M. P.; Grüning, W. R.; Rossini, A. J.; Zagdoun, A.; Lelli, M.; Yulikov, M.; Jeschke, G.; Sauvée, C.; et al. Solid-Phase Polarization Matrixes for Dynamic Nuclear Polarization from Homogeneously Distributed Radicals in Mesostructured Hybrid Silica Materials. 7. Am. Chem. Soc. 2013 135 (41), 15459-15466.

(57) Alemany, L. B.; Grant, D. M.; Pugmire, R. J.; Alger, T. D.; Zilm, K. W. Cross Polarization and Magic Angle Sample Spinning NMR Spectra of Model Organic Compounds. 2. Molecules of Low or Remote Protonation. 7. Am. Chem. Soc. 1983, 105 (8), 21422147

(58) Lesage, A.; Bardet, M.; Emsley, L. Through-Bond Carbon-Carbon Connectivities in Disordered Solids by NMR. 7. Am. Chem. Soc. 1999, 121 (47), 10987-10993. 
(59) Lee, D.; Monin, G.; Duong, N. T.; Lopez, I. Z.; Bardet, M.; Mareau, V.; Gonon, L.; De Paëpe, G. Untangling the Condensation Network of Organosiloxanes on Nanoparticles Using 2D ${ }^{29} \mathrm{Si}-{ }^{29} \mathrm{Si}$ Solid-State NMR Enhanced by Dynamic Nuclear Polarization. F. Am. Chem. Soc. 2014, 136 (39), 13781-13788.

(60) Xue, X.; Kanzaki, M. Proton Distributions and Hydrogen Bonding in Crystalline and Glassy Hydrous Silicates and Related Inorganic Materials: Insights from High-Resolution Solid-State Nuclear Magnetic Resonance Spectroscopy. F. Am. Ceram. Soc. 2009, 92 (12), 2803-2830.

(61) Richardson, I. G. The Nature of C-S-H in Hardened Cements. Cem. Concr. Res. 1999, 29 (8), 1131-1147.

(62) Bonaccorsi, E.; Merlino, S.; Kampf, A. R. The Crystal Structure of Tobermorite $14 \AA$ (Plombierite), a C-S-H Phase. $\mathcal{F}$. Am. Ceram. Soc. 2005, 88 (3), 505-512.

(63) Merlino, S.; Bonaccorsi, E.; Armbruster, T. The Real Structures of Clinotobermorite and Tobermorite $9 \AA$ : OD Character, Polytypes, and Structural Relationships. Eur. F. Mineral. 2000, 411-429.

(64) Merlino, S.; Bonaccorsi, E.; Armbruster, T. The Real Structure of Tobermorite 11 A. Eur. F. Mineral. 2001, 13 (3), 577590.

(65) Bonaccorsi, E.; Merlino, S.; Kampf, A. R. The Crystal Structure of Tobermorite $14 \AA$ (Plombierite), a C-S-H Phase. f. Am. Ceram. Soc. 2005, 88 (3), 505-512.
(66) Renaudin, G.; Russias, J.; Leroux, F.; Frizon, F.; Cau-ditCoumes, C. Structural Characterization of C-S-H and C-A-S-H Samples-Part I: Long-Range Order Investigated by Rietveld Analyses. F. Solid State Chem. 2009, 182, 3312-3319.

(67) Grangeon, S.; Claret, F.; Linard, Y.; Chiaberge, C. XRay Diffraction: A Powerful Tool to Probe and Understand the Structure of Nanocrystalline Calcium Silicate Hydrates. Acta Crystallogr., Sect. B: Struct. Sci., Cryst. Eng. Mater. 2013, 69 (5), 465-473.

(68) Roosz, C.; Gaboreau, S.; Grangeon, S.; Prêt, D.; Montouillout, V.; Maubec, N.; Ory, S.; Blanc, P.; Vieillard, P.; Henocq, P. Distribution of Water in Synthetic Calcium Silicate Hydrates. Langmuir 2016, 32 (27), 6794-6805.

(69) Nonat, A.; Lecoq, X. The Structure, Stoichiometry and Properties of C-S-H Prepared by C3S Hydration Under Controlled Condition. In Nuclear Magnetic Resonance Spectroscopy of Cement-Based Materials; Colombet, D. P., Zanni, P. H., Grimmer, D. A.-R., Sozzani, P. P., Eds.; Springer Berlin Heidelberg, 1998; pp 197-207.

(70) Richardson, I. G. Tobermorite/Jennite- and Tobermorite/Calcium Hydroxide-Based Models for the Structure of C-SH: Applicability to Hardened Pastes of Tricalcium Silicate, $\beta$ Dicalcium Silicate, Portland Cement, and Blends of Portland Cement with Blast-Furnace Slag, Metakaolin, or Silica Fume. Cem. Concr. Res. 2004, 34 (9), 1733-1777. 
Insert Table of Contents artwork here

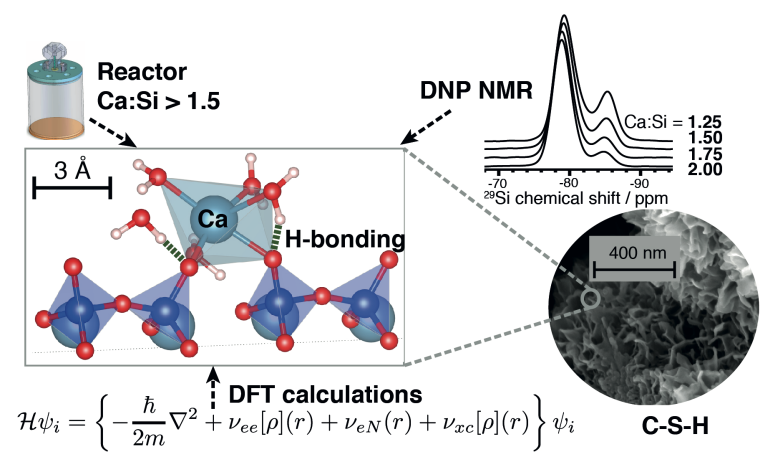




\section{The Atomic-Level Structure of Cementitious Calcium Silicate Hydrate - Supporting Information}

Abhishek Kumar, ${ }^{1}$ Brennan J. Walder, ${ }^{2}$ Aslam. K. Mohamed, ${ }^{1}$ Albert Hofstetter, ${ }^{2}$ Bhuvanesh Srinivasan, ${ }^{1,3}$ Aaron J. Rossini, ${ }^{4}$ Karen Scrivener, ${ }^{5}$ Lyndon Emsley ${ }^{2}$ and Paul Bowen ${ }^{1}$

${ }^{1}$ Powder Technology Laboratory, Institut des Matériaux, Ecole Polytechnique Fédérale de Lausanne (EPFL), CH-1015 Lausanne, Switzerland

${ }^{2}$ Institut des Sciences et Ingénierie Chimiques, Ecole Polytechnique Fédérale de Lausanne (EPFL), CH-1015 Lausanne, Switzerland

${ }^{3}$ Department of Earth \& Environmental Sciences, Ludwig-Maximilian University, D-80333, Munich, Germany

${ }^{4}$ Department of Chemistry, Iowa State University, Ames, IA 50011-3020, USA

${ }^{5}$ Construction Material Laboratory, Institut des Matériaux, Ecole Polytechnique Fédérale de Lausanne (EPFL), CH-1015 Lausanne, Switzerland 


\section{Table of Contents}

THE ATOMIC-LEVEL STRUCTURE OF CEMENTITIOUS CALCIUM SILICATE HYDRATE SUPPORTING INFORMATION 1

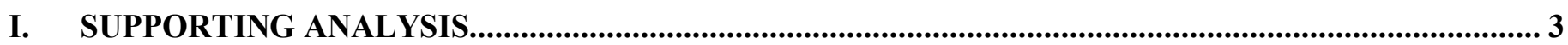

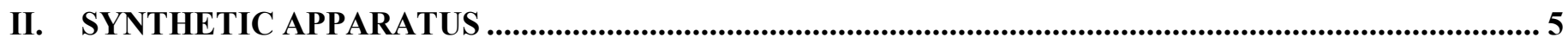

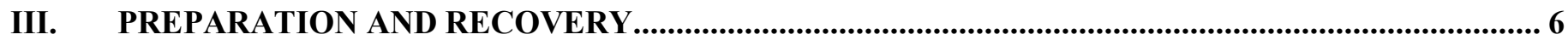

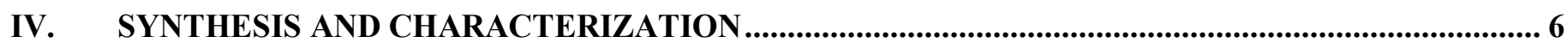

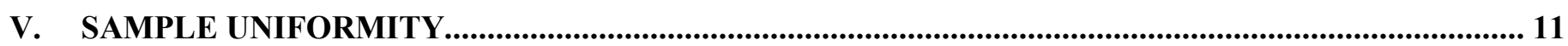

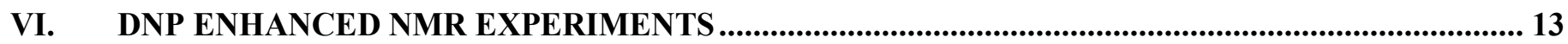

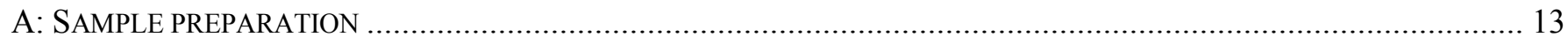

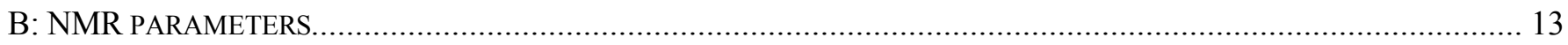

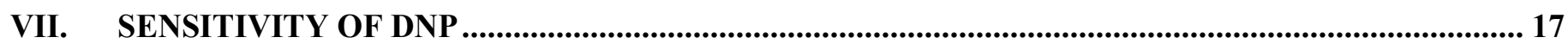

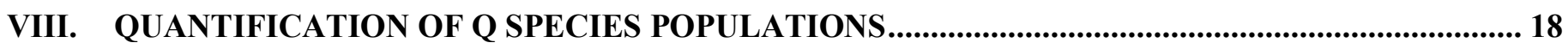

IX. QUANTIFICATION OF CHAIN DISTRIBUTIONS ........................................................................ 22

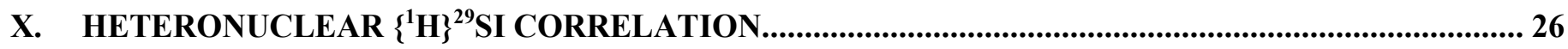

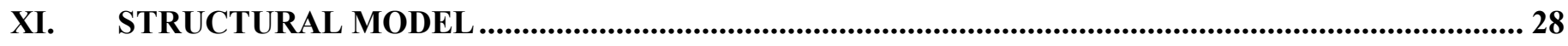

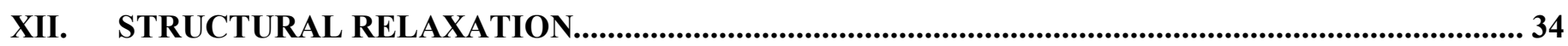

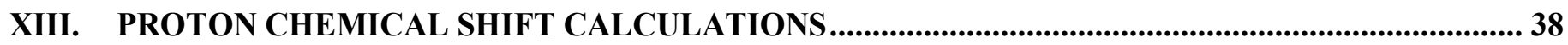

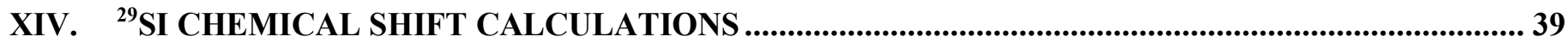

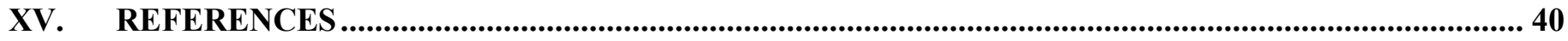




\section{Supporting Analysis}

$X R D$ : X-ray diffraction data was collected with a Bruker D8 Discover X-Ray diffractometer using double bounced monochromatic $\mathrm{CuK}$ alpha radiation $(\lambda=1.54 \AA)$ with a fixed divergence slit size $0.5^{\circ}$ and rotating sample stage. Freshly prepared C-S-H collected after washing with a water-ethanol solution followed by vacuum filtration was placed onto the sample stage and XRD patterns were recorded.

STEM EDX: Uniformity of the C-S-H was proved by chemical mapping or EDX measurements in STEM mode, using an FEI Tecnai Osiris analytical TEM instrument optimized for speed and sensitivity. The four windowless Super-X SDD EDX detectors integrated into the pole piece allow detection of 200,000 X-ray counts/s over a 0.9 srad solid angle. A high brightness XFEG gun allows EDX maps to be acquired in seconds to minutes. With a $11 \mathrm{Mpx}$ Gatan Orius CCD camera, the microscope is also suitable for conventional BF/DF and high resolution TEM imaging. A BF, two ADF, and an HAADF STEM detector provide a wide range of diffraction and Z-contrast conditions. It operates with $200 \mathrm{kV}$ high brightness XFEG with a point resolution of $0.24 \mathrm{~nm}$ and a probe current of $2 \mathrm{nA}$ for EDX studies. The sample was prepared by dispersing $50 \mathrm{mg}$ of $\mathrm{C}-\mathrm{S}-\mathrm{H}$ in $40 \mathrm{~mL}$ of isopropanol. A drop of the suspended liquid was allowed to dry on a 300 mesh copper grid.

$X R F$ : In order to cross check the ICP results the samples were analyzed using X-Ray fluorescence spectroscopy (Optim'X 9900 Ceram XRF model). $20 \mathrm{~g}$ of hydrated sample was dried at $105{ }^{\circ} \mathrm{C}$ for 24 hours and ignited at $950{ }^{\circ} \mathrm{C}$ for 1 hour. $7.7 \mathrm{~g}$ of lithium tetraborate $\left(\mathrm{Li}_{2} \mathrm{~B}_{4} \mathrm{O}_{7}\right)$ was added to the $0.7 \mathrm{~g}$ of calcinated sample to make a fused bead.

$T G A$ : Samples were heated at $10^{\circ} \mathrm{C} / \mathrm{min}$ from $30^{\circ} \mathrm{C}$ to $1000^{\circ} \mathrm{C}$ to record the weight losses in setup from Mettler Toledo AG (TGA/SDTA851e). The total water bound in C-S-H was quantified from the total water loss between 30 and $250^{\circ} \mathrm{C}$. The amount of portlandite is quantified from the water loss around of the peak in the range from $400-480{ }^{\circ} \mathrm{C}$ and calcium carbonate was around $630-710^{\circ} \mathrm{C}$. No prior sample preparation involved. 
ICP: ICP was performed on an ICPE-9000 series (Shimadzu) instrument, a multi-type ICP emission spectrometer with a near ppb detection limit. The sample compositions were analyzed using Optical Emission Spectroscopy mode (ICP-OES). $7 \mathrm{~mL}$ of $65 \% \mathrm{HNO}_{3}$ was added to a $0.25 \mathrm{~g}$ sample of C-S-H, then another $5 \mathrm{~mL}$ of fuming $100 \%$ ultra-pure $\mathrm{HNO}_{3}$ was added to ensure complete dissolution. Each analysis consists of verification at further levels of 1-, 10-, and 100-fold dilution in pure water, with the 10fold dilution affording concentrations best situated in the calibrated range of the instrument. Each analysis was repeated three times to check consistency. 


\section{Synthetic apparatus}

The reaction system was fabricated in-house for the synthesis of C-S-H. The construction material is poly(methyl methacrylate), which is chemically stable under acidic or basic conditions. Figure S1 shows a schematic of the reactor. It has four main parts - base, cylindrical wall, lid and micromixer unit. Calcium ion selective, conductivity, and $\mathrm{pH}$ measurement electrodes are inserted into the lid for real-time monitoring of the reaction conditions. There are also channels that allow for a purging flow of nitrogen gas across the main reaction chamber and an opening used for withdrawing small amounts of sample for kinetic analysis. A micromixer system is mounted on top of the vessel, consisting of three channels emerging form a central vertical column. The length of the column is fitted with a spiral static mixer to combine the reactant solutions prior to admission into the reaction chamber.

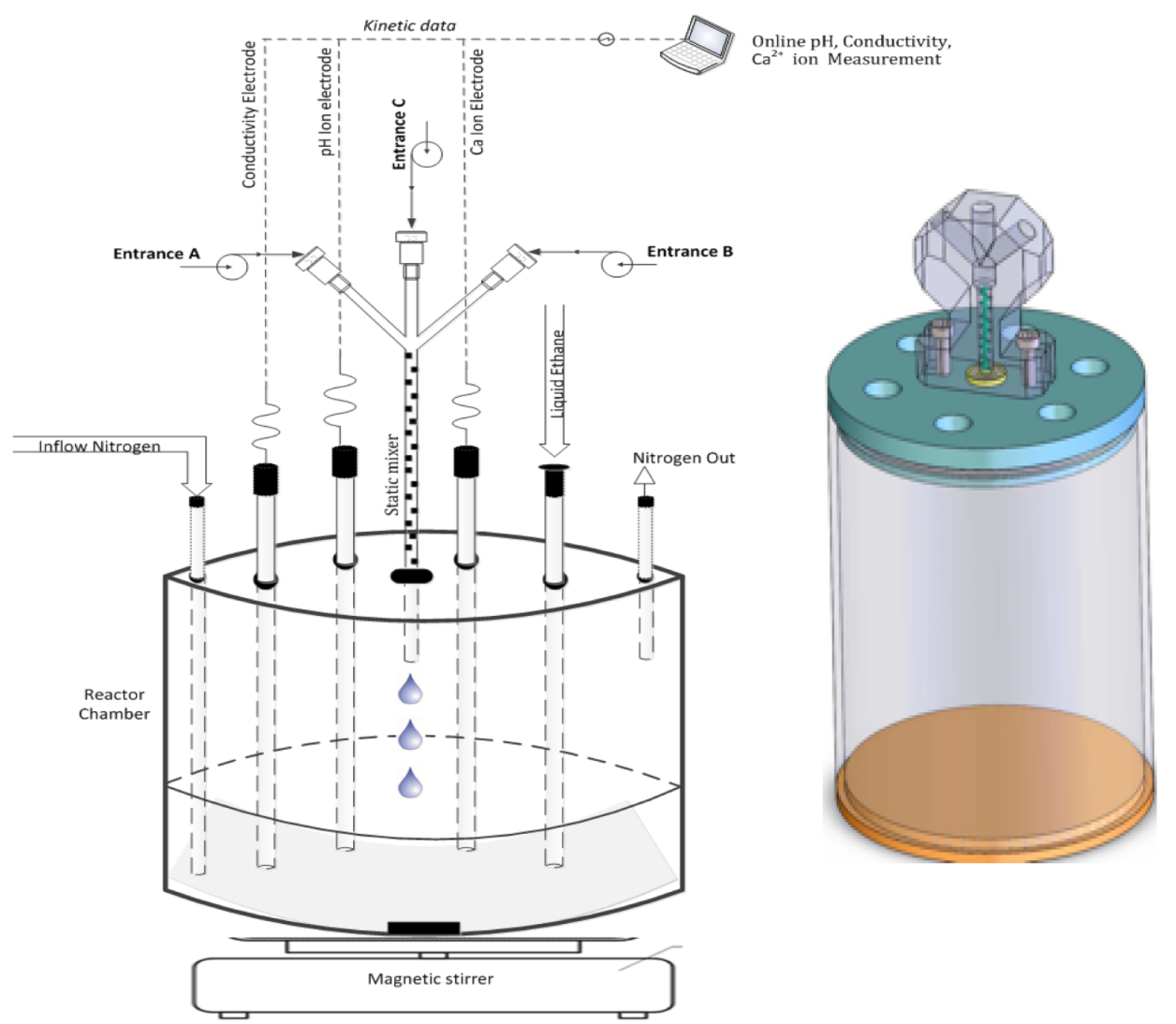

Figure S1 | Schematic of the reaction vessel. A low pulsation piston pump was used to feed the reactants into the channels $\mathrm{A}, \mathrm{B}$, and $\mathrm{C}$ at rates between $0.01 \mathrm{~mL} / \mathrm{min}$ to $5 \mathrm{~mL} / \mathrm{min}$. The off-axis reactant channels join the mixing column at an angle of $60^{\circ}$. The stirring rate was $700-800 \mathrm{rpm}$. Calcium ion selective, conductivity, and pH measurement electrodes are inserted into the lid for real-time monitoring of the reaction conditions. There are also channels that allow for a purging flow of nitrogen gas across the main reaction chamber and an opening used for withdrawing small amounts of sample for kinetic analysis. Nitrogen gas flowing at a rate of $20 \mathrm{~mL} / \mathrm{min}$ was used to purge the chamber over the course of the reaction. Data was Recorded on a PC using LabX software (Mettler-Toledo). 


\section{Preparation and recovery}

Solutions of calcium nitrate and sodium silicate were prepared in decarbonized water by boiling demineralized ultra-pure water (milliQ) for one hour and cooling in an ice bath. Solutions were immediately prepared after cooling. The quantity of solute used was measured with high accuracy. Measuring electrodes were calibrated twice before each synthesis. To avoid premature nucleation, all chemical glassware was washed and dried under laminar flow hood (Skanair ${ }^{\circledR}$, Scan AG). After crystallization, the precipitated solids were recovered by washing and vacuum filtration. For each $200 \mathrm{~mL}$ aliquot, an equal amount of ultrapure water mixed with ethanol (50:50 v:v), followed by pure ethanol, was used for the wash. Vacuum filtration was done on $20 \mathrm{~nm}$ filter paper (Whatman ${ }^{\mathrm{TM}}$, GE health care, $\varnothing 50 \mathrm{~mm}$ ) to recover the washed CS-H. The precipitated gel was carefully taken off the filter paper and stored in an airtight container. For characterization by TGA and XRD, drying of the filtered solid was necessary. This was performed under nitrogen flow at $70^{\circ} \mathrm{C}$ for 3 hours or 6 hours. All other characterizations were carried out in the native gel form.

\section{Synthesis and characterization}

For the current synthetic system, $\mathrm{pH}$ is a determining parameter for precipitation and ultimately controls the $\mathrm{Ca}$ :Si ratio and morphology. This is a consequence of how $\mathrm{pH}$ determines the predominant type of silicate species available in solution for reaction. Orthosilicic acid $\left(\mathrm{Si}(\mathrm{OH})_{4}\right)$ resists hydrolyzation even near neutral $\mathrm{pH}$ conditions owing to its small ionic radius $(0.42 \AA)$ and is therefore the predominant solution species below $\mathrm{pH}$ 7. In addition to $\mathrm{pH}$, the silicate species which appear in an aqueous system is a sensitive function of cation type and concentration, such that the presence of small quantities of impurities can yield different synthetic results. In general, hydrolysis proceeds according to the following reaction to produce anionic species:

$$
\mathrm{Si}(\mathrm{OH})_{\mathrm{x}}(\mathrm{aq}) \rightarrow \mathrm{SiO}_{\mathrm{x}}(\mathrm{OH})_{4-\mathrm{x}} \mathrm{x}^{-}+x \mathrm{H}^{+}
$$




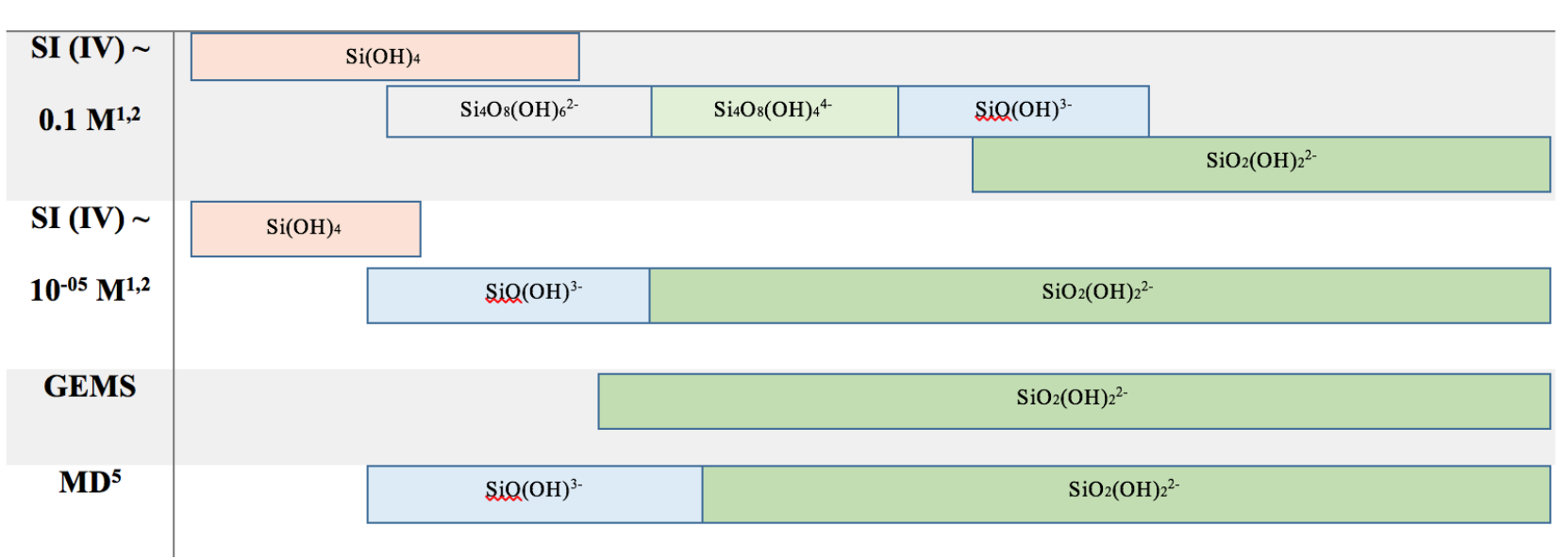

Figure S2 | Predominant silicate species in aqueous solution as a function of pH according to different conditions and methods. ${ }^{1,2}$

Sodium silicate solutions at high $\mathrm{pH}$ are likely to contain silicates such as $\mathrm{SiO}_{2}(\mathrm{OH})_{2}{ }^{2-}$. Gibbs energy minimization software ${ }^{3}$ (GEMS) predicts the same species in solution under these conditions. In conjunction with molecular dynamics $(\mathrm{MD})^{4}$, we summarize the presumable possible silicate species in solution as a function of $\mathrm{pH}$ in Figure $\mathrm{S} 2$. As long as an appropriate target $\mathrm{pH}$ range $(\mathrm{pH}>11)$ is maintained, a chemical equilibrium favoring the silicate species $\mathrm{SiO}_{2}(\mathrm{OH})_{2}{ }^{2-}$ can be achieved under a wide variety of chemical conditions even at high silicate concentrations. In other words, regardless of whether or not an initially high concentration (high supersaturation) or low concentration (low supersaturation) of aqueous silicates is used, the $\mathrm{pH}$ can be used to favor high concentrations of the important silicate species $\mathrm{SiO}_{2}(\mathrm{OH})_{2}{ }^{2-}$, leading to the production of pure uniform product C-S-H, so long as the mixing is adequate.

We begin by setting a 2:1 ratio of calcium to silicon in the starting solution using equal volumes of $0.2 \mathrm{M}$ and $0.1 \mathrm{M}$ calcium nitrate to sodium silicate. $\mathrm{GEMS}^{3,5}$ was used to calculate the $\mathrm{pH}$ required to achieve different $\mathrm{Ca}: \mathrm{Si}$ ratios, and this $\mathrm{pH}$ was achieved during synthesis by adding an appropriate amount of concentrated $\mathrm{NaOH}$, which is given in Table S1. Precipitation was allowed to occur for 24 hours before the product was collected and analyzed. The $\mathrm{pH}$ calculated according to GEMS agrees with the experimentally measured $\mathrm{pH}$. We see the amount of $\mathrm{OH}^{-}$added in the system leads to a consistently increasing Ca:Si ratio in the solid precipitating phase. 
TEM analysis shows that the morphology of the precipitated particles changes at $\mathrm{pH} 11$ and a Ca:Si ratio of 1.25. The morphology resembles foils (nanofoils) for $\mathrm{pH} \geq 11, \mathrm{Ca}: \mathrm{Si} \geq 1.25$; and globules (nanoglobules) for $\mathrm{pH}<11, \mathrm{Ca}: \mathrm{Si}<1.25$. Repeat analysis confirms that these results can be easily replicated by our synthetic apparatus.

\begin{tabular}{cccc}
\hline $\begin{array}{c}\text { Target Ca:Si } \\
\text { (GEMS) }\end{array}$ & $\begin{array}{c}\text { NaOH } \\
\text { (GEMS) }\end{array}$ & $\begin{array}{c}\text { pH } \\
\text { (GEMS) }\end{array}$ & $\begin{array}{c}\text { pH } \\
\text { (Experiment) }\end{array}$ \\
\hline 1.0 & $0.05 \mathrm{~mL}$ & 10.87 & 11.1 \\
1.25 & $5.16 \mathrm{~mL}$ & 11.47 & 12.5 \\
1.5 & $10.58 \mathrm{~mL}$ & 12.05 & 12.6 \\
1.75 & $16.62 \mathrm{~mL}$ & 12.55 & 12.7 \\
2 & $20.00 \mathrm{~mL}$ & 12.81 & 12.8 \\
\hline
\end{tabular}

Table S1 | Amount of $\mathrm{NaOH}$ added to the reaction in order to achieve the $\mathrm{pH}$ necessary to produce the targeted Ca:Si ratio according to GEMS. The actual $\mathrm{pH}$ during the reaction is given in the final column.

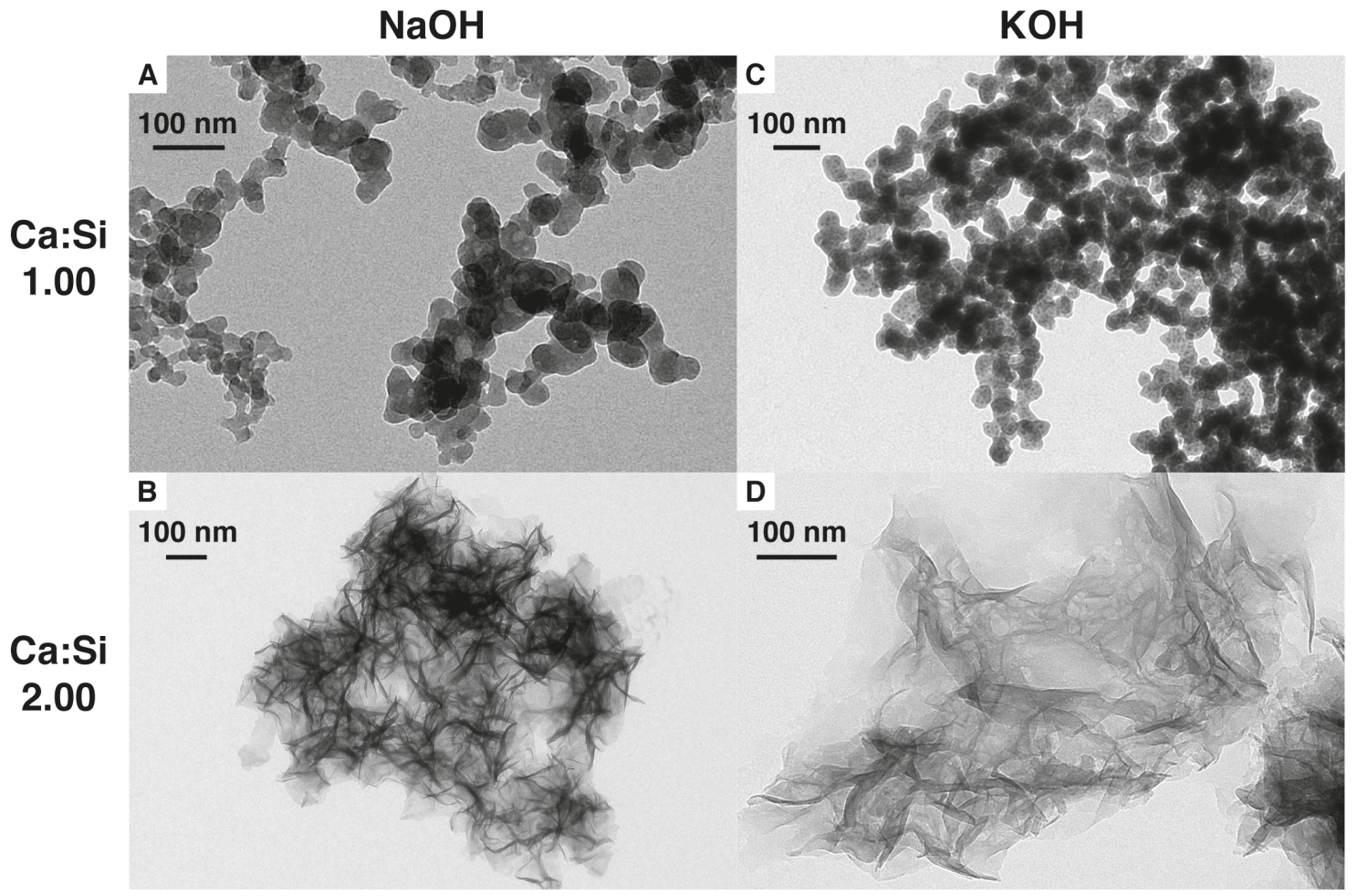

Figure S3 | TEM imagery showing the morphology of the C-S-H produced for the Ca:Si ratio extremes when different alkali cations are present in the reaction. (A) Globule morphology produced for the $\mathrm{Ca}: \mathrm{Si}=1.00 \mathrm{composition}$ using $\mathrm{NaOH}$ as pH regulator. (B) Foil morphology produced in the $\mathrm{NaOH}$ regulated reaction for the $\mathrm{Ca}: \mathrm{Si}=2.00$ composition. $(\mathrm{C}, \mathrm{D})$ Same as $\mathrm{A}$ and $\mathrm{B}$, respectively, but for the $\mathrm{KOH}$ regulated reactions. 
The composition of C-S-H produced by the rapid precipitation method is summarized in Table S2. Elemental analysis for calcium, silicon, and sodium by ICP-OES indicates that the rapid precipitation method described here succeeds in synthesizing C-S-H with the targeted Ca:Si ratios. Despite the low measured sodium concentration, we cannot completely exclude the possibility that inclusion of some sodium may affect the structure. Nevertheless, when $\mathrm{KOH}$ is used as the $\mathrm{pH}$ regulator, we observe the formation of C-S-H globules for the $\mathrm{Ca}: \mathrm{Si}=1.00$ composition and $\mathrm{C}-\mathrm{S}-\mathrm{H}$ foils for the $\mathrm{Ca}: \mathrm{Si}=2.00$ composition. These products have the same morphological properties as the product obtained when $\mathrm{NaOH}$ is used as the $\mathrm{pH}$ regulator, as shown in Figure S3. On the other hand, the presence of cations such as $\mathrm{Mg}^{2+}$ or $\mathrm{Ba}^{2+}$ leads to the formation of a heterogeneous mixture of products. This strongly suggests that alkali cations are not critical structure determining factors, and that they serve primarily as charge balancing spectators.

Furthermore, our key structural insight is the necessity of the bridging calcium, $\mathrm{Ca}_{\mathrm{B}}$, which we propose is attendant to almost every defect site at high $\mathrm{Ca}$ :Si ratios. Considering sodium substitution of $\mathrm{Ca}_{\mathrm{B}}$, we calculate the Na:defect ratio, $2\left(n_{\mathrm{Na}} / n_{\mathrm{Si}}\right) / \mathrm{P}\left(\mathrm{Q}^{(1)}\right)$, where $n_{\mathrm{Na}} / n_{\mathrm{Si}}$ is the Na:Si mole ratio by ICP-OES and $\mathrm{P}\left(\mathrm{Q}^{(1)}\right)$ is the population of $\mathrm{Q}^{(1)}$ sites determined by NMR. We find this ratio is between $10 \mathrm{~mol} \%$ and $30 \mathrm{~mol} \%$ for each of the compositions with $\mathrm{Ca}: \mathrm{Si}$ mole ratios at or above 1.25 . This means that even in the worst-case scenario, in which every sodium atom substitutes a bridging calcium in a one-to-one fashion (for which we see no driving force), there is not enough sodium to accommodate every defect. In consideration of these matters, we remain confident that the key structural properties of our C-S-H systems can be analyzed in neglect of the small residual alkali content.

\begin{tabular}{ccccc}
\hline $\begin{array}{c}\text { Nominal } \\
\text { Ca:Si }\end{array}$ & $\begin{array}{c}\text { Ca:Si } \\
\text { (XRF) }\end{array}$ & $\begin{array}{c}\text { Ca:Si } \\
\text { (ICP-OES) }\end{array}$ & $\begin{array}{c}\text { Na:Ca } \\
\text { (ICP-OES) }\end{array}$ & $\begin{array}{c}\text { Na:defect } \\
\text { (ICP-OES/NMR) }\end{array}$ \\
\hline 1.00 & 1.04 & $1.01 \pm 0.03$ & $0.13 \pm 0.01$ & $0.88 \pm 0.13$ \\
1.25 & 1.21 & $1.24 \pm 0.01$ & $0.05 \pm 0.02$ & $0.20 \pm 0.07$ \\
1.50 & 1.51 & $1.51 \pm 0.03$ & $0.02 \pm 0.01$ & $0.09 \pm 0.06$ \\
1.75 & 1.77 & $1.78 \pm 0.04$ & $0.07 \pm 0.02$ & $0.30 \pm 0.08$ \\
2.00 & 1.94 & $2.00 \pm 0.07$ & $0.05 \pm 0.01$ & $0.25 \pm 0.04$ \\
\hline
\end{tabular}

Table S2 | Mole ratios of important C-S-H components determined by various characterization methods. 

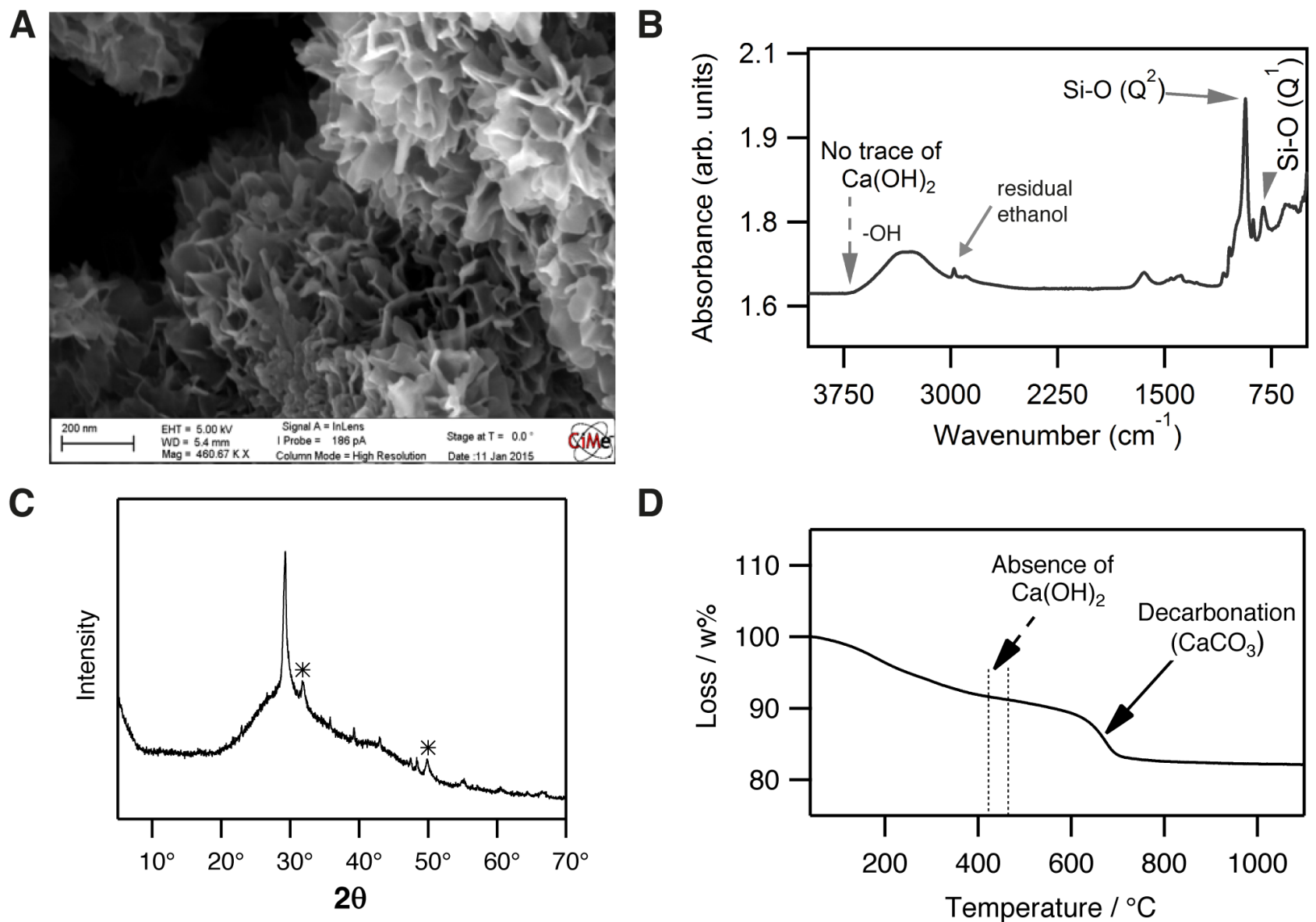

Figure S4 | Characterization of freshly prepared C-S-H for Ca:Si ratio of 2. (A) SEM image showing foil morphology. (B)

FTIR analysis. (C) XRD analysis. Resolved peaks corresponding to C-S-H are indicated with stars. Minor peaks correspond to calcium carbonate, which also contributes to the major peak at $29^{\circ}$ where it overlaps a C-S-H peak. (d) TGA analysis. A calcium hydroxide phase is never observed, but XRD and TGA reveal that C-S-H is susceptible to the formation of calcium carbonate after prolonged air exposure.

These results confirm that our synthetic procedure yields particles of C-S-H with the targeted Ca:Si ratios. Importantly, the formation of $\mathrm{Ca}(\mathrm{OH})_{2}$ is never observed, as illustrated by the FTIR, TGA and XRD analyses of the $\mathrm{Ca}: \mathrm{Si}=2.00$ sample shown in Figure S4. It is worth noting, however, that long exposure of fresh C-S-H samples in open air (for example in TGA or XRD analysis) does eventually lead to the formation of $\mathrm{CaCO}_{3}$. 


\section{Sample uniformity}

\section{Determination by non-invasive Raman microscopy}

We demonstrated compositional uniformity on pellet of C-S-H with a smoothed surface. The spot analysis

$\left(1 \mu \mathrm{m}^{2}\right)$ analyzed more than 30 points on the particle surface. At depths of $4 \mu \mathrm{m}$ and $8 \mu \mathrm{m}$ the characteristic peaks positions in the $\mathrm{C}-\mathrm{S}-\mathrm{H}$ do not change, indicating the chemical environment uniformity of the sample at the micron level. A visual overview of the sampling and the results are given in Figure S5.

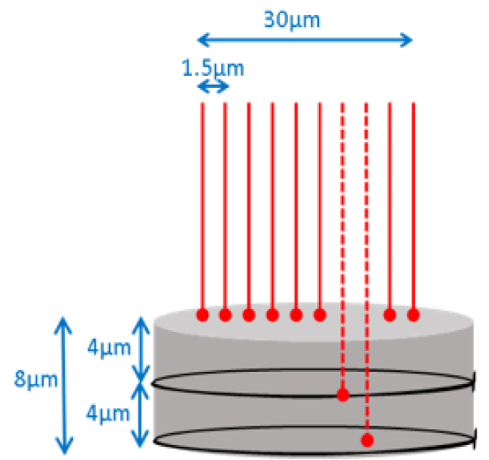

a) Sample area \& scanning points

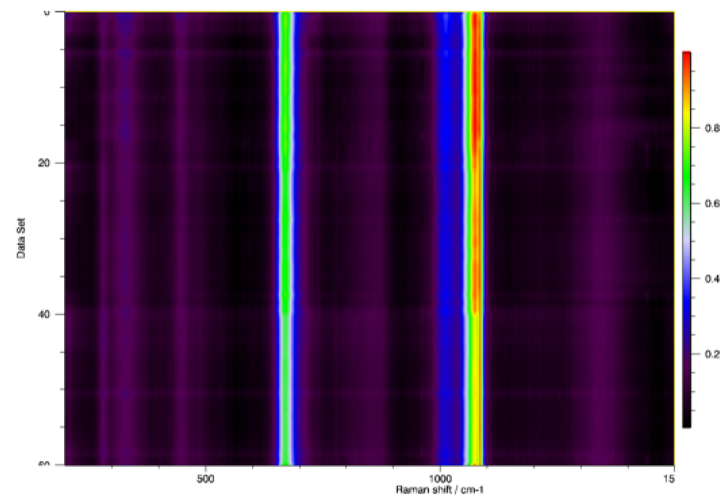

c) Top view of the raman spectra

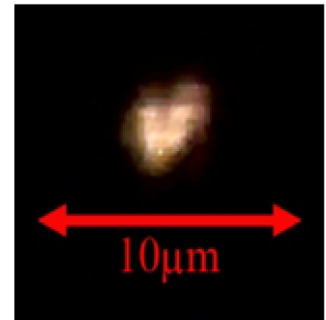

b) Spot size $4 \mu \mathrm{m} 2$

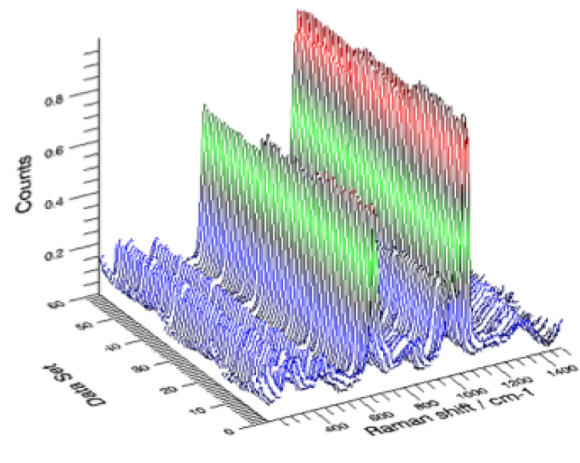

d) 2-D view of the raman spectra

Figure S5 | Raman microscopic analysis: a) Sample pellet preparation, b) Spot size used for analysis, c) intensity plot comparing Raman spectra of all 30 spots, d) stacked plot comparing Raman spectra of all 30 spots. 


\section{Determination by STEM-EDX}

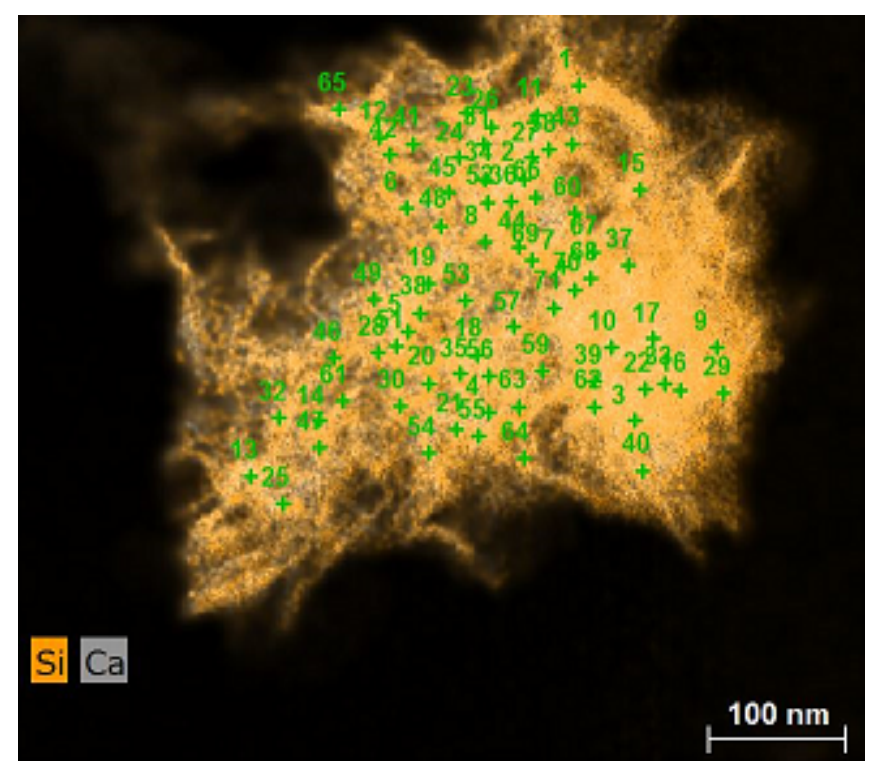

Figure S6 | C-S-H chemical map revealing the spots used for the EDX analysis.

In order to prove the uniformity and consistency of the C-S-H samples to an even greater degree of spatial resolution, EDX in STEM mode was performed on the predefined grids. Once STEM micrographs are obtained, post-processing is performed using Bruker Esprit 1.8 software to obtain the corresponding chemical maps for the samples. The exported STEM image is processed for several parameters like detector effect corrections, Bremsstrahlung background, and Cliff-Lorimer quantification. The major constituents of our C-S-H system are defined for elemental identification. The maps are binned after defining the evaluation methods. As shown in Figure S6, about 50 - 60 points are analyzed individually from the chemical maps. Each spot corresponds to one pixel whose size is $2.34 \mathrm{~nm} \times 2.34 \mathrm{~nm}$. The signal obtained from each spot is processed to arrive at the final $\mathrm{Ca}: \mathrm{Si}$ ratio at these points. A large background contribution to the signal is removed throughout the signal range spectra deconvolution is to be performed to address overlapped lines in the spectrum. The final quantification results of $\mathrm{Ca}: \mathrm{Si}$ for each of these spots are recorded. For each sample, the standard deviation of the Ca:Si ratios measurements is less than $1 \%$. EDX analysis provides us with useful information on the consistency of the Ca:Si ratio within the structure but due to the difficulty of accurately calibrating the instrument the actual Ca:Si determined ratio systematically less than that obtained from the XRF and ICP methods. 


\section{DNP enhanced NMR experiments}

\section{A: Sample preparation}

Table S3 describes the formulation of the samples, which were prepared as described in the Methods section of the main text.

\begin{tabular}{|c|c|c|c|c|}
\hline Sample & $m_{\text {gel }} / \mathrm{mg}$ & $m_{\text {agent }} / \mathrm{mg}$ & $m_{\text {in }} / \mathrm{mg}$ & $t_{\text {prep }} / \mathrm{min}$ \\
\hline $\mathrm{Ca}: \mathrm{Si}=1.00$ & 124.1 & 25 & - & 60 \\
\hline $\mathrm{Ca}: \mathrm{Si}=1.25$ & 133.3 & 33.3 & 26.6 & 75 \\
\hline $\mathrm{Ca}: \mathrm{Si}=1.50$ & 119.3 & 31.8 & 23.8 & 15 \\
\hline $\mathrm{Ca}: \mathrm{Si}=1.75$ & 114.1 & 27.0 & 23.4 & 15 \\
\hline $\mathrm{Ca}: \mathrm{Si}=2.00$ & 121.0 & 30.6 & 25.4 & 15 \\
\hline
\end{tabular}

Table S3 | Formulation of samples used for DNP experiments. $m_{\text {gel }}$ gives the mass of gel mixed with $m_{\text {agent }}$ amount of DNP polarization agent. $m_{\text {in }}$ is the amount of DNP ready C-S-H slurry that was put into in the rotor. $t_{\text {prep }}$ is the estimated out of time between release of the C-S-H from storage in a saturated atmosphere to insertion of the sample into the DNP probe at $100 \mathrm{~K}$.

The C-S-H gels do not have an indefinite shelf life and are observed to harden over several weeks to months even in airtight containers. Driving off supernatant water from the gels accelerates this process. By drying the gels on a watch glass for about half an hour, very high DNP enhancements approaching 100 could be obtained, but the line shape would exhibit comparatively large $\mathrm{Q}^{(2)}$ signals. Occasionally, signals from $\mathrm{Q}^{(3)}$ and $\mathrm{Q}^{(4)}$ species were observed, confirming that silicate polymerization accompanied the drying process.

\section{B: NMR parameters}

Table S4 gives the list of experimental parameters common to all NMR experiments, unless otherwise noted.

\begin{tabular}{|c|c|}
\hline MAS rate & $12.5 \mathrm{kHz}$ \\
\hline${ }^{1} \mathrm{H}$ contact $\mathrm{rf}$ & $60 \mathrm{kHz}$ \\
\hline${ }^{1} \mathrm{H}$ pulse/dec rf & $100 \mathrm{kHz}$ \\
\hline${ }^{1} \mathrm{H}$ ramp profile & $0.9 \rightarrow 1.0$ \\
\hline $\mathrm{X}$ contact $\mathrm{RF}$ & $46 \mathrm{kHz}$ \\
\hline $\mathrm{X}$ pulse rf & $66 \mathrm{kHz}$ \\
\hline Recycle delay & $3.0 \mathrm{~s}$ \\
\hline
\end{tabular}

aRecycle delay of $1.5 \mathrm{~s}$ used for $2 \mathrm{D}$ experiments on the $\mathrm{Ca}: \mathrm{Si}=1.00$ sample.

Table S4 | Parameters common to all NMR experiments. 
All processing for the spectra presented here was performed using $R M N .^{6}$ Line shape analysis was performed using gnuplot. 1D CP MAS shifted echo experiments were performed using the sequence shown in Figure S7. In the presence of significant inhomogeneous broadening, advantages of the shifted echo experiment over conventional CP-detect are an improvement in sensitivity and improved accuracy of phase correction procedures.

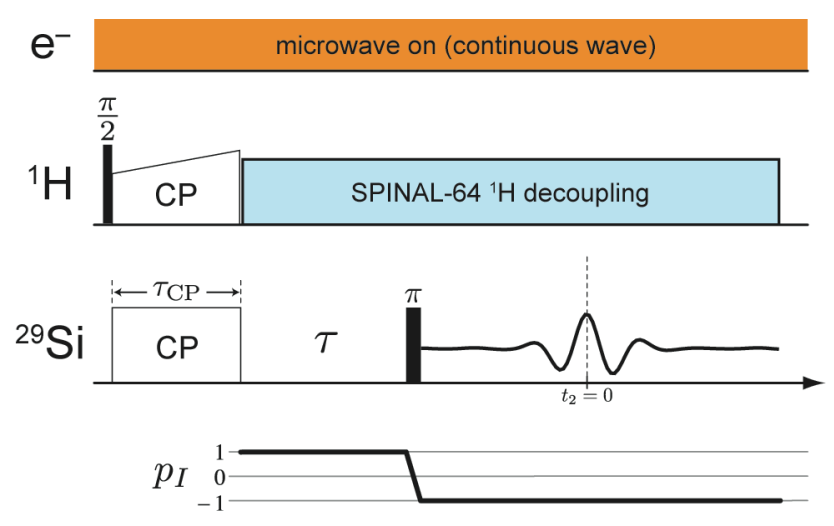

Figure S7 | DNP enhanced CP MAS shifted echo pulse sequence used in this work.

For each sample, $\tau=9.6 \mathrm{~ms}, \tau_{\mathrm{CP}}=7 \mathrm{~ms}$, and 32 transients were collected for a total experiment time of 1.6 min each. Gaussian apodization with a $\sigma$ of $4.243 \mathrm{~ms}$ was applied to the $t_{2}$ signal envelope.

This experiment formed the basis of the variable contact time experiments, which nonuniformly sampled 49

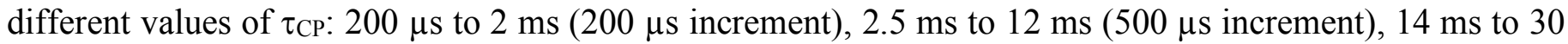
$\mathrm{ms}$ (2 $\mathrm{ms}$ increment), and $35 \mathrm{~ms}$ to $80 \mathrm{~ms}$ (5 ms increment). 2D CP MAS refocused whole echo INADEQUATE experiments ${ }^{7}$ were performed using the sequence shown in Figure S8. In addition to the use of hyper complex acquisition ${ }^{8}$ to collect echo and anti-echo pathways, acquisition was initiated after the final $\pi$ pulse in order to collect the entire signal envelope. This improves the sensitivity of the experiment and minimizes phasing artifacts during processing. 


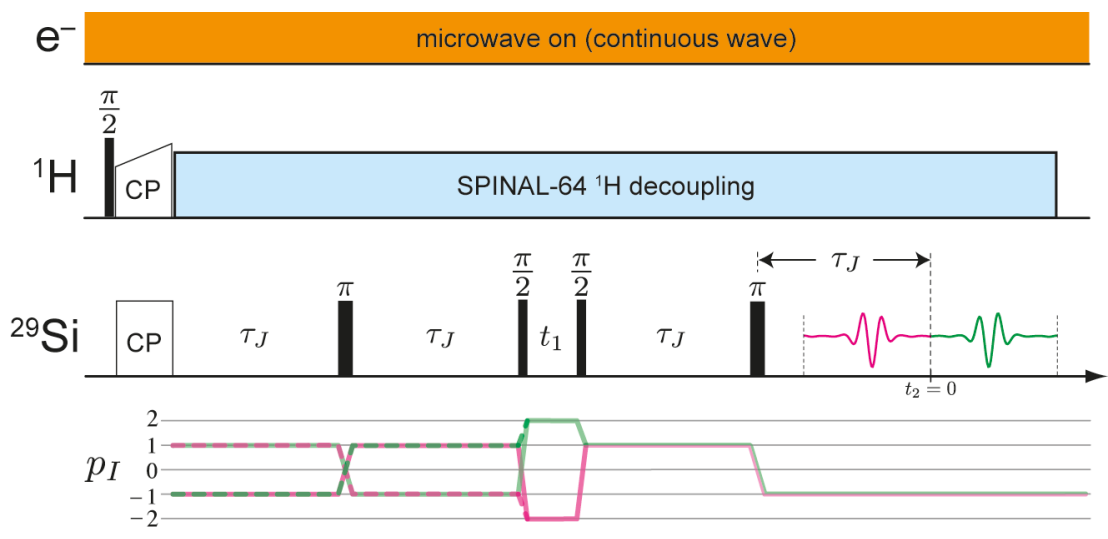

Figure S8 | DNP enhanced CP MAS refocused whole echo INADEQUATE pulse sequence used in this work. The two $p_{I}$ symmetry pathways (dashed and solid green) and anti-pathways (dashed and solid magenta) were collected and processed using hypercomplex acquisition. Whole signal envelopes were acquired during $t_{2}$ for path and anti-pathways.

For each sample, $\tau_{\mathrm{J}}=36 \mathrm{~ms}, \tau_{\mathrm{CP}}=7 \mathrm{~ms}$. The $t_{1}$ increment used was $240 \mu \mathrm{s}$. 16 complex $t_{1}$ points were collected. Other acquisition parameters are given in Table S5 below.

\begin{tabular}{|c|c|c|}
\hline Sample & Transients & Experiment Time \\
\hline $\mathrm{Ca}: \mathrm{Si}=1.00^{\mathrm{a}}$ & 640 & $9.6 \mathrm{~h}$ \\
\hline $\mathrm{Ca}: \mathrm{Si}=1.25$ & 320 & $9.0 \mathrm{~h}$ \\
\hline $\mathrm{Ca}: \mathrm{Si}=1.50$ & 320 & $9.0 \mathrm{~h}$ \\
\hline $\mathrm{Ca}: \mathrm{Si}=1.75$ & 512 & $14.5 \mathrm{~h}$ \\
\hline $\mathrm{Ca}: \mathrm{Si}=2.00$ & 512 & $14.5 \mathrm{~h}$ \\
\hline
\end{tabular}

aA gyrotron outage, lasting about an hour, occurred near the end of the experiment. The spectrum is qualitatively unaffected.

Table S5 | Acquisition parameters for 2D refocused INADEQUATE experiments.

A shearing transformation was used to create a representation of the 2D INADEQUATE data that correlates two independent single-quantum dimensions. ${ }^{9}$ Gaussian apodization with $\sigma$ of $6 \mathrm{~ms}$ and $3 \mathrm{~ms}$ were applied to the $t_{2}$ and $t_{1}$ signal envelopes, respectively.

The HETCOR echo sequence was performed using the sequence shown in Figure S9, utilizing the eDUMBO-22 homonuclear decoupling scheme ${ }^{10,11}$ to suppress the line broadening from ${ }^{1} \mathrm{H}-{ }^{1} \mathrm{H}$ dipolar interactions. This also scales the chemical shift and introduces an additional offset into the spectrum which were determined by comparison to a reference HETCOR spectrum of L-alanine. These values were used to present a corrected ${ }^{1} \mathrm{H}$ chemical shift dimension for the spectra shown in Figure S14 and Figure S15, as well as the main text Figure 3. 


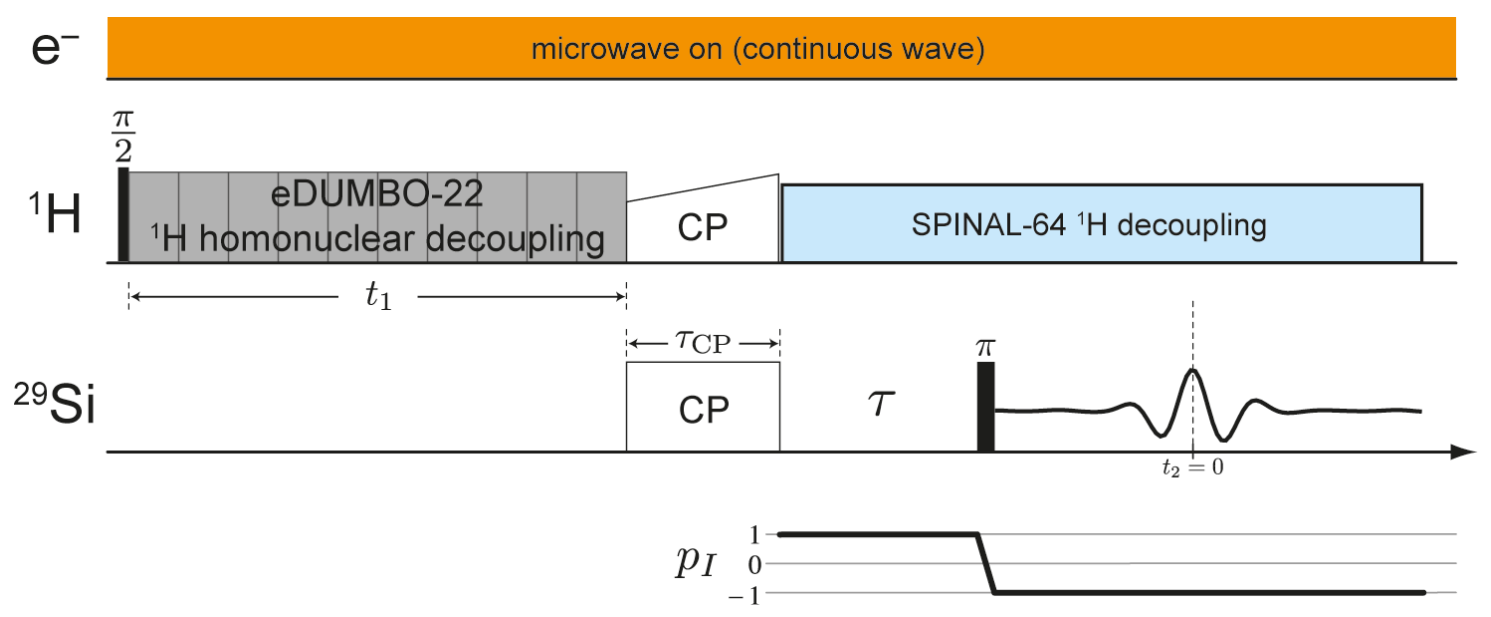

Figure S9 | DNP enhanced HETCOR echo sequences used in this work. Hypercomplex acquisition was used to collect path and anti-pathways for $t_{1}$ evolution. Homonuclear decoupling was applied during $t_{l}$. Whole signal envelopes were acquired during $t_{2}$ for path and anti-pathways.

For each sample, $\tau=9.6 \mathrm{~ms}$. The eDUMBO pulse length was $32 \mu \mathrm{s}$. Other acquisition parameters are given in Table S6 below.

\begin{tabular}{|c|c|c|c|c|c|}
\hline Sample & $\tau_{\mathrm{CP}}$ & Complex $t_{l}$ points & $\Delta t_{l}$ & Transients & Experiment Time \\
\hline $\mathrm{Ca}: \mathrm{Si}=1.00$ & $0.7 \mathrm{~ms}$ & 48 & $32 \mu \mathrm{s}$ & 24 & $61 \mathrm{~min}$ \\
\hline & $7 \mathrm{~ms}$ & 48 & $32 \mu \mathrm{s}$ & 8 & $20 \mathrm{~min}$ \\
\hline $\mathrm{Ca}: \mathrm{Si}=1.25$ & $0.7 \mathrm{~ms}$ & 48 & $32 \mu \mathrm{s}$ & 12 & $59 \mathrm{~min}$ \\
\hline & $7 \mathrm{~ms}$ & 48 & $32 \mu \mathrm{s}$ & 4 & $20 \mathrm{~min}$ \\
\hline $\mathrm{Ca}: \mathrm{Si}=1.50$ & $0.7 \mathrm{~ms}$ & 44 & $32 \mu \mathrm{s}$ & 12 & $55 \mathrm{~min}$ \\
\hline & $7 \mathrm{~ms}$ & 48 & $32 \mu \mathrm{s}$ & 4 & $20 \mathrm{~min}$ \\
\hline $\mathrm{Ca}: \mathrm{Si}=1.75$ & $0.7 \mathrm{~ms}$ & 20 & $64 \mu \mathrm{s}$ & 32 & $66 \mathrm{~min}$ \\
\hline & $7 \mathrm{~ms}$ & 20 & $64 \mu \mathrm{s}$ & 16 & $33 \mathrm{~min}$ \\
\hline $\mathrm{Ca}: \mathrm{Si}=2.00$ & $0.7 \mathrm{~ms}$ & 20 & $64 \mu \mathrm{s}$ & 32 & $66 \mathrm{~min}$ \\
\hline & $7 \mathrm{~ms}$ & 20 & $64 \mu \mathrm{s}$ & 16 & $33 \mathrm{~min}$ \\
\hline
\end{tabular}

Table S6 | Acquisition parameters for HETCOR experiments.

Gaussian apodization with decay constant of $4.243 \mathrm{~ms}$ and $1.2 \mathrm{~ms}$ were applied to the $t_{2}$ and $t_{1}$ signal envelopes, respectively. The apodization was applied to the $t_{1}$ dimension prior to multiplying the sampling interval by the chemical shift correction factor $\lambda_{\mathrm{cs}}=0.57$. 


\section{Sensitivity of DNP}

For each sample, ${ }^{1} \mathrm{H}$ spectra were acquired both in the presence and absence of microwaves to measure the DNP enhancement of the protons. The enhancement level could not be determined accurately on the basis of the ${ }^{1} \mathrm{H}$ spectra alone due to a nonuniform enhancement of the broad line shape. The estimated proton enhancements $\varepsilon_{\text {DNP }}\left({ }^{1} \mathrm{H}\right)$ are shown in Table S7 below. Whereas a nonexponential recovery was observed for a ${ }^{1} \mathrm{H}$ saturation recovery experiment with approximate $\mathrm{T}_{\mathrm{DNP}}\left({ }^{1} \mathrm{H}\right)=1.3 \mathrm{~s}$, a ${ }^{29} \mathrm{Si} \mathrm{CP}$ saturation recovery experiment revealed a nearly exponential buildup with $\mathrm{T}_{\mathrm{DNP}}\left(\left\{{ }^{1} \mathrm{H}\right\}^{29} \mathrm{Si}\right)=2.4 \mathrm{~s}$. This suggests polarization relay into C-S-H particles with a steady state polarization reached after about ten seconds.

\begin{tabular}{|c|c|}
\hline Sample & $\varepsilon_{\text {DNP }}\left({ }^{1} \mathrm{H}\right)$ \\
\hline $\mathrm{Ca}: \mathrm{Si}=1.00$ & 40 \\
\hline $\mathrm{Ca}: \mathrm{Si}=1.25$ & 70 \\
\hline $\mathrm{Ca}: \mathrm{Si}=1.50$ & 40 \\
\hline $\mathrm{Ca}: \mathrm{Si}=1.75$ & 45 \\
\hline $\mathrm{Ca}: \mathrm{Si}=2.00$ & 35 \\
\hline
\end{tabular}

Table S7 | Proton signal enhancements.

The sensitivity enhancement for DNP is called $\Sigma^{\dagger}$ and can be written as the product of several factors, ${ }^{12}$

$$
\Sigma^{\dagger}=\varepsilon_{D N P} \theta d_{\text {formulation }}\left(\frac{S_{100 K}}{S_{298 K}}\right) \sqrt{\frac{T_{1}}{T_{D N P}}}
$$

$\theta$ is the fraction of observable nuclei in the sample, which is less than unity due to depolarization and quenching by the radical. $d_{\text {formulation }}$ is a dilution factor related to the fact that additional of the polarization agent may reduce the amount of sample that can be placed into the rotor. The ratio $S_{100 \mathrm{~K}} / S_{298 \mathrm{~K}}$ is generally accounts for the improvement in sensitivity gained by going to $100 \mathrm{~K}$ due to the $\sim 2.8$ improvement in the Boltzmann polarization as well as, e.g., an improvement in the probe quality factors. $T_{\mathrm{DNP}}$ is the approximate polarization build up time of the protons under DNP, and is to be compared room temperature proton $T_{1}$ values for C-S-H measured to be around $0.2 \mathrm{~s}^{13}$

Equation (S1) applies strictly only to signal from the polarizing agent and surface signals. Because the proton polarization is relayed into the $\mathrm{C}-\mathrm{S}-\mathrm{H}$ nanoparticles by proton spin diffusion, it is only of approximate validity. Nonetheless, taking $\theta \approx 1$ (signal is dominated by bulk C-S-H), $d_{\text {formulation }} \approx 0.8$ (on 
the basis of Table S3), $S_{100 \mathrm{~K}} / S_{298 \mathrm{~K}} \approx 5$, and $\left(T_{1} / T_{\mathrm{DNP}}\right)^{1 / 2} \approx 0.25$, and the proton enhancements measured in Table S7, the sensitivity enhancement by DNP is generally the same as $\varepsilon_{\mathrm{DNP}}\left({ }^{1} \mathrm{H}\right)$, indicating reduction of corresponding cross-polarization experiment times by $\left(\varepsilon_{\mathrm{DNP}}\left({ }^{1} \mathrm{H}\right)\right)^{2}$, or about three orders of magnitude.

\section{Quantification of Q species populations}

Relative signal intensities in DNP enhanced CP MAS experiments are not usually in proportion to the relative populations of the nuclei generating the signal as they often are in experiments using direct excitation without hyperpolarization. Nonetheless, we can still use these signals for site quantification provided we assume that:

1. The length scale of hyperpolarization nonuniformity is larger than the unit cell of the particle, and

2. Cross-polarization kinetics can be measured and used to adjust the signal intensities appropriately.

The size of the C-S-H particles are sufficiently small (characteristic length $\sim 100 \mathrm{~nm}$ ) and have a proton density sufficient for nearly uniform polarization of the particles over the recycle period. To the second point, we performed cross-polarization measurements for different values of the cross-polarization contact time $\tau_{C P}$, as shown in the first column of Figure III. This data was fit to a simple $I S$ model of CP kinetics for each $\operatorname{site}^{14}$. For our kinetic model, the signal intensities due to cross-polarization are given as a function of the cross-polarization contact time $\tau_{C P}$ by

$$
I\left(\tau_{C P}\right)=I_{0} \frac{e^{-\frac{\tau_{C P}}{T_{1 \rho}}}-e^{-\frac{\tau_{C P}}{T_{I S}}}}{1-\frac{T_{I S}}{T_{1 \rho}}}
$$

where $T_{1 \rho}$ is the spin-lattice relaxation constant during rf irradiation and $T_{I S}$ is the cross-relaxation time. $I_{0}$ is the base intensity, proportional to the equilibrium magnetization and hence number of nuclei generating the NMR signal for the given site. The 1D CP echo line shape was used in an initial unconstrained fit to three independent Gaussian functions, each representing the $\mathrm{Q}^{(1)}, \mathrm{Q}^{(2 \mathrm{~b})}$, and $\mathrm{Q}^{(2 \mathrm{p})}$ contributions. From this a set of mean Gaussian shift $(\delta)$ and widths $(\sigma)$ for the frequency spectrum was determined and used to constrain the fit to the variable contact time data for the cross-polarization kinetic parameters. Stack plots representing the best fit and residual plots to this data are shown as the second and third columns of Figure S10. The cross-polarization kinetic parameters we determine from this analysis is given in Table S8. 


\begin{tabular}{|l|c|c|c|c|c|c|}
\hline \multirow{2}{*}{ Sample } & \multicolumn{2}{|c|}{$\mathrm{Q}^{(1)}$} & \multicolumn{2}{c|}{$\mathrm{Q}^{(2 \mathrm{~b})}$} & \multicolumn{2}{c|}{$\mathrm{Q}^{(2 \mathrm{p})}$} \\
\cline { 2 - 7 } & $T_{1 \rho} / \mathrm{ms}$ & $T_{I S} / \mathrm{ms}$ & $T_{1 \rho} / \mathrm{ms}$ & $T_{I S} / \mathrm{ms}$ & $T_{1 \rho} / \mathrm{ms}$ & $T_{I S} / \mathrm{ms}$ \\
\hline $\mathrm{Ca}: \mathrm{Si}=1.00$ & $32.5 \pm 0.6$ & $1.81 \pm 0.04$ & $25.6 \pm 0.8$ & $1.09 \pm 0.04$ & $44.4 \pm 0.6$ & $4.07 \pm 0.06$ \\
\hline $\mathrm{Ca}: \mathrm{Si}=1.25$ & $27.1 \pm 0.3$ & $2.31 \pm 0.02$ & $26.1 \pm 0.9$ & $1.41 \pm 0.05$ & $38.2 \pm 0.9$ & $5.14 \pm 0.13$ \\
\hline $\mathrm{Ca}: \mathrm{Si}=1.50$ & $33.8 \pm 0.3$ & $2.19 \pm 0.02$ & $34.6 \pm 2.1$ & $1.24 \pm 0.09$ & $45.6 \pm 1.7$ & $4.78 \pm 0.18$ \\
\hline $\mathrm{Ca}: \mathrm{Si}=1.75$ & $25.9 \pm 0.2$ & $2.22 \pm 0.02$ & $28.6 \pm 1.9$ & $1.49 \pm 0.12$ & $38.1 \pm 1.9$ & $4.62 \pm 0.24$ \\
\hline $\mathrm{Ca}: \mathrm{Si}=2.00$ & $28.0 \pm 0.2$ & $2.40 \pm 0.02$ & $30.9 \pm 2.7$ & $1.29 \pm 0.14$ & $40.3 \pm 2.5$ & $4.91 \pm 0.32$ \\
\hline
\end{tabular}

Table S8 | Cross-polarization kinetic parameters determined by the variable contact time experiments.

To complete the quantification, the 1D CP echo data was refit using Equation (S2) for the base intensities as well as new Gaussian shift parameters. The previously determined $T_{1 \rho}, T_{I S}$, and Gaussian width parameters, averaged across the compositions with $\mathrm{Ca}: \mathrm{Si} \geq 1.25$ for each site, were used for determination of the base intensities. The exception was the $\mathrm{Ca}: \mathrm{Si}=1.00$ composition, where its own $T_{1 \rho}$ and $T_{I S}$ parameters were used. In accordance with the dreierketten model, the additional constraint $I_{0}\left(\mathrm{Q}^{(2 \mathrm{p})}\right)=2 I_{0}\left(\mathrm{Q}^{(2 \mathrm{~b})}\right)$ was enforced. The 1D CP echo spectra, best fit to this constrained 1D model, and best fit residuals are shown in Figure S11. Associated Gaussian shift and width parameters are given in Table S9.

\begin{tabular}{|c|c|c|c|c|c|c|}
\hline \multirow{2}{*}{ Sample } & \multicolumn{2}{|c|}{$\mathrm{Q}^{(1)}$} & \multicolumn{2}{c|}{$\mathrm{Q}^{(2 \mathrm{~b})}$} & \multicolumn{2}{c|}{$\mathrm{Q}^{(2 \mathrm{p})}$} \\
\cline { 2 - 7 } & $\delta / \mathrm{ppm}$ & $\sigma / \mathrm{ppm}$ & $\delta / \mathrm{ppm}$ & $\sigma / \mathrm{ppm}$ & $\delta / \mathrm{ppm}$ & $\sigma / \mathrm{ppm}$ \\
\hline $\mathrm{Ca}: \mathrm{Si}=1.00$ & $-79.71 \pm 0.08$ & $1.34 \pm 0.05$ & $-82.72 \pm 0.08$ & $1.08 \pm 0.11$ & $-85.77 \pm 0.04$ & $1.29 \pm 0.03$ \\
\hline $\mathrm{Ca}: \mathrm{Si}=1.25$ & $-79.17 \pm 0.02$ & $1.25 \pm 0.03$ & $-81.85 \pm 0.08$ & $1.42 \pm 0.31$ & $-85.33 \pm 0.03$ & $1.25 \pm 0.04$ \\
\hline $\mathrm{Ca}: \mathrm{Si}=1.50$ & $-79.10 \pm 0.01$ & $1.31 \pm 0.02$ & $-81.64 \pm 0.07$ & $1.03 \pm 0.21$ & $-85.17 \pm 0.03$ & $1.27 \pm 0.06$ \\
\hline $\mathrm{Ca}: \mathrm{Si}=1.75$ & $-78.90 \pm 0.01$ & $1.27 \pm 0.01$ & $-81.54 \pm 0.07$ & $1.20 \pm 0.19$ & $-84.90 \pm 0.03$ & $1.24 \pm 0.05$ \\
\hline $\mathrm{Ca}: \mathrm{Si}=2.00$ & $-78.87 \pm 0.01$ & $1.27 \pm 0.01$ & $-81.53 \pm 0.08$ & $1.11 \pm 0.15$ & $-84.81 \pm 0.03$ & $1.30 \pm 0.05$ \\
\hline
\end{tabular}

Table S9 | Shift $(\delta)$ and width $(\sigma)$ parameters determined by the three Gaussian fit to the 1D CP MAS shifted echo data.

The $\delta$ parameters were found in a fit subject to the constraint $I_{0}\left(Q^{(2 \mathrm{p})}\right)=2 I_{0}\left(\mathrm{Q}^{(2 \mathrm{~b})}\right) ; \sigma$ parameters were carried over from a prior unconstrained fit.

By normalizing the sum of the base intensities to unity, we determine the Q species populations, reported in Table S10. As the residuals in Figure S11 indicate, the analysis is not valid for the $\mathrm{Ca}: \mathrm{Si}=1.00$ composition.

\begin{tabular}{|c|c|c|c|}
\hline Sample & $P\left(\mathrm{Q}^{(1)}\right)$ & $P\left(\mathrm{Q}^{(2 \mathrm{~b})}\right)$ & $P\left(\mathrm{Q}^{(2 \mathrm{p})}\right)$ \\
\hline $\mathrm{Ca}: \mathrm{Si}=1.00$ & $0.290 \pm 0.027$ & $0.237 \pm 0.009$ & $0.473 \pm 0.018$ \\
\hline $\mathrm{Ca}: \mathrm{Si}=1.25$ & $0.597 \pm 0.107$ & $0.134 \pm 0.036$ & $0.269 \pm 0.071$ \\
\hline $\mathrm{Ca}: \mathrm{Si}=1.50$ & $0.700 \pm 0.051$ & $0.100 \pm 0.017$ & $0.200 \pm 0.034$ \\
\hline $\mathrm{Ca}: \mathrm{Si}=1.75$ & $0.783 \pm 0.053$ & $0.072 \pm 0.018$ & $0.145 \pm 0.035$ \\
\hline $\mathrm{Ca}: \mathrm{Si}=2.00$ & $0.830 \pm 0.036$ & $0.057 \pm 0.012$ & $0.113 \pm 0.024$ \\
\hline
\end{tabular}

Table $\mathrm{S} 10$ | Q species populations, subject to the constraint $P\left(Q^{(2 \mathrm{p})}\right)=2 P\left(\mathrm{Q}^{(2 \mathrm{~b})}\right)$. 
$\begin{array}{lll}\text { Experiment } & \text { Fit } & \text { Residuals }\end{array}$
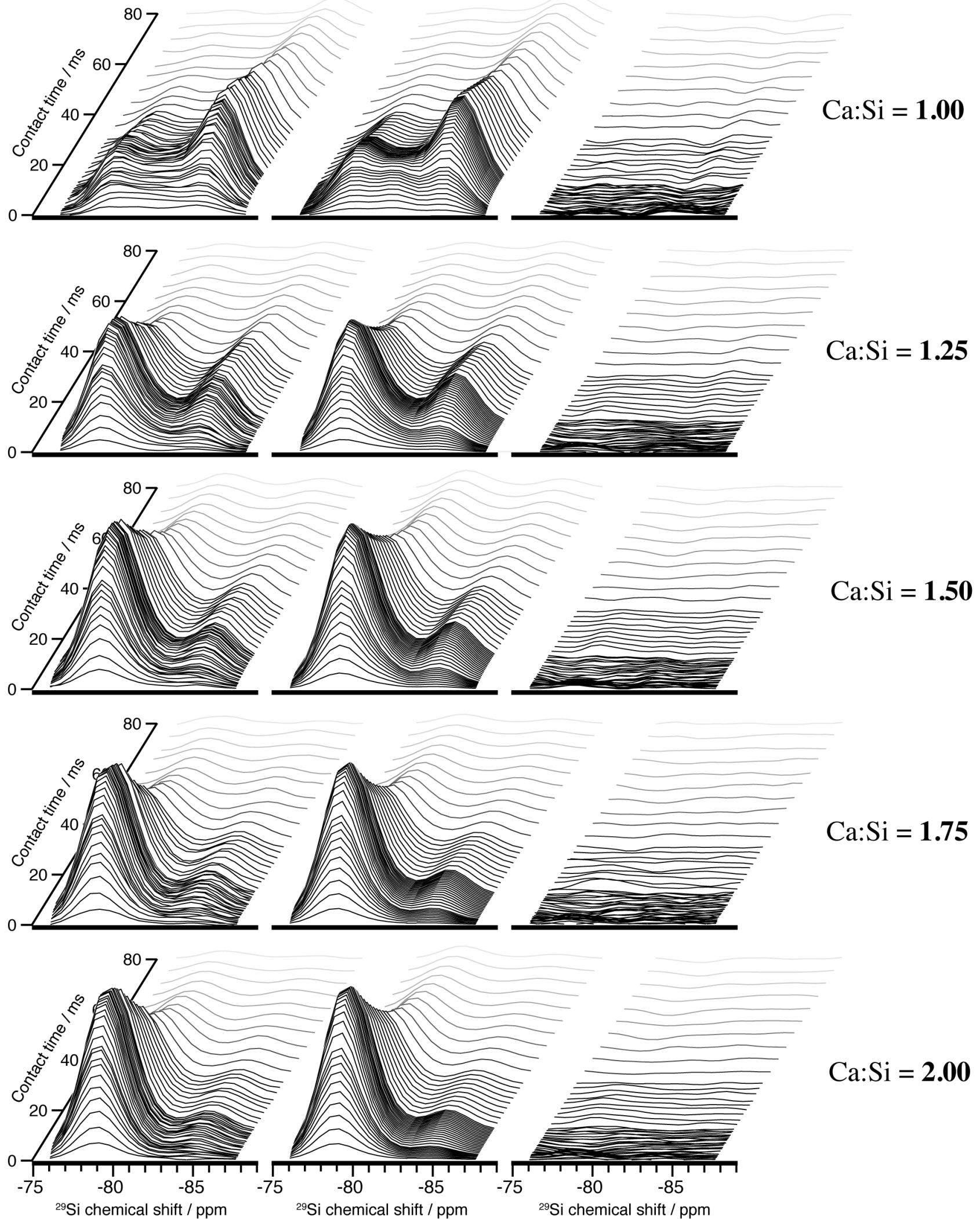

Figure S10 | Stacked plots for the variable contact time spectra, best fit using the kinetic model, and the best fit residuals. 


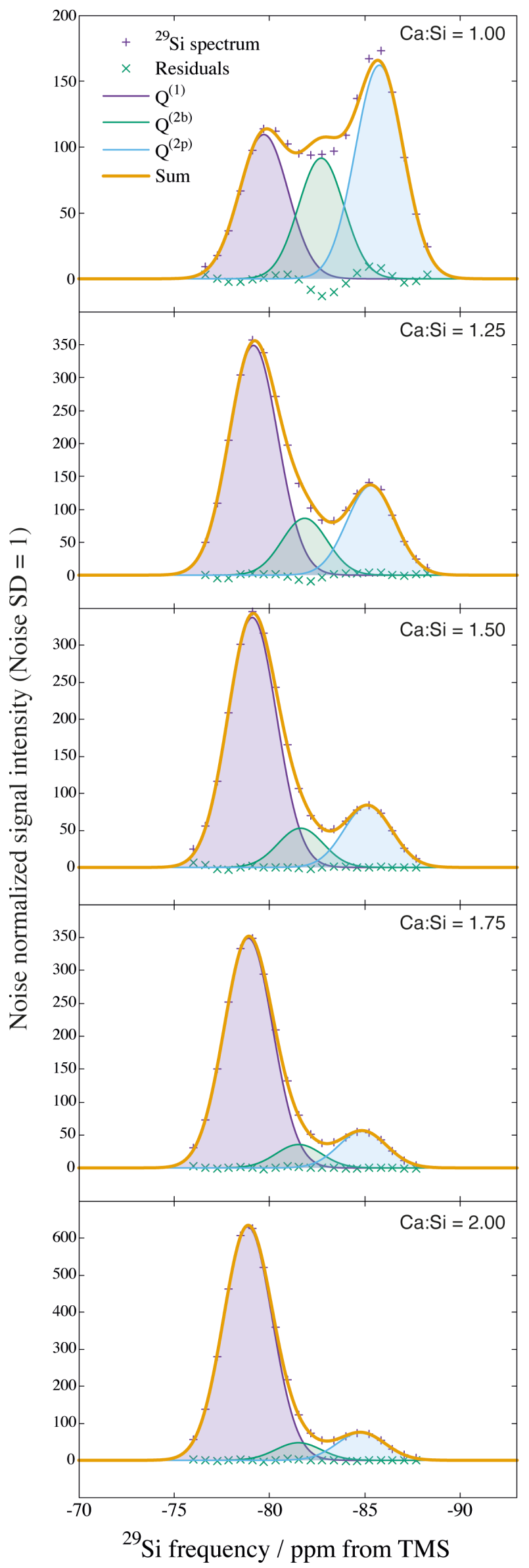

Figure S11 | Deconvolution of the line shapes obtained in the DNP enhanced 1D CP MAS shifted echo experiments using the three Gaussian model described in the main text. The intensities are subject to the constraint $I_{0}\left(Q^{(2 \mathrm{p})}\right)=2 I_{0}\left(Q^{(2 b)}\right)$. 


\section{Quantification of chain distributions}

Each peak in the A-B chemical shift correlation line shapes presented by the INADEQUATE spectra in the first column of Figure S12 were modeled by a 2D Gaussian function with zero correlation between independent A and B chemical shift dimensions. The shifts of the Gaussian functions along each dimension was constrained to the values shown in Table S9. The Gaussian width parameters were fixed to the same values for each fit, which were obtained by fitting the $1 \mathrm{D}$ projection onto the A chemical shift axis to three independent 1D Gaussian functions for the $\mathrm{Ca}: \mathrm{Si} \geq 1.25$ compositions and taking the mean for each corresponding Q site. The 2D line shape model permits up to nine independent 2D Gaussian functions to be used; however, the functions corresponding to the $\mathrm{Q}^{(1)}-\mathrm{Q}^{(2 \mathrm{~b})}, \mathrm{Q}^{(2 \mathrm{~b})}-\mathrm{Q}^{(1)}$, and $\mathrm{Q}^{(2 \mathrm{~b})}-\mathrm{Q}^{(2 \mathrm{~b})}$ correlation peaks were omitted on the basis of the dreierketten model and validated by the absence of significant signal in the corresponding regions of the INADEQUATE spectra. The 2D experimental line was then fit for the intensities of the six constituent 2D Gaussian functions. The second and third columns of Figure S12 shows the best fit results and residuals. Table S11 gives the unnormalized peak intensities. 


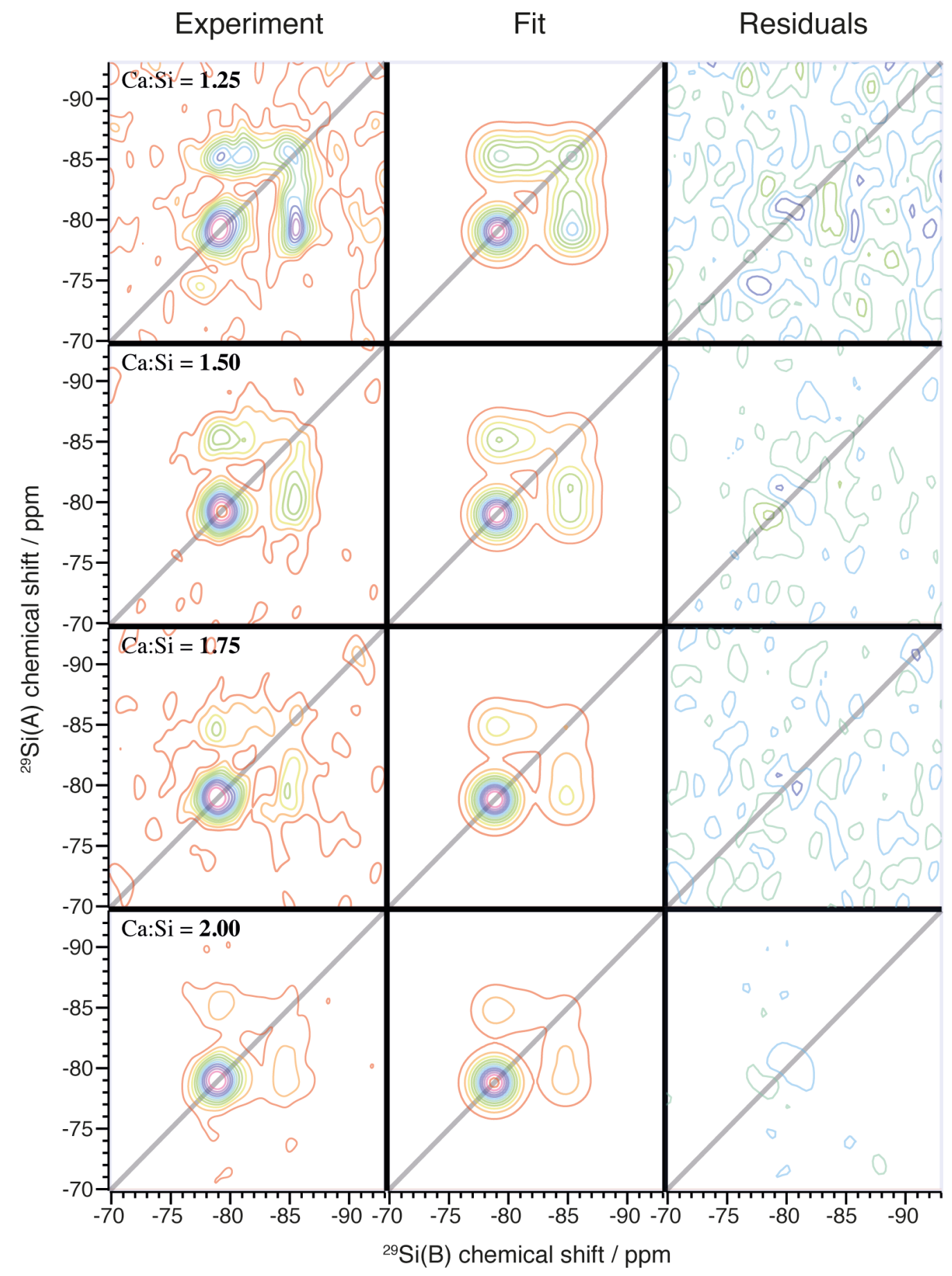

Figure S12 | Experimental A-B correlated 2D refocused INADEQUATE spectra, best fit to the 2D Gaussian model, and best fit residuals for the $\mathrm{C}-\mathrm{S}-\mathrm{H}$ compositions with $\mathrm{Ca}: \mathrm{Si} \leq 1.25$. Contours are drawn in $10 \%$ intervals beginning at $5 \%$ of the maximum signal intensity; the residual plots are relative to the experimental maximum and both positive (blue) and negative (green) contours are shown. 


\begin{tabular}{|c|c|c|c|c|c|c|}
\hline Sample & $I\left(\mathrm{Q}^{(1)} \mid \mathrm{Q}^{(2 \mathrm{p})}\right)$ & $I\left(\mathrm{Q}^{(2 \mathrm{~b})} \mid \mathrm{Q}^{(2 \mathrm{p})}\right)$ & $I\left(\mathrm{Q}^{(2 \mathrm{p})} \mid \mathrm{Q}^{(2 \mathrm{p})}\right)$ & $I\left(\mathrm{Q}^{(2 \mathrm{p})} \mathrm{Q}^{(2 \mathrm{~b})}\right)$ & $I\left(\mathrm{Q}^{(1)} \mid \mathrm{Q}^{(1)}\right)$ & $I\left(\mathrm{Q}^{(2 \mathrm{p})} \mid \mathrm{Q}^{(1)}\right)$ \\
\hline $\mathrm{Ca}: \mathrm{Si}=1.25$ & 78.95 & 59.84 & 86.91 & 58.78 & 153.31 & 94.12 \\
\hline $\mathrm{Ca}: \mathrm{Si}=1.50$ & 135.28 & 72.49 & 83.05 & 113.60 & 347.60 & 122.16 \\
\hline $\mathrm{Ca}: \mathrm{Si}=1.75$ & 64.82 & 34.32 & 36.35 & 40.77 & 247.07 & 59.04 \\
\hline $\mathrm{Ca}: \mathrm{Si}=2.00$ & 94.99 & 44.51 & 44.13 & 60.77 & 498.70 & 95.04 \\
\hline
\end{tabular}

Table S11 | Unnormalized best fit intensities of the A-B correlation peaks of the 2D refocused INADEQUATE spectra to the 2D Gaussian line shape model.

The intensity of an A-B correlation peak, denoted $I(\mathrm{~B} \mid \mathrm{A})$, is given by

$$
I(B \mid A)=f(B \mid A) P(B \mid A) P_{w}(A)
$$

We solve for the conditional probability $P(\mathrm{~B} \mid \mathrm{A})$ : the probability that a ${ }^{29} \mathrm{Si}$ nucleus of species $\mathrm{B}$ was detected given that it evolved with partner ${ }^{29} \mathrm{Si}$ nucleus of species A. They are normalized,

$$
\sum_{B} P(B \mid A)=1
$$

and Baye's theorem relates $P(\mathrm{~B} \mid \mathrm{A})$ to $P(\mathrm{~A} \mid \mathrm{B})$ :

$$
P(B \mid A)=\frac{P(A \mid B) P_{w}(B)}{P_{w}(A)} .
$$

$P_{w}(\mathrm{~A})$ is the population of species A weighted for pair participation. At the sparse $4.7 \%$ natural abundance of ${ }^{29} \mathrm{Si}$, the $\mathrm{Q}^{(2)}$ sites are nearly twice as likely to have a ${ }^{29} \mathrm{Si}$ partner; therefore, $P_{w}\left(\mathrm{Q}^{(2 \mathrm{~b})}\right)$ and $P_{w}\left(\mathrm{Q}^{(2 \mathrm{p})}\right)$ are obtained from the populations measured in the 1D experiments by doubling the population measured from the $1 \mathrm{D}$ experiments and renormalizing. Note that the sparse labeling simplifies the weighting analysis since the entire NMR signal is assumed to be derived only from isolated pairs and not triplets, etc. Finally, $f(\mathrm{~B} \mid \mathrm{A})$ is an amplitude transfer factor that accounts for $\mathrm{Q}$ site differences in e.g. $\mathrm{CP}$ efficiency, $T_{2}$ ' relaxation, and $J$-coupling distributions, and were assumed not to change as a function of Ca:Si ratio.

The experimental intensities were normalized for each composition by dividing out $I\left(\mathrm{Q}^{(1)} \mid \mathrm{Q}^{(1)}\right)$. Through the laws given above and the constraints imposed by the dreierketten model, any other conditional probability can be determined once $P\left(\mathrm{Q}^{(1)} \mid \mathrm{Q}^{(1)}\right)$ is known. Upon substitution of Equation (S3) for each composition and using $P_{w}(\mathrm{~A})$ values determined from the $1 \mathrm{D}$ quantitative analysis, the five transfer factor ratios (Table $\mathrm{S} 12$ ) and $P\left(\mathrm{Q}^{(1)} \mid \mathrm{Q}^{(1)}\right)$ for each composition were determined through a simultaneous fit of the twenty intensity ratios (five for each composition). 


\begin{tabular}{|c|c|c|c|c|c|}
\hline$f\left(\mathrm{Q}^{(1)} \mid \mathrm{Q}^{(2 \mathrm{p})}\right)$ & $f\left(\mathrm{Q}^{(2 \mathrm{~b})} \mid \mathrm{Q}^{(2 \mathrm{p})}\right)$ & $f\left(\mathrm{Q}^{(2 \mathrm{p})} \mid \mathrm{Q}^{(2 \mathrm{p})}\right)$ & $f\left(\mathrm{Q}^{(2 \mathrm{p})} \mid \mathrm{Q}^{(2 \mathrm{~b})}\right)$ & $f\left(\mathrm{Q}^{(1)} \mid \mathrm{Q}^{(1)}\right)$ & $f\left(\mathrm{Q}^{(2 \mathrm{p})} \mid \mathrm{Q}^{(1)}\right)$ \\
\hline 1.64 & 0.64 & 2.09 & 0.72 & 1 (defined $)$ & 1.74 \\
\hline
\end{tabular}

Table S12 | Transfer factors determined for each type of correlation peak.

The conditional probabilities are related to the distribution of chain species by

$$
\begin{gathered}
P\left(\mathrm{Q}^{(1)} \mid \mathrm{Q}^{(1)}\right)=x_{0} \\
P\left(\mathrm{Q}^{(1)} \mid \mathrm{Q}^{(2 \mathrm{p})}\right)=\frac{\sum_{n=1} x_{n}}{\sum_{n=1} x_{n}(2 n)} \\
P\left(\mathrm{Q}^{(2 \mathrm{~b})} \mid \mathrm{Q}^{(2 \mathrm{p})}\right)=\frac{1}{2} \\
P\left(\mathrm{Q}^{(2 \mathrm{p})} \mid \mathrm{Q}^{(2 \mathrm{p})}\right)=\frac{\sum_{n=1} x_{n}(n-1)}{\sum_{n=1} x_{n}(2 n)}
\end{gathered}
$$

where the mole fractions of chains with repeat index $n$ is denoted $x_{n}$. Application of the laws of conditional probability lead to the constraints reported in the main text. The parameters determined by our analysis are given in Table 1 of the main text.

Recalling that previous studies have generally focused on $\mathrm{Ca}: \mathrm{Si}<1.50$, which are not relevant to industrial formulations, we highlight that the $\mathrm{Ca}: \mathrm{Si}=1.00$ composition is remarkable in that silicate dimers appear to be completely absent $\left(x_{0}=0\right)$, as noted by the lack of a prominent $\mathrm{Q}^{(1)}-\mathrm{Q}^{(1)}$ correlation peak observed for all of the other C-S-H compositions. This is shown in Figure S13.

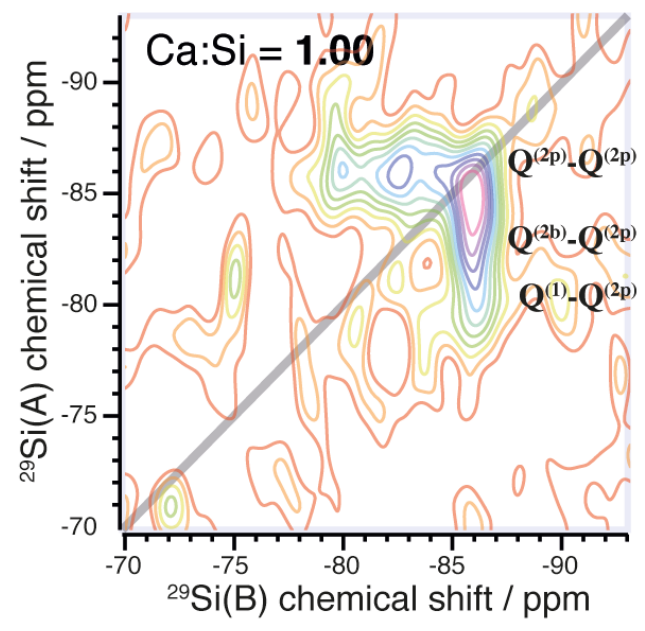

Figure S13 | Experimental A-B correlated 2D refocused INADEQUATE spectrum for $\mathrm{Ca}: \mathrm{Si}=1.00$. A gyrotron outage, lasting about an hour, occurred near the end of the experiment. The spectrum is qualitatively unaffected. 


\section{Heteronuclear $\left\{{ }^{1} \mathrm{H}\right\}^{29} \mathrm{Si}$ correlation}

For each composition, a 2D HETCOR experiment using the pulse sequence described in Figure S9 was performed for both a short $(0.7 \mathrm{~ms})$ and long $(7 \mathrm{~ms})$ values of $\tau_{\mathrm{CP}}$. The use of a short contact time biases the contribution to the NMR signal from those protons that are close to the correlating ${ }^{29} \mathrm{Si}$ nuclei, though without significant proton density fewer than three bonds away from the Si nuclei, the notion of a welldefined cutoff distance for the signals which appear in the correlation spectrum loses significance. ${ }^{14}$

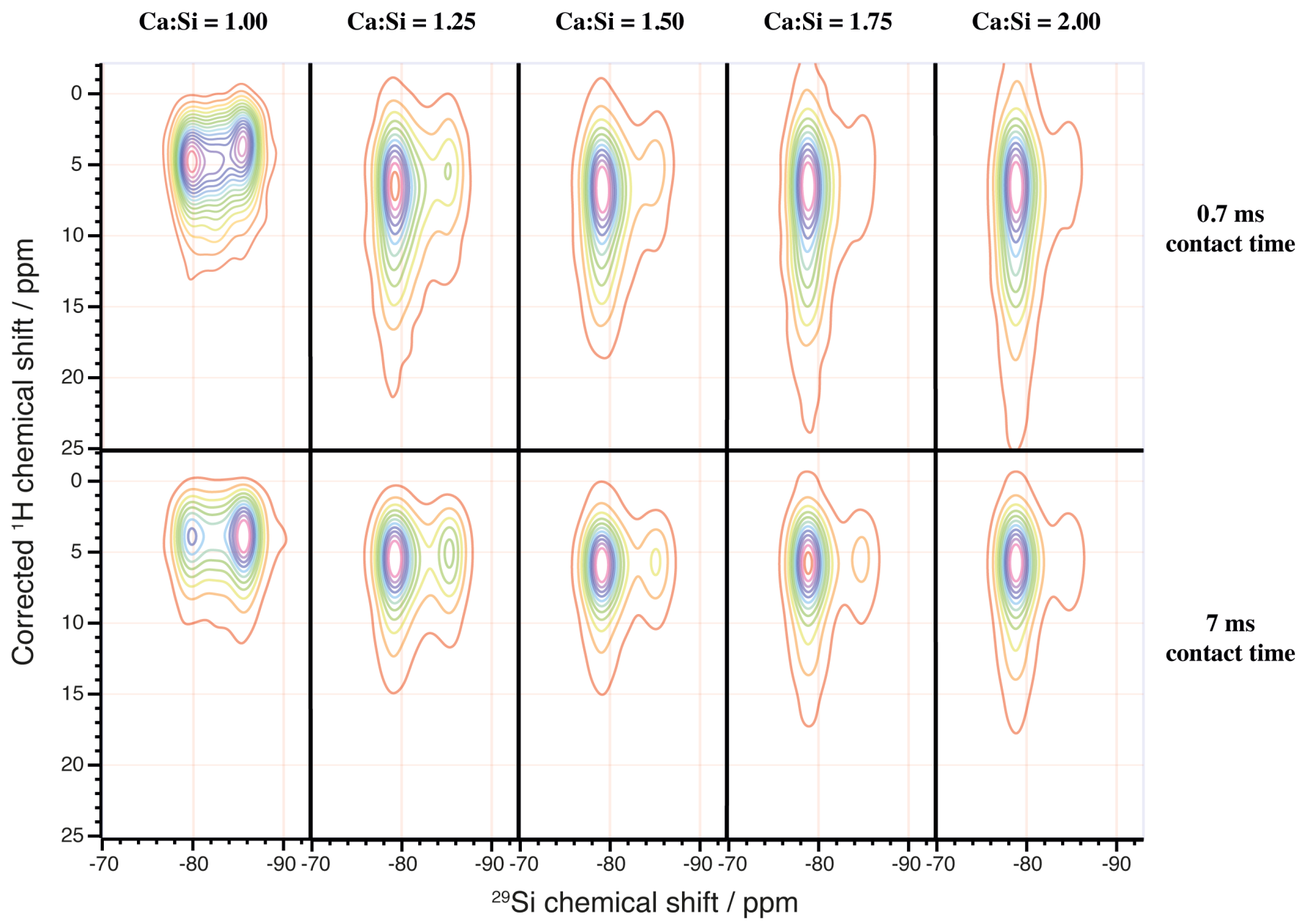

Figure S14 | Complete series of DNP enhanced HETCOR spectra at both short and long contact times for all compositions studied. 

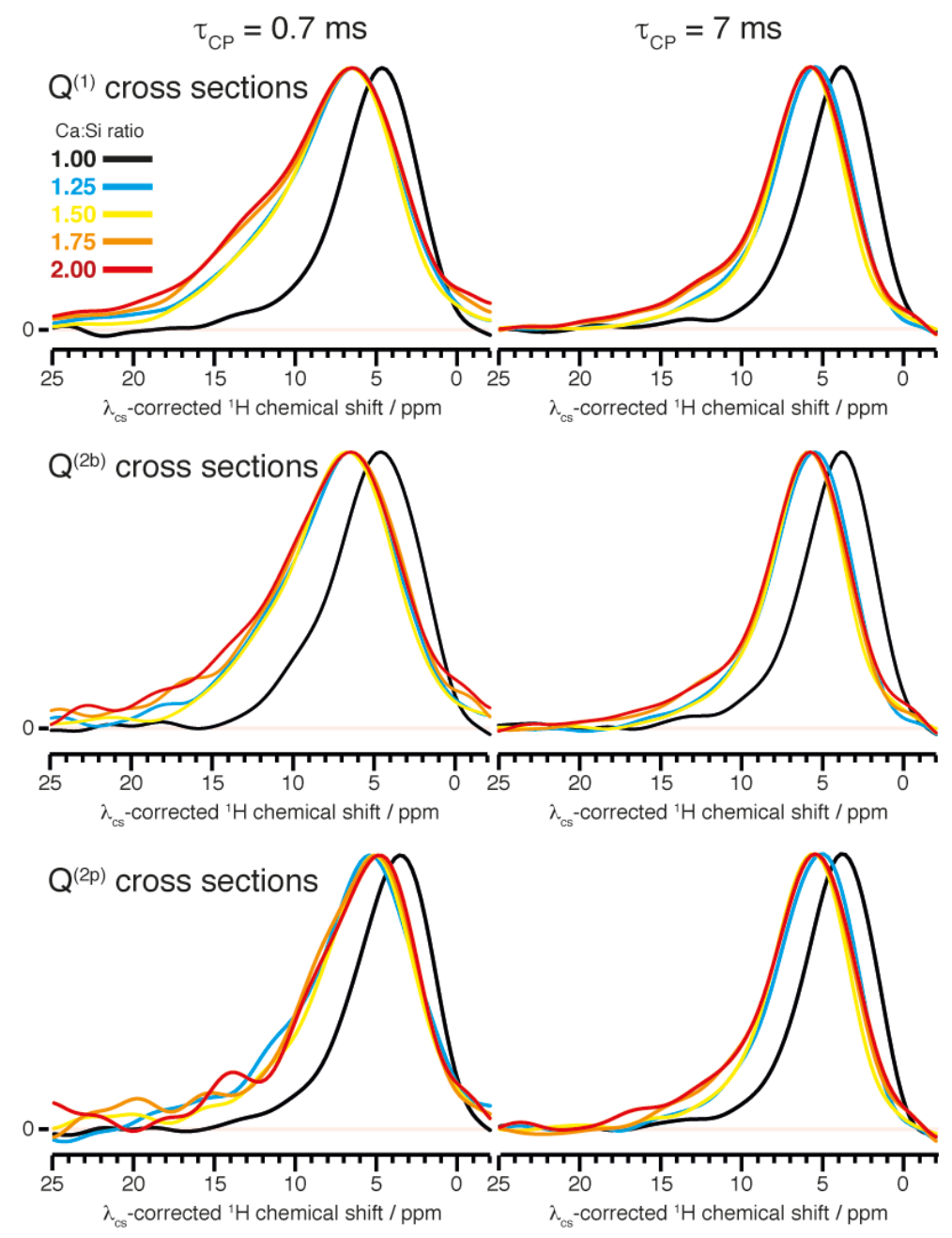

Figure $\mathrm{S} 15 \mid{ }^{29} \mathrm{Si}$ site correlated ${ }^{1} \mathrm{H}$ spectra taken as cross sections from the full $2 \mathrm{D}$ HETCOR spectra at the appropriate ${ }^{29}$ Si chemical shifts. 


\section{Structural model}

It is known that C-S-H resembles a defective tobermorite. ${ }^{15,16}$ To create a structure based on defective tobermorite that possesses high $\mathrm{Ca}: \mathrm{Si}$ ratios, we build substructures of $\mathrm{C}-\mathrm{S}-\mathrm{H}$ according to the following procedure:

- Deprotonate silanol in the bridging tetrahedrons and replace it with a $\mathrm{CaOH}^{+}$ion in the interlayer.

- Remove a bridging silicate tetrahedron, performing charge compensation by adding two protons or a proton and $\mathrm{CaOH}^{+}$ion or addition of $\mathrm{C} \mathrm{Ca}^{2+}$ to coordinate the bridging site ( $\mathrm{Ca}_{\mathrm{B}}$ site in Figure $\left.\mathrm{S} 16\right)$.

- Add $\mathrm{Ca}(\mathrm{OH})_{2}$ units in the interlayer space $\left(\mathrm{Ca}_{\mathrm{I}}\right.$ and $\left.\mathrm{Ca}_{\mathrm{A}}\right)$ to obtain higher $\mathrm{Ca}$ :Si ratios.

We study the effect of these different defect units (Figure S16A) on the ${ }^{1} \mathrm{H}$ chemical shifts. Reduced unit cells are constructed by connecting the defect units through an aqueous interlayer or an aqueous interlayer with a $\mathrm{Ca}_{\mathrm{I}}$ and additional $\mathrm{OH}^{-}$for charge balance (Figure $\mathrm{S} 16 \mathrm{~B}$ ). In order to study medium range effects, we also consider different ways to combine the reduced unit cells, resulting in chain, dimer, and pentamer motifs (Figure S16C).

All the structures are first partially relaxed with energy minimization using METADISE ${ }^{17}$ with a force field potential previously used for cementitious materials. ${ }^{18}$ If the atomic bond distances, calcium coordination and local charge neutrality are satisfactory then they are relaxed using density function theory (DFT). For the former two criteria, we require specifically that $\mathrm{Ca}-\mathrm{O}$ bonds are between $2.2 \AA$ and $2.9 \AA$ and that calcium coordination numbers are near six. The condition of local charge neutrality is implemented as systems with large distances between charged species consistently exhibit higher energies than systems for which this is not the case. Additional water molecules can be added to the interlayer to help satisfy these criteria. Depending on the initial atomic coordinates, especially those that specify the positioning of the interlayer water, the reduced unit cells may relax into different structures with the same defect classification.

These structures are again checked for the calcium coordination, lack of disruption of the main layer calcium-silicate backbone chain, and local charge neutrality. Once all the criteria are met, ${ }^{1} \mathrm{H}$ and ${ }^{29} \mathrm{Si}$ chemical shift calculations are performed on the candidates. The chemical shielding $\sigma_{\text {calc }}$ was calculated using the generalized gradient approximation (GGA) functional $\mathrm{PBE}^{19}$ within the Quantum Espresso code ${ }^{20}$ and the GIPAW method. ${ }^{21}$ For each calculation a plane-wave maximum cutoff energy of 80 Ry, and a 
Monkhorst-Pack grid of $k$-points ${ }^{22}$ corresponding to $0.033 \AA^{-1}$ in reciprocal space was employed. These values were tested for convergence of calculated energy and chemical shielding.

The convergence criteria for force, energy and pressure for structural relaxation were set to $10^{-3} \mathrm{E}_{\mathrm{h}} / \mathrm{a}_{0}, 10^{-4}$ $\mathrm{E}_{\mathrm{h}}$, and 500 bar respectively. The final pressure of each relaxed structure was less than 150 bar. For structures which contain CaI, the final pressure was usually below 50 bar. To ensure this 500 bar threshold was sufficient, we performed an additional DFT relaxation of the structure based upon the ACcaV2 motif, setting a cell pressure threshold of 0.01 bar. Because of this stricter convergence criteria, $\mathrm{O}-\mathrm{O}$ distances throughout the structure change by $0.05-0.1 \AA$, resulting in a ${ }^{1} \mathrm{H}$ chemical shift RMSD of 0.59 ppm and a ${ }^{29} \mathrm{Si}$ chemical shift RMSD of $0.34 \mathrm{ppm}$ relative to the structure calculated with the higher convergence threshold for pressure. The higher ${ }^{1} \mathrm{H}$ chemical shift RMSD corresponds to the fact that proton chemical shifts are more sensitive to changes in the hydrogen bonding network than ${ }^{29} \mathrm{Si}$. In NMR crystallography, two systems are considered identical if the ${ }^{1} \mathrm{H}$ chemical shift RMSD is below $0.5 \mathrm{ppm} .{ }^{23}$ We justify a slightly higher limit for the C-S-H considering that most of the protons of weakly bonded interlayer species have lower barriers to conformational rearrangement relative to crystals of small organic molecules. Indeed, there is a correlation between the largest ${ }^{1} \mathrm{H}$ chemical shift changes occur for species near $0 \mathrm{ppm}$, as shown in Figure S17. If the proton chemical shifts corresponding to these non-hydrogen bonded $\mathrm{H}_{2} \mathrm{O}$ are excluded from the comparison, we calculate a ${ }^{1} \mathrm{H}$ chemical shift RMSD of $0.38 \mathrm{ppm}$, which is well below the cutoff of $0.5 \mathrm{ppm}$. Therefore, a stricter convergence criterion for the DFT relaxation does not affect our interpretation of the ${ }^{1} \mathrm{H}$ chemical shifts nor the conclusions drawn from them. 
A

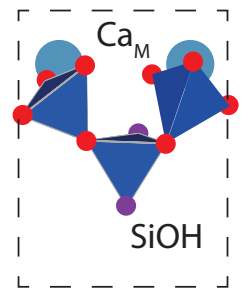

A: "intact" $Q^{2 b}$ site

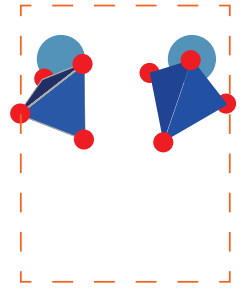

D: defect site, negatively charged

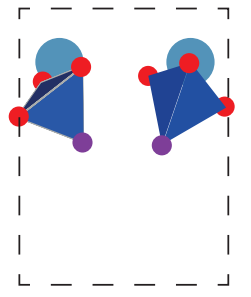

B: two Silanols at defect site

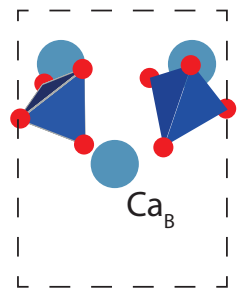

C: $\mathrm{Ca}_{\mathrm{B}}$ bridging defect site

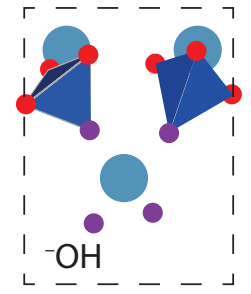

H: two Silanols at defect site with $\mathrm{Ca}_{\mathrm{A}}$

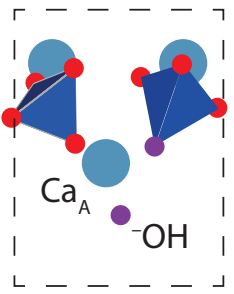

G: $\mathrm{Ca}_{\mathrm{A}^{\prime}}$ Silanol and $\mathrm{HO}^{-}$at defect site
B

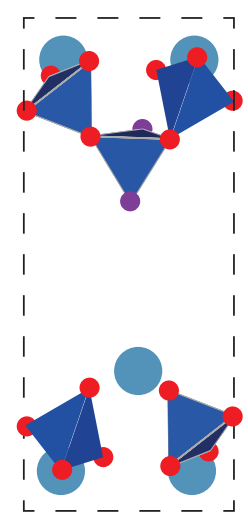

AC: $A$ and $B$ motive connected trough an aqueous interlayer.
C

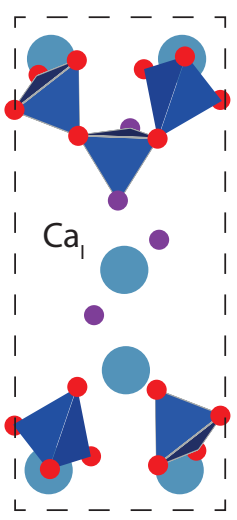

ACca: A and B motif connected trough an aqueous interlayer with a $\mathrm{Ca}_{1}$ and charge balanced by additional $-\mathrm{OH}$.

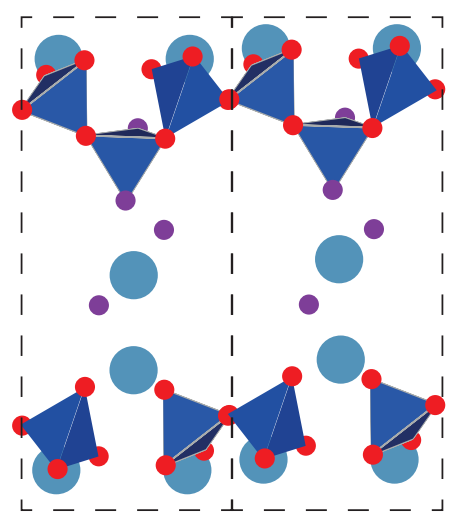

ACca: used as a reduced unit cell, resulting in a chain and dimer motif.

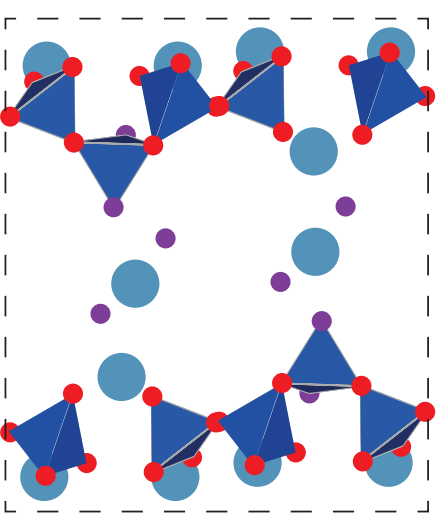

ACcaCAca: two reduced unit cells combined by rotating the second unit cell about $180^{\circ}$ around the horizontal axis, resulting in a double pentamer motif.

Figure S16 | Defect classification. (A) Simple defect units. (B) Simple defect units are combined with added interlayer water to form reduced unit cells. ${ }^{1} \mathrm{H}$ chemical shifts are calculated for structurally viable reduced unit cells. (C) Two possible ways of combining two reduced unit cells, showing how infinite chain, dimer, and pentamer motifs can be generated. The water in the aqueous interlayer and the hydrogen atoms are not shown.
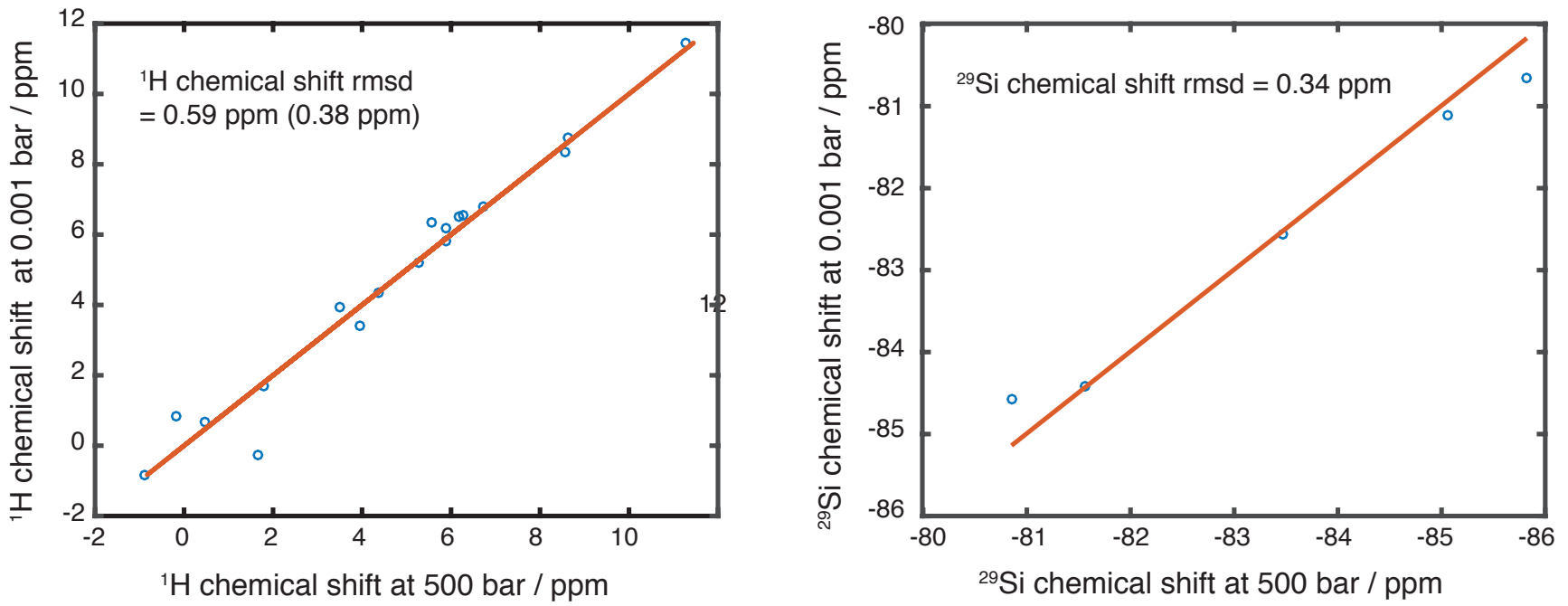

Figure S17 | Calculated chemical shift correlations between DFT structures of C-S-H based upon the ACcaV2 motif at 500 bar and 0.001 bar. 
Using the constraints from $1 \mathrm{D}{ }^{29} \mathrm{Si}$ NMR and INADEQUATE experiments, we have calculated the number of dimers and the mean repeat index of the distribution. These two values are then used to fit a chain distribution, which was determined using the following Monte Carlo procedure:

1. We define a cutoff of $n=10$ for the repeat index $\left(x_{n}=0\right.$ for $\left.n \geq 11\right)$.

2. For $n \geq 2$, the mole fractions are generated by a random number that is uniformly distributed between 0 to its theoretical maximum value given by the contribution to the $Q^{(2 p)}-Q^{(2 p)}$ correlation for that $\mathrm{Ca}: \mathrm{Si}$ ratio:

$$
x_{n \geq 2}=r \text { where } 0 \leq r \leq \frac{1-x_{0}}{n-1}
$$

3. Pentamers constitute the remaining fraction.

4. A chain distribution is accepted only if the difference between mean repeat index $\left(\sum_{n} x_{n} n\right)$ obtained from the distribution and that calculated from the NMR constraints is less than 0.0005 .

5. This procedure is iterated and the average fractions are stored.

6. The iteration is continued until the average values of the distribution converge to a unique distribution.

The random chain distributions calculated for each $\mathrm{Ca}: \mathrm{Si}$ ratio are shown in Figure S19. For constructing our representative C-S-H structures, the longest chain used is a tetradecamer $(n=4)$, as indicated in Figure S19C.

The reduced unit cells deemed likely structural elements (see Section XIII) are permuted and stacked in the directions of the crystal axes in order to build a three-dimensional crystal structure satisfying all of our experimental NMR constraints. The proposed structures are shown in Figure S18 and their silicate species distributions are compared with the experimental values in Figure S19 (A and B). 


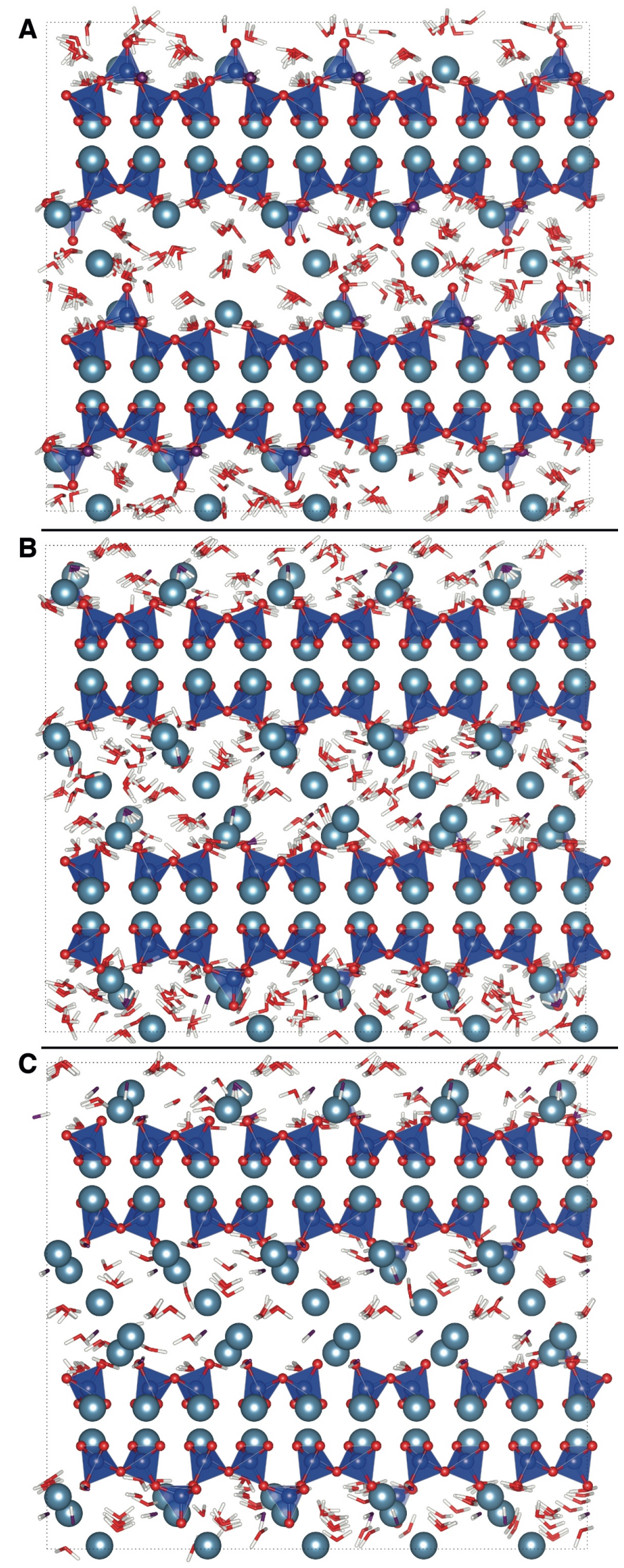

Figure S18 | Proposed structures satisfying the NMR constraints for $\mathrm{Ca}: \mathrm{Si}=1.25(\mathrm{~A}), \mathrm{Ca}: \mathrm{Si}=1.75(\mathrm{~B})$ and $\mathrm{Ca}: \mathrm{Si}=\mathbf{2 . 0 0}$ (C) viewed along the [100] direction. The relative positions of hydroxyls and water molecules have been relaxed with energy minimization at $0 \mathrm{~K}$. Corresponding relaxed structures using MD are shown in Figure S20. 

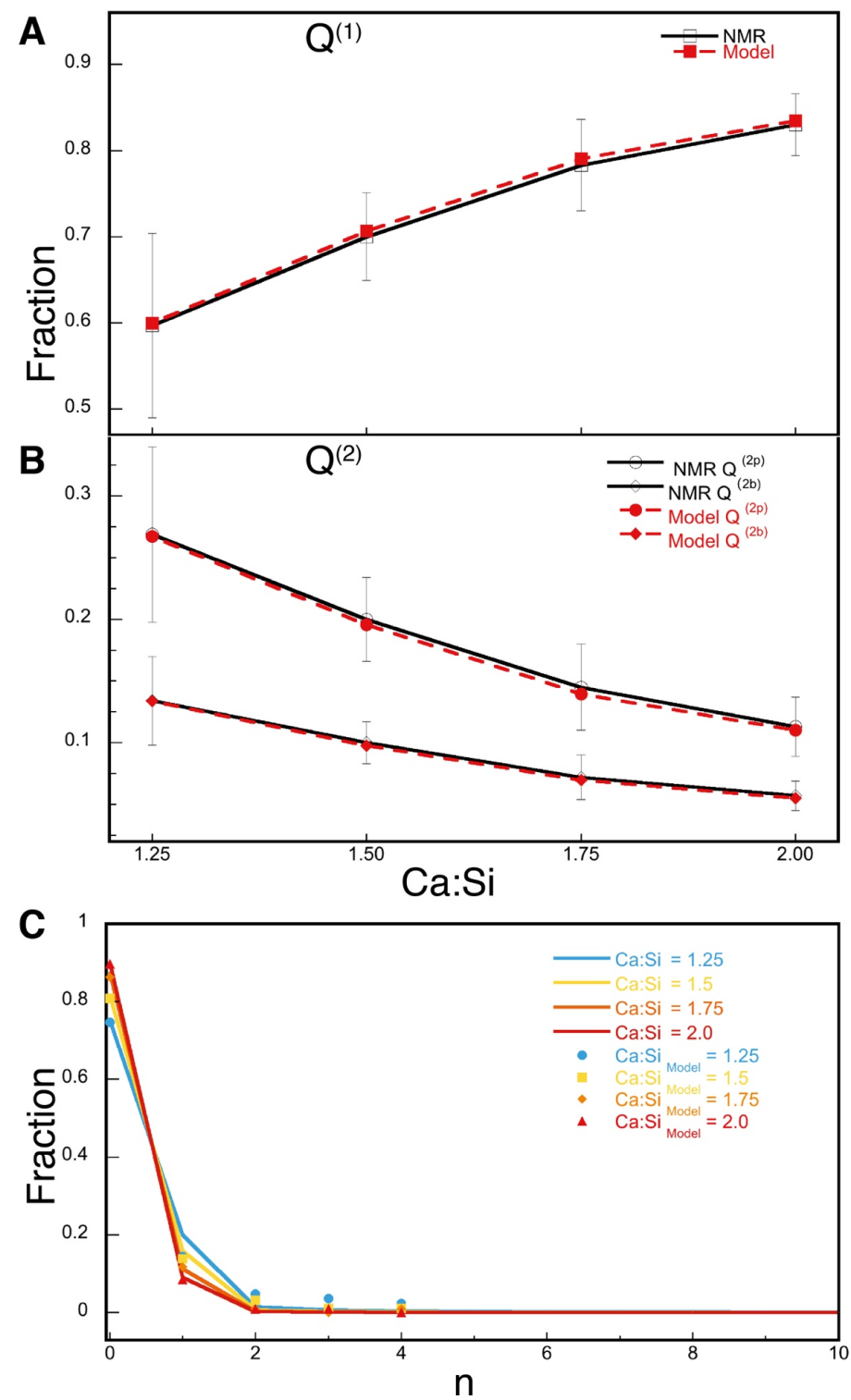

Figure S19 | Distribution of silicate species determined by NMR compared to those predicted by the random distribution model. (A) Comparison between $Q^{(1)}$ populations and (B) $Q^{(2)}$ populations. The experimental values are shown in unfilled markers connected by solid lines whereas the corresponding values in our proposed structures are shown in filled markers connected by dashed lines. (C) Distribution of silicate chains according to the random distribution model. The mole fractions (up to $n=4$ ) used in our representative C-S-H structures are shown as markers. 


\section{Structural Relaxation}

Initial structural relaxation was performed with classical molecular dynamics using force field potentials. The force field parameters used are known to describe well cementitious material systems. ${ }^{18}$ Simulations were done using a constant pressure ensemble at $300 \mathrm{~K}$ and a time step of $0.7 \mathrm{fs}$ using Velocity Verlet integration algorithms implemented in DLPOLY.${ }^{24}$ Ewald summation was used to take into account the long range forces above a cutoff distance of $8.5 \AA$. Snapshots after 2 ns of molecular dynamics simulation of each structure are shown in Figure S20 and are found to be structurally stable. Stoichiometry of the structures, bond distances and average calcium coordination numbers of bulk structures minimized after 2 ns are presented in Table S13. The bond distances from MD simulations are realistic. Histograms showing the distribution of coordination numbers for main phase calcium, interlayer calcium, and grand total of all calcium in these bulk C-S-H representations are shown in Figure S21. A systematic shift of the coordination number toward lower values is inevitable due to anharmonic vibrational motion of the atoms with respect to their proper equilibrium positions, an effect which is a function of the choice of force field used for the simulations. To estimate the magnitude of this shift for these systems, we carried out MD simulations on the known structure of $14 \AA$ tobermorite for which $20 \%$ of the calcium are six coordinate and $80 \%$ are seven coordinate. The 2 ns MD snapshot of $14 \AA$ tobermorite indicates roughly $30 \%$ fivefold coordination and $70 \%$ sixfold coordination. Therefore, we expect the results in Figure S21 to systematically underestimate a proper coordination number by nearly one. 


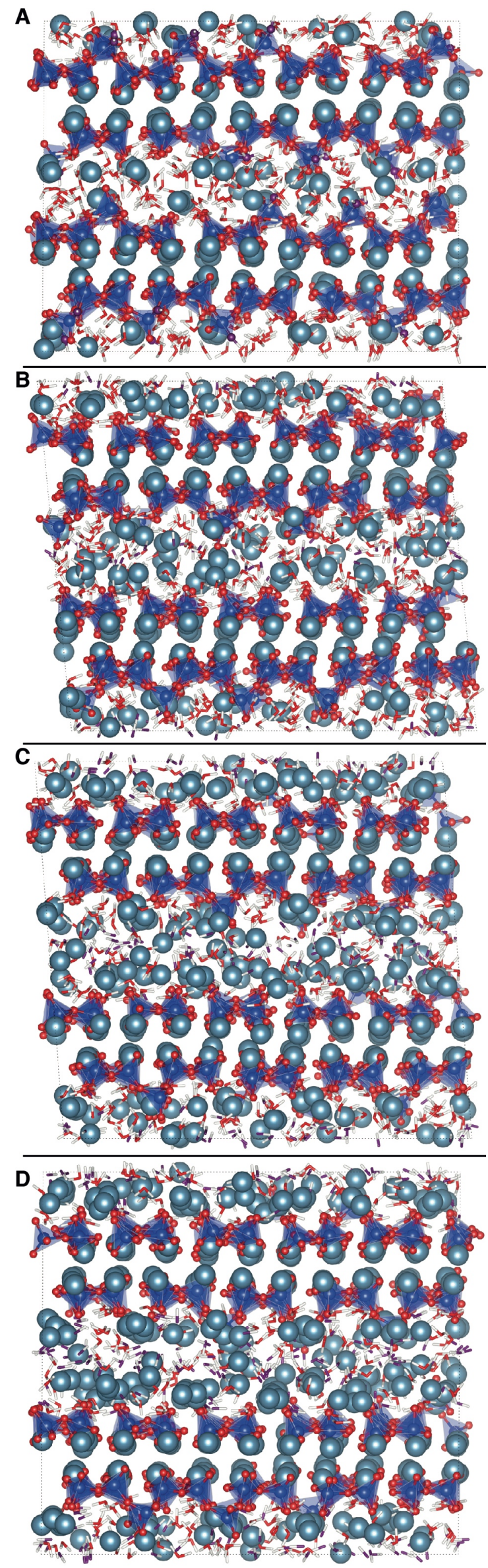

Figure S20 | Snapshots of bulk structures relaxed for 2 ns using classical MD simulations. The structures shown are (A) $\mathrm{Ca}: \mathrm{Si}=1.25,(\mathrm{~B}) \mathrm{Ca}: \mathrm{Si}=1.5,(\mathrm{C}) \mathrm{Ca}: \mathrm{Si}=1.75$ and $(\mathrm{D}) \mathrm{Ca}: \mathrm{Si}=2.0$ respectively viewed along the $[100]$ axes. All simulations produced structurally stable defective tobermorite features. 


\begin{tabular}{|c|c|c|c|c|c|}
\hline $\mathrm{Ca}: \mathrm{Si}$ & Chemical formula & $\begin{array}{c}\mathrm{Ca}-\mathrm{OH} / \mathrm{Ca} \\
{[\%]}\end{array}$ & $\begin{array}{c}\mathrm{Ca}-\mathrm{O} \\
{[\AA]}\end{array}$ & $\begin{array}{c}\mathrm{Si}-\mathrm{O} \\
{[\AA]}\end{array}$ & $\begin{array}{c}C N \\
(\mathrm{Ca}-\mathrm{O})\end{array}$ \\
\hline 1.25 & $\mathrm{Ca}_{1.25} \mathrm{Si} \mathrm{O}_{3.2}(\mathrm{OH})_{0.1}\left(\mathrm{H}_{2} \mathrm{O}\right)_{1.82}$ & 0 & $2.3 \pm 0.12$ & $1.55 \pm 0.08$ & 5.9 \\
\hline 1.50 & $\mathrm{Ca}_{1.5} \mathrm{Si} \mathrm{O}_{3.35}(\mathrm{OH})_{0.30}\left(\mathrm{H}_{2} \mathrm{O}\right)_{1.91}$ & 10 & $2.3 \pm 0.12$ & $1.55 \pm 0.08$ & 5.9 \\
\hline 1.75 & $\mathrm{Ca}_{1.75} \mathrm{Si} \mathrm{O}_{3.39}(\mathrm{OH})_{0.71}\left(\mathrm{H}_{2} \mathrm{O}\right)_{1.72}$ & 20.1 & $2.3 \pm 0.12$ & $1.55 \pm 0.08$ & 5.8 \\
\hline 2.00 & $\mathrm{Ca}_{2} \mathrm{Si} \mathrm{O}_{3.41}(\mathrm{OH})_{1.18}\left(\mathrm{H}_{2} \mathrm{O}\right)_{1.31}$ & 29.4 & $2.3 \pm 0.12$ & $1.55 \pm 0.08$ & 5.8 \\
\hline
\end{tabular}

Table S13 | Structural characteristics of the representative C-S-H structures. These values are given for MD structures relaxed for $2 \mathrm{~ns}$. These values show that the chemical and physical environment in the structures are realistic. $\mathrm{Ca}-\mathrm{OH} / \mathrm{Ca}$ indicates the percentage of $\mathrm{Ca}$ atoms charge compensated by hydroxyl ions. The errors on the force field were estimated to be around $5 \%$ on distances ${ }^{25}$
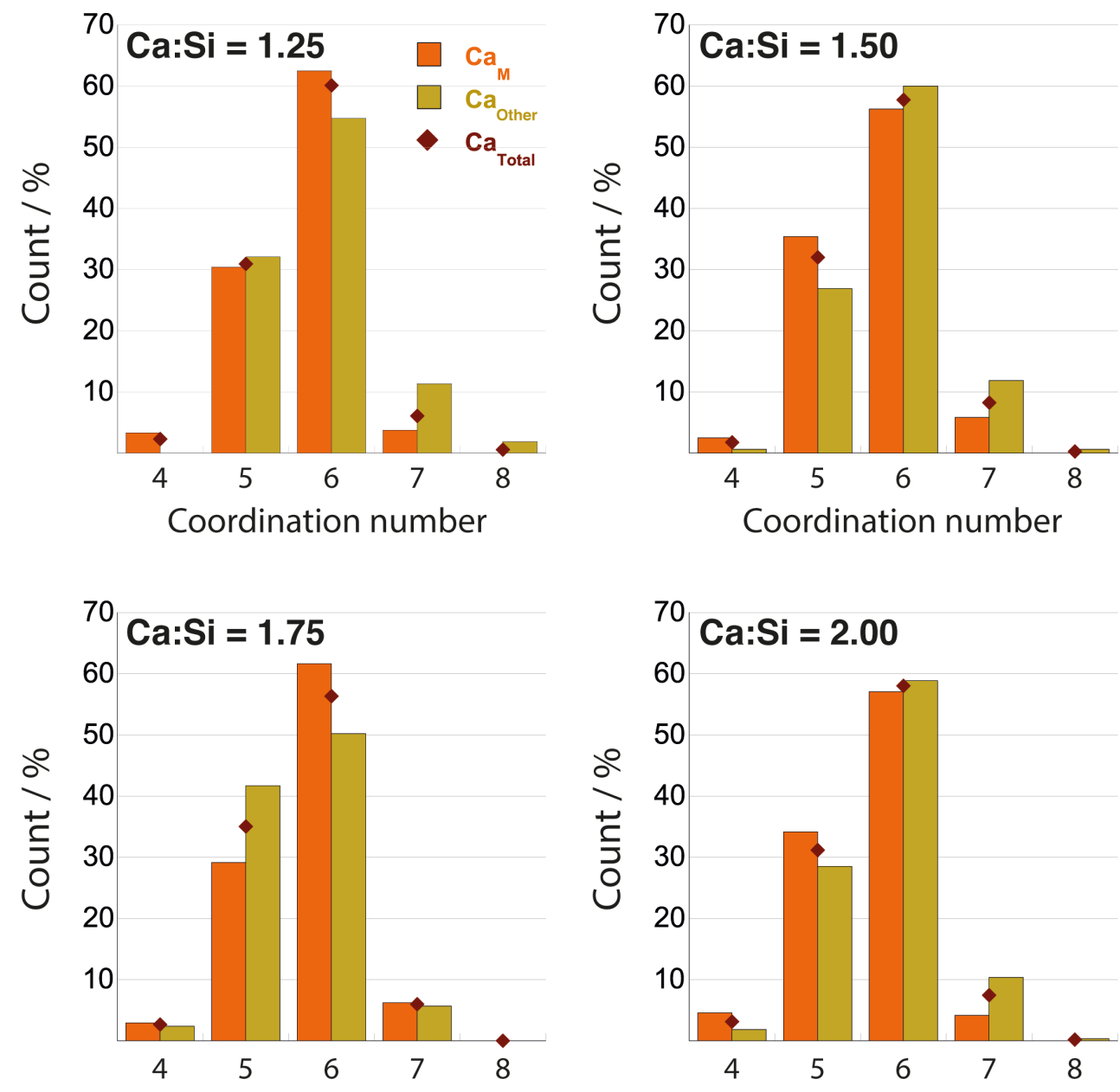

Coordination number

Coordination number

Figure S21 | Histograms showing populations of coordination numbers for each of the representative C-S-H structures. These values are given for MD structures relaxed for 2 ns. Orange and green bars indicate coordination of main phase and all other calcium, defined as $\mathrm{Ca}_{M}$ and Caother. The black markers indicate the coordination over all calcium in the structure (Catotal). Owing to positional bias in the MD simulated structures, the populations are systematically shifted toward lower coordination number by nearly one. 
We also find that in the $\mathrm{Ca}: \mathrm{Si}=1.75$ structure $20 \%$ of $\mathrm{Ca}$ atoms are charge compensated by hydroxyl ions. Thomas et al. ${ }^{26}$ calculated this value to be $23 \%$ in $\mathrm{C}-\mathrm{S}-\mathrm{H}$ with $\mathrm{Ca}: \mathrm{Si}=1.7$ in hydrated cement samples and argued that such a bonding is possible only if a structural motif resembling jennite is present. Our results show that the jennite structural motif is not required to give this hydroxyl charge compensation - a highly defective tobermorite is sufficient. We have not considered any structures with a defective jennite motif, in which a missing dimer is replaced by two $\mathrm{OH}^{-}$groups. Pentamers, octamers, undecamers and tetradecamers are the only non-dimers in our proposed structures limited by the box size considered. Generally, the interlayer separation distance shrinks up to $2 \AA$ (down from $14 \AA$ ) upon structural relaxation for Ca:Si $\leq 1.5$, affirming our choice of $14 \AA$ tobermorite as a reasonable base structure. Clinotobermorite or other orthotobermorites can also be treated as the base structure satisfying the ${ }^{29} \mathrm{Si}$ and ${ }^{1} \mathrm{H}$ NMR constraints but without additional information describing the calcium environment in C-S-H it is difficult to evaluate which form of tobermorite would serve as the best base structure. 


\section{Proton chemical shift calculations}

The ${ }^{1} \mathrm{H}$ chemical shift calculations are performed on the set of reduced unit cells displayed in Figure S22.

These reduced unit cells are selected to ensure a wide variety of different local defect environments, classified according to Figure S16A, are captured. We also probe the influence of $\mathrm{Ca}_{\mathrm{I}}$ in the aqueous interlayer and perform a test of the influence of medium range interactions by studying the containing pentamers rather than infinitely long silicate chains and dimers, which are the only types of chains possible without juxtaposition of different reduced unit cells. Calculated proton chemical shift spectra for each of these structural candidates are shown in Figure S23. Structures that are not distinguishable on the basis of defect classification may have different arrangements of water molecules in the interlayer, representing viable structures with different local energy minima and indicated as different "versions" in Figure S23.
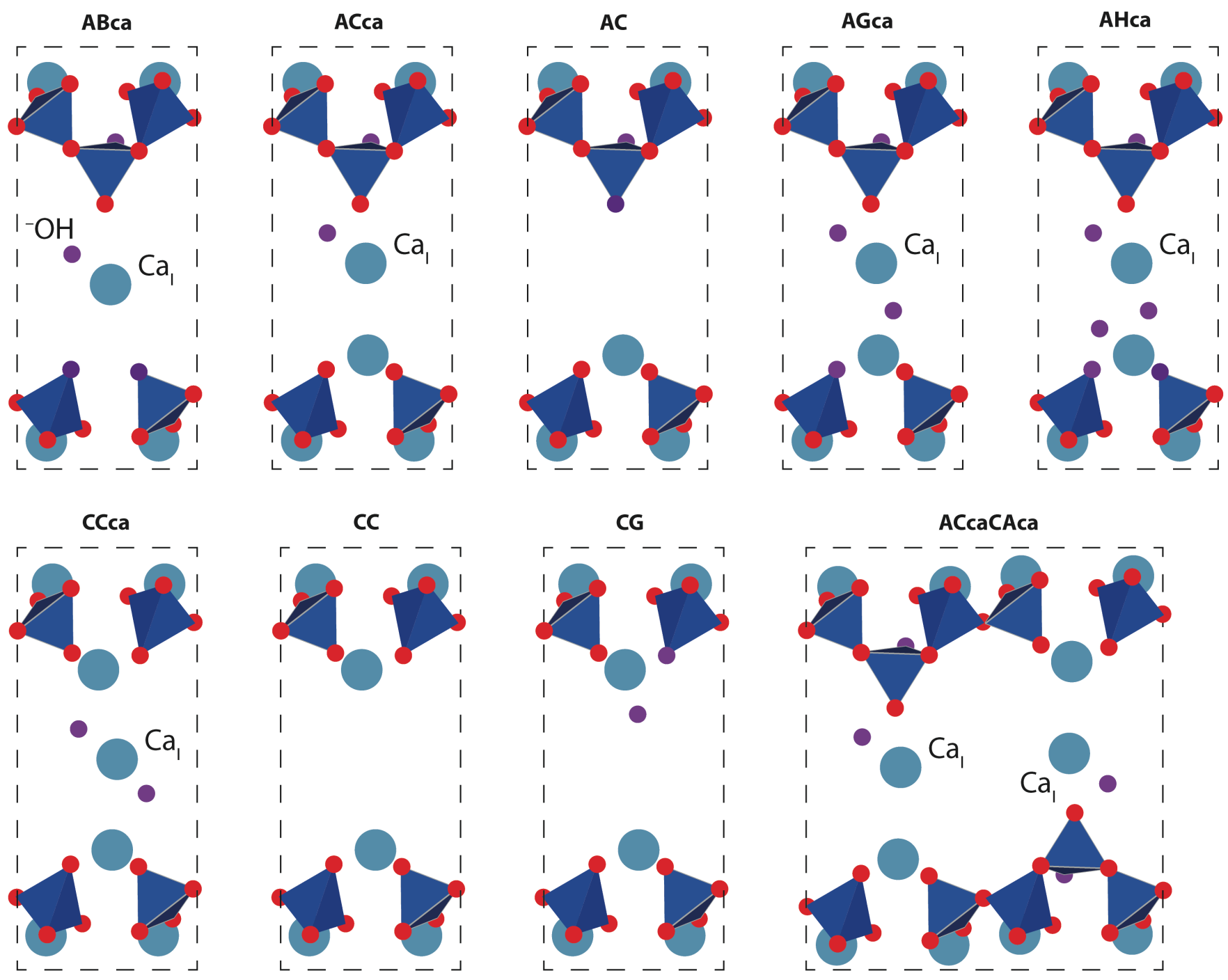

Figure S22 | Reduced unit cells used in ${ }^{1} \mathrm{H}$ and ${ }^{29} \mathrm{Si}$ chemical shift calculations. Interlayer water molecules are not shown. 


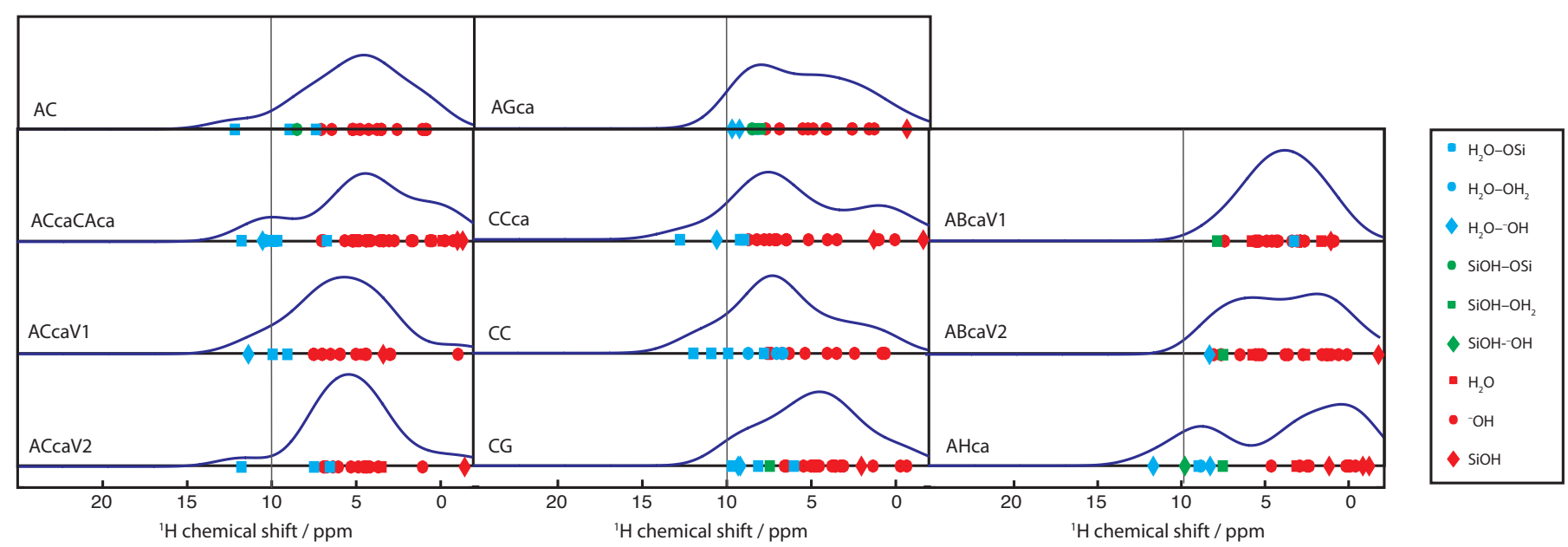

Figure S23 | Calculated spectra of ${ }^{1} \mathrm{H}$ GIPAW isotropic magnetic shifts for the investigated reduced unit cells of C-S-H. The line-shapes $S(\delta)$ are extrapolated from the calculated chemical shifts $\delta_{\text {calc }}$ as $S(\delta)=\frac{1}{\sqrt{2 \pi R^{2}}} \exp \left[-\frac{1}{2}\left(\frac{\delta-\delta_{\text {calc }}}{R}\right)^{2}\right]$ with $R=1.5 \mathrm{ppm}$. In general, structures with $\mathrm{CaB}$ at the bridging site (types $\mathrm{AC}, \mathrm{CC}, \mathrm{CG})$ better reproduce the characteristic tail in the ${ }^{1} \mathrm{H}$ line shape above $10 \mathrm{ppm}$. Structures that are identical according to our defect classification scheme but possess different arrangements of water molecules in the interlayer are distinguished by V1 or V2.

\section{XIV. $\quad{ }^{29}$ Si chemical shift calculations}

In addition to the ${ }^{1} \mathrm{H}$ chemical shift calculations, we also calculate ${ }^{29} \mathrm{Si}$ chemical shift parameters (Figure S24) for all structures used in Figure S23. The calculated ${ }^{29} \mathrm{Si}$ chemical shifts are compared to previous calculations ${ }^{27}$ and to our experimental results. To the level of intrinsic accuracy of ${ }^{29} \mathrm{Si}$ chemical shift calculations, there is good agreement between the three datasets, allowing us to conclude that the C-S-H models proposed here are a good approximation of the studied systems.

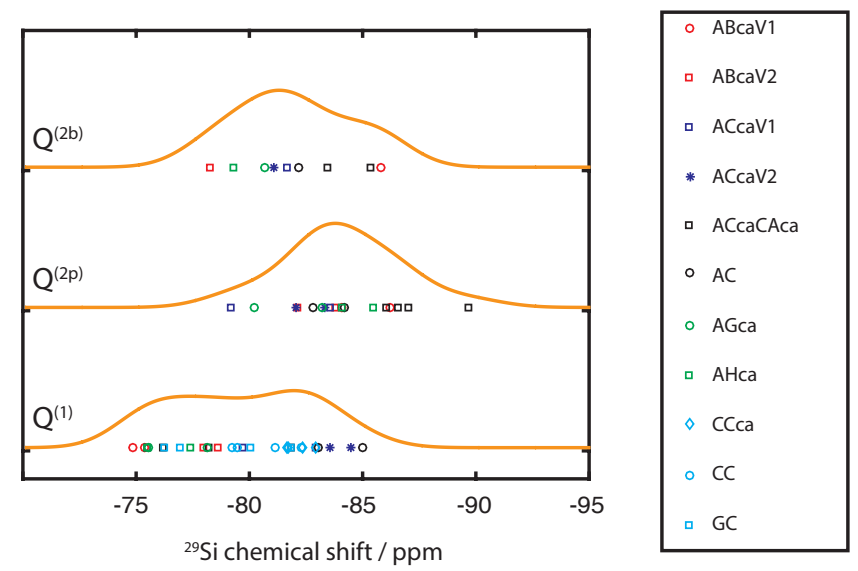

Figure S24 | Overlap of calculated ${ }^{29}$ Si GIPAW isotropic magnetic shift spectra for each different Si site in the calculated structures shown in Figure S23. The line-shapes $S(\delta)$ are extrapolated from the calculated chemical shifts $\delta_{\text {calc }}$ as $S(\delta)=$ $\frac{1}{\sqrt{2 \pi R^{2}}} \exp \left[-\frac{1}{2}\left(\frac{\delta-\delta_{\text {calc }}}{R}\right)^{2}\right]$ with $R=1.5 \mathrm{ppm}$. 
(1) Brinker, C. J.; Scherer, G. W. Sol-Gel Science: The Physics and Chemistry of Sol-Gel Processing; Gulf Professional Publishing, 1990.

(2) Iller, R. K. The Chemistry of Silica: Solubility, Polymerization, Colloid and Surface Properties and Biochemistry of Silica; Wiley, 1979.

(3) Kulik, D. A.; Wagner, T.; Dmytrieva, S. V.; Kosakowski, G.; Hingerl, F. F.; Chudnenko, K. V.; Berner, U. R. GEM-Selektor Geochemical Modeling Package: Revised Algorithm and GEMS3K Numerical Kernel for Coupled Simulation Codes. Comput. Geosci. 2012, 17 (1), 1-24.

(4) Galmarini, S. Atomistic Simulation of Cementitious Systems, Ecole Polytechnique Fédérale de Lausanne: Lausanne, 2013.

(5) Kulik, D. A. Improving the Structural Consistency of C-S-H Solid Solution Thermodynamic Models. Cem. Concr. Res. 2011, 41 (5), 477-495.

(6) $R M N$, version 1.8.4; software for multi-dimensional signal processing; PhySy Ltd: Grandview Heights, OH, 2016.

(7) Lesage, A.; Bardet, M.; Emsley, L. Through-Bond Carbon-Carbon Connectivities in Disordered Solids by NMR. J. Am. Chem. Soc. 1999, 121 (47), 10987-10993.

(8) States, D. J.; Haberkorn, R. A.; Ruben, D. J. A Two-Dimensional Nuclear Overhauser Experiment with Pure Absorption Phase in Four Quadrants. J Magn. Reson. 1982, 48, 286-292.

(9) Ernst, R. R.; Bodenhausen, G.; Wokaun, A. Principles of Nuclear Magnetic Resonance in One and Two Dimensions; International Series of Monographs on Chemistry; Clarendon Press, 1987.

(10) van Rossum, B.-J.; Förster, H.; de Groot, H. J. M. High-Field and High-Speed CP-MAS ${ }^{13}$ C NMR Heteronuclear Dipolar-Correlation Spectroscopy of Solids with Frequency-Switched Lee-Goldburg Homonuclear Decoupling. J. Magn. Reson. 1997, 124 (2), 516-519.

(11) Elena, B.; de Paëpe, G.; Emsley, L. Direct Spectral Optimisation of Proton-Proton Homonuclear Dipolar Decoupling in Solid-State NMR. Chem. Phys. Lett. 2004, 398 (4-6), 532-538.

(12) Rossini, A. J.; Zagdoun, A.; Lelli, M.; Gajan, D.; Rascón, F.; Rosay, M.; Maas, W. E.; Copéret, C.; Lesage, A.; Emsley, L. One Hundred Fold Overall Sensitivity Enhancements for Silicon-29 NMR Spectroscopy of Surfaces by Dynamic Nuclear Polarization with CPMG Acquisition. Chem Sci 2012, $3(1), 108-115$.

(13) Brunet, F.; Bertani, P.; Charpentier, T.; Nonat, A.; Virlet, J. Application of ${ }^{29}$ Si Homonuclear and ${ }^{1} \mathrm{H}^{-29} \mathrm{Si}$ Heteronuclear NMR Correlation to Structural Studies of Calcium Silicate Hydrates. J. Phys. Chem. B 2004, 108 (40), 15494-15502.

(14) Alemany, L. B.; Grant, D. M.; Pugmire, R. J.; Alger, T. D.; Zilm, K. W. Cross Polarization and Magic Angle Sample Spinning NMR Spectra of Model Organic Compounds. 2. Molecules of Low or Remote Protonation. J. Am. Chem. Soc. 1983, 105 (8), 2142-2147.

(15) Richardson, I. G. The Nature of C-S-H in Hardened Cements. Cem. Concr. Res. 1999, 29 (8), 11311147.

(16) Cong, X.; Kirkpatrick, R. J. ${ }^{29}$ Si MAS NMR Study of the Structure of Calcium Silicate Hydrate. $A d v$. Cem. Based Mater. 1996, 3 (3-4), 144-156.

(17) Watson, G. W.; Kelsey, E. T.; Leeuw, N. H. de; Harris, D. J.; Parker, S. C. Atomistic Simulation of Dislocations, Surfaces and Interfaces in MgO. J. Chem. Soc., Faraday Trans. 1996, 92 (3), 433-438.

(18) Galmarini, S.; Kunhi Mohamed, A.; Bowen, P. Atomistic Simulations of Silicate Species Interaction with Portlandite Surfaces. J. Phys. Chem. C 2016, 120 (39), 22407-22413.

(19) Perdew, J. P.; Burke, K.; Ernzerhof, M. Generalized Gradient Approximation Made Simple. Phys. Rev. Lett. 1996, 77 (18), 3865-3868.

(20) Giannozzi, P.; Baroni, S.; Bonini, N.; Calandra, M.; Car, R.; Cavazzoni, C.; Ceresoli, D.; Chiarotti, G. L.; Cococcioni, M.; Dabo, I.; et al. QUANTUM ESPRESSO: A Modular and Open-Source Software Project for Quantum Simulations of Materials. J. Phys. Condens. Matter 2009, 21, 395502.

(21) Yates, J. R.; Pickard, C. J.; Mauri, F. Calculation of NMR Chemical Shifts for Extended Systems Using Ultrasoft Pseudopotentials. Phys. Rev. B 2007, 76 (2), 24401.

(22) Pack, J. D.; Monkhorst, H. J. Special Points for Brillouin-Zone Integrations. Phys. Rev. B 1977, 16 (4), 1748-1749. 
(23) Salager, E.; Day, G. M.; Stein, R. S.; Pickard, C. J.; Elena, B.; Emsley, L. Powder Crystallography by Combined Crystal Structure Prediction and High-Resolution 1H Solid-State NMR Spectroscopy. $J$. Am. Chem. Soc. 2010, 132 (8), 2564-2566.

(24) Todorov, I. T.; Smith, W.; Trachenko, K.; Dove, M. T. DL_POLY 3: New Dimensions in Molecular Dynamics Simulations via Massive Parallelism. J. Mater. Chem. 2006, 16 (20), 1911-1918.

(25) Galmarini, S.; Bowen, P. Atomistic Simulation of the Adsorption of Calcium and Hydroxyl Ions onto Portlandite Surfaces - towards Crystal Growth Mechanisms. Cem. Concr. Res. 2016, 81, 16-23.

(26) Thomas, J. J.; Chen, J. J.; Jennings, H. M.; Neumann, D. A. Ca-OH Bonding in the C-S-H Gel Phase of Tricalcium Silicate and White Portland Cement Pastes Measured by Inelastic Neutron Scattering. Chem. Mater. 2003, 15 (20), 3813-3817.

(27) Rejmak, P.; Dolado, J. S.; Stott, M. J.; Ayuela, A. ${ }^{29}$ Si NMR in Cement: A Theoretical Study on Calcium Silicate Hydrates. J. Phys. Chem. C 2012, 116 (17), 9755-9761. 